\title{
DESENVOLVIMENTO DE UM ALGORITMO DE ESCALONAMENTO PARA REDE FOUNDATION FIELDBUS
}

Daniele Aparecida Cicillini

Dissertação apresentada à Escola de Engenharia de São Carlos da Universidade de São Paulo, como parte dos requisitos para obtenção do título de Mestre em Engenharia Mecânica.

ORIENTADOR: Prof. Tit. Mário Pinotti Junior 

A Deus força suprema

E Senhor de todo meu existir. 





\section{AGRADECIMENTOS}

Agradeço primeiramente ao professor Dr. Mario Pinotti Junior, pela confiança, amizade e por toda orientação ao longo deste trabalho.

Agradeço também de uma maneira especial ao professor Dr. Dennis Brandão, pelo imenso carinho, amizade, colaboração, orientação e por todo ensinar, você faz parte dessa história.

A Smar Equipamentos Industriais pelo incentivo à pós-graduação.

A todos os amigos da Divisão de Desenvolvimento Eletrônico, em especial aos colegas do grupo Equipamentos de Campo, destaco aqui a amiga e companheira de estudo Valéria Venturini, pela amizade, cooperação e incentivo.

A todos os meus amigos, os presentes e ausentes, que de alguma maneira me ajudaram para a realização deste trabalho, destaco a amiga Vanessa e o meu namorado Ary, obrigada a cada um de vocês por emprestar o ombro amigo, todo auxílio, companheirismo e por todas as palavras de motivações.

Aos meus familiares, tios, primos e meus avós Dirce e Sebastião obrigada pelas orações e amor.

Aos meus pais Ernesto e Maria Aparecida, por proporcionarem a mim todo incentivo em ir além das fronteiras, em me ensinar a ser perseverante, lutar sempre com dignidade e honestidade, tudo o que eu disser aqui é pouco para agradecê-los. Eu os amo.

As minhas doces e amadas irmãs Fernanda e Natalia, amigas para todas as horas, meu porto seguro, o que posso dizer a não ser: eu amo vocês.

Enfim eu louvo o criador, o meu Deus pra quem eu dedico todo esse trabalho, que com esse presente fez um marco na minha vida. 



\section{SUMÁRIO}

LISTA DE FIGURAS ...............................................................................................

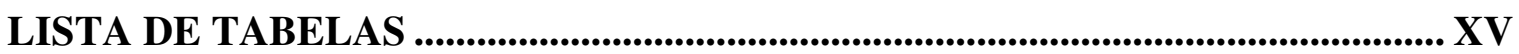

LISTA DE SIGLAS .................................................................................................. XVII

RESUMO .......................................................................................................................................XXI

ABSTRACT ...............................................................................................................................XXIII

1 INTRODUÇÃO .............................................................................................................. 25

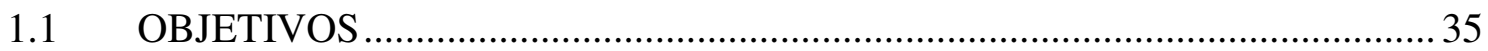

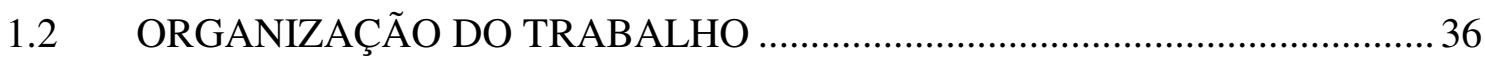

2 FOUNDATION FIELDBUS ..................................................................................................37

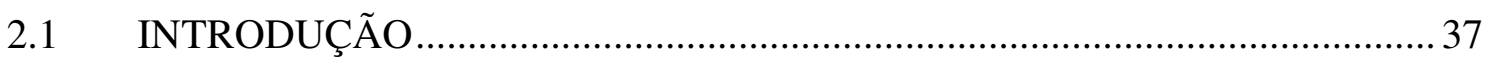

$2.2 \quad$ PROTOCOLO FOUNDATION FIELDBUS ……………………………......... 39

2.2.1 BLOCO FUNCIONAL …………………………………………………. 41

2.2.2 TRÁFEGO DE COMUNICAÇÃO …………………………………….... 45

2.2.3 CAMADAS, GERENCIAMENTO E SERVIÇOS DE REDE.......................... 49

2.2.4 A CAMADA DE APLICAÇÃO DO USUÁRIO ………………………….....59

3 REVISÃO BIBLIOGRÁFICA................................................................................63

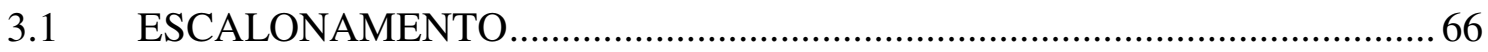

4 DESENVOLVIMENTO ......................................................................................................... 83

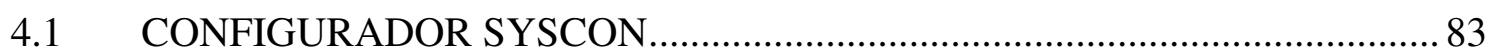

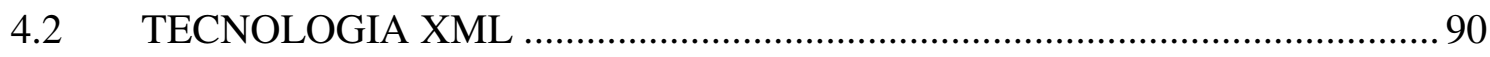




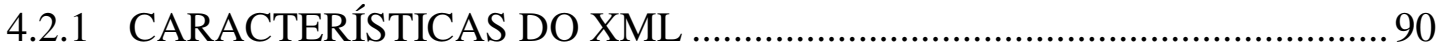

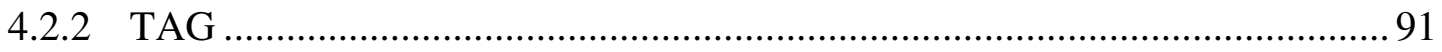

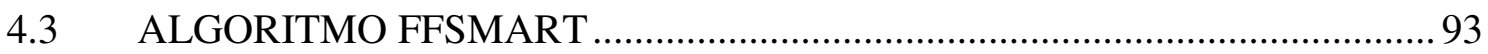

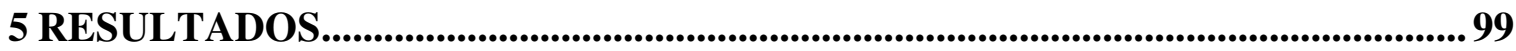

5.1 EXPERIMENTO 1 - CONTROLE DA TEMPERATURA DE SAÍDA DO PRODUTO USANDO VAPOR PARA AQUECÊ-LO .................................... 100

5.2 EXPERIMENTO 2 - DUPLO LIMITE CRUZADO ...................................... 105

5.3 EXPERIMENTO 3 - APLICAÇÃO DE CONTROLE DE UMA EMPRESA DE

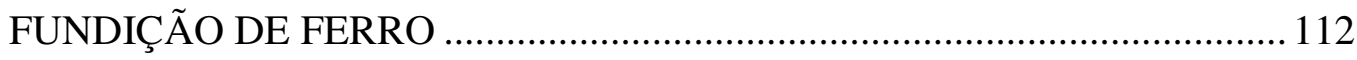

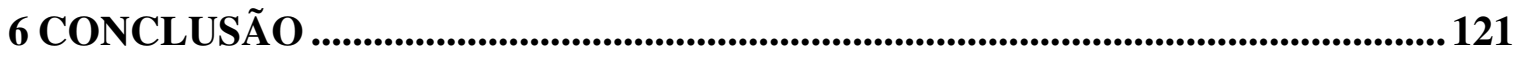

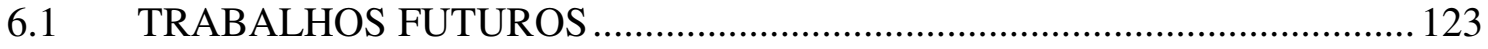

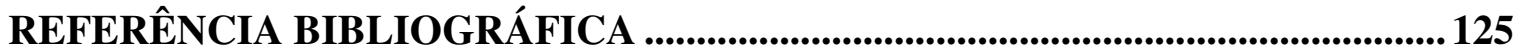




\section{LISTA DE FIGURAS}

Figura 1 - Representação da estrutura em camadas do protocolo FOUNDATION FIELDBUS 32

Figura 2 - Exemplo de malha de controle distribuída..........................................................33

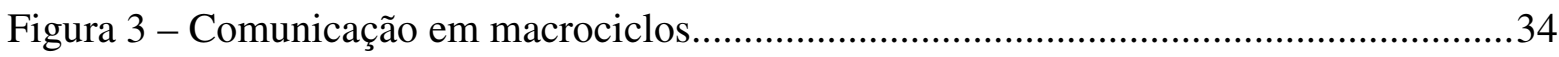

Figura 4 - Arquitetura de controle (Regh, Swain e Yangula, 1999) ....................................38

Figura 5 - Estrutura em camadas do protocolo FOUNDATION FIELDBUS ......................40

Figura 6 - Tipos de blocos da camada de aplicação do usuário (FOUNDATION FIELDBUS, 2003)

Figura 7- Tipos de blocos funcionais (FOUNDATION FIELDBUS, 2003).....

Figura 8 - Comunicação de troca de dados no protocolo FOUNDATION FIELDBUS

Figura 9 - Macrociclos e o escalonamento no barramento (FOUNDATION FIELDBUS, 2003) 48

Figura 10 - Camada do modelo OSI no FOUNDATION FIELDBUS (FOUNDATION

FIELDBUS, 2003)

Figura 11 - Divisão da camada de aplicação e funcionalidades das subcamadas FAS e FMS

Figura 12 - Comunicação do LAS com o dispositivo ou equipamento através do compel data (FOUNDATION FIELDBUS, 2003) 54

Figura 13 - LAS e o serviço do pass token (FOUNDATION FIELDBUS, 2003) ................56

Figura 14 - Fluxograma do algoritmo do LAS - Link Active Schedule (IEC, 2005) .57 
Figura 15 - Serviços do LAS no barramento H1 (FOUNDATION FIELDBUS, 2003) .......58

Figura 16 - (a) Topologia Single Link e (b) Topologia Bridged Network 59

Figura 17 - Malhas de controle na camada de aplicação do usuário (FOUNDATION

FIELDBUS, 2003)

Figura 18 - Exemplo do escalonamento pré-run-time de Almeida (1990) 71

Figura 19 - Algoritmo de escalonamento pré-run-time, segundo Henriques (2005).............78

Figura 20 - Descrição do algoritmo de escalonamento run-time de Henriques (2005) .........79

Figura 21 - Estratégia de controle simples e composta (Henriques, 2000) ..........................81

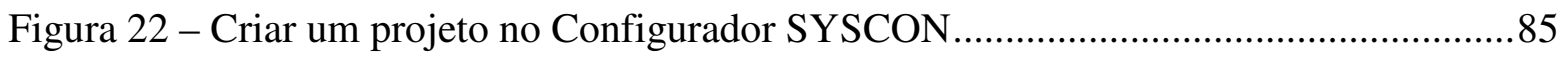

Figura 23 - Criação de um novo processo ..................................................................... 85

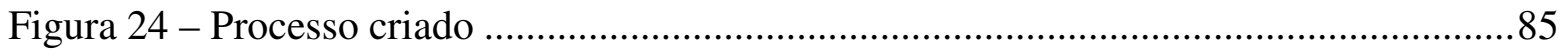

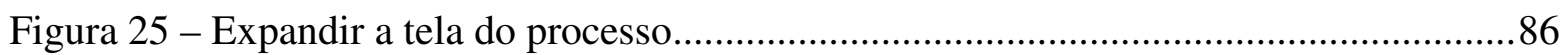

Figura 26 - Criação no novo módulo para, a seguir, acessar o ambiente da estratégia .........86

Figura 27 - Início do ambiente de configuração de estratégia para os diagramas de bloco ..86

Figura 28 - Inserção do equipamento de campo juntamente com o bloco.

Figura 29 - Diagrama da lógica do bloco de controle PID (Proporcional Integral Derivativo)

e suas entradas e saídas .88

Figura 30 - Estratégia de controle 89

Figura 31 - Geração do arquivo XML 89

Figura 32 - Exemplo de um código em HTML com a utilização de tags. 91

Figura 33 - Exemplo de um código em XML com utilização de tags ..................................92

Figura 34 - Exemplo do código do arquivo XML gerado no SYSCON...............................92

Figura 35 - Informações do arquivo XML armazenadas na tabela de escalonamento ..........95

Figura 36 - Fluxograma do algoritmo FFSMART ..................................................... 97

Figura 37 - Tabela de resultados do escalonamento das mensagens ..................................98 
Figura 38 - Estratégia do controle de temperatura........................................................ 100

Figura 39 - Estratégia de blocos configurada no SYSCON para o experimento 1 ..............101

Figura 40 - Tabela de informações da configuração do experimento 1 ..............................102

Figura 41 - Tabela de resultados do escalonamento do experimento 1 .............................102

Figura 42 - Gráfico do escalonamento para o experimento 1 .........................................102

Figura 43 - Análise e otimização do resultado do algoritmo FFSMART para o experimento 1

Figura 44 - "Duplo Limite Cruzado" para controlar a temperatura de um forno industrial 106

Figura 45 - Estratégia de blocos configurada no SYSCON do experimento 2 $2 . . \ldots \ldots \ldots \ldots \ldots \ldots . . . .108$

Figura 46 - Tabela de informações da configuração do experimento 2 ...............................109

Figura 47 - Tabela de resultados do escalonamento do experimento 2 ............................. 109

Figura 48 - Gráfico do Escalonamento para o experimento 2 ........................................110

Figura 49 - Análise e otimização do resultado do algoritmo FFSMART para o experimento 2

Figura 50 - Estratégia de blocos configurada no SYSCON para o experimento $3 \ldots \ldots \ldots \ldots . . . .114$

Figura 51 - Tabela de informações da configuração do experimento $3 . . . \ldots \ldots \ldots \ldots \ldots \ldots \ldots \ldots \ldots \ldots . . . . . .115$

Figura 52 - Tabela de resultados do escalonamento do experimento 3 ............................115

Figura 53 - Gráfico do escalonamento para o experimento 3 .......................................116

Figura 54 - Análise e otimização do resultado do algoritmo FFSMART para o experimento 3 



\section{LISTA DE TABELAS}

Tabela 1 - Evolução das tecnologias no mercado de instrumentação (Scott e Buchanan, 2000) 37

Tabela 2 - Dispositivos e Blocos Funcionais da SMAR utilizados no experimento 1 ........101

Tabela 3 - Dispositivos e Blocos Funcionais da SMAR utilizados no experimento 2 ........107

Tabela 4 - Dispositivos e Blocos Funcionais da SMAR utilizados no experimento 3 ........112 



\section{LISTA DE SIGLAS}

\begin{tabular}{|c|c|}
\hline AI & Analog Input \\
\hline $\mathrm{AO}$ & Analog Output \\
\hline APD & Application Process Directory \\
\hline CD & Compel Data \\
\hline CSMA/CD & Carrier Sense Multiple Access with Collision Detection \\
\hline DCS & Distributed Control Systems \\
\hline DD & Device Descriptions \\
\hline DDC & Direct Digital Control \\
\hline DDS & Deadline Driven Scheduler \\
\hline DLL & Data Link Layer \\
\hline $\mathrm{DM}$ & Deadline Monotonic \\
\hline DT & Data Transfer \\
\hline DTD & Document Type Definition \\
\hline EDF & Earliest Deadline First \\
\hline EDFM & Earliest Deadline First Multicycle \\
\hline EDS & Earliest Deadline Scheduler \\
\hline ERF & Earliest Release First \\
\hline FAS & Fieldbus Access Sublayer - Subcamada e Acesso Fieldbus \\
\hline FB & Function Block / Bloco Funcional \\
\hline FBAP & Function Block Application Process \\
\hline
\end{tabular}


FCS

FMS

HSE

HTML

$\mathrm{I} / \mathrm{O}$

ISO/OSI

LAS

LLC

LLF

LST

MA

MAC

MoPS

$\mathrm{ms}$

MuPS

OD

OSI

PID

PLC

PN

PT

$\mathrm{RM}$
Field Control Systems

Fieldbus Message Specification - Subcamada de Especificação de Mensagem Fieldbus

High Speed Ethernet

Hypertext Markup Language

Input / Output

International Organization for Standardization / Open System Interconection

Link Active Scheduler

Logical Link Control

Least Laxity First

Least Slack Time

Macrociclo

Medium Access Control

Monocycle Polling Scheduling

Milisegundos

Multicycle Polling Scheduling

Object Dictionary - Dicionário de Objeto

Open System Interconection

Proporcional Integral Derivativo - Controlador de ação Proporcional Integral Derivativa

Programmable Logical Controller

Probe Node

Pass Token

Rate Monotonic 


$\begin{array}{ll}\text { RMM } & \text { Rate Monotonic Multicycle } \\ \text { s } & \text { Segundos } \\ \text { SISO } & \text { Single Input, Single Output } \\ \text { TD } & \text { Time Distribution } \\ \text { VB } & \text { Visual Basic } \\ \text { VCR } & \text { Virtual Communication Relationship } \\ \text { VFD } & \text { Virtual Field Device } \\ \text { XML } & \text { EXtensible Markup Language }\end{array}$





\section{RESUMO}

CICILLINI, D. A. (2007). Desenvolvimento de um Algoritmo de Escalonamento para Rede FOUNDATION FIELDBUS. Dissertação (Mestrado) - Escola de Engenharia de São Carlos, Universidade de São Paulo, São Carlos, 2007.

Este trabalho apresenta e implementa um algoritmo de escalonamento para a tecnologia FOUNDATION FIELDBUS. O algoritmo denominado FFSMART escalona as mensagens de comunicação cíclica ou periódica entre os dispositivos de campo que estão no barramento fieldbus. Trate-se de um algoritmo de escalonamento pré-run-time, que permite atender às restrições de precedência dos blocos funcionais, personalizando e otimizando o uso dos recursos do sistema.

O algoritmo foi implementado na linguagem de programação Visual Basic e sua validação ocorreu em um ambiente real de aplicação através de estratégias de configuração, cujos resultados foram satisfatórios.

Palavras-chave: automação industrial, rede fieldbus, protocolo FOUNDATION FIELDBUS, algoritmo de escalonamento. 



\begin{abstract}
CICILLINI, D. A. (2007). Desenvolvimento de um Algoritmo de Escalonamento para Rede FOUNDATION FIELDBUS. Dissertation (Master's Degree) - São Carlos School of Engineering, University of São Paulo, São Carlos, 2007.

This dissertation presents and implements a scheduling algorithm for the FOUNDATION FIELDBUS technology. The algorithm named FFSMART schedules cyclic or periodic communication messages among field devices connected to a fieldbus. The FFSMART is a pre-runtime scheduling algorithm, which allows meeting the restrictions of precedence from function blocks, customizing and optimizing the use of the system resources.

The algorithm was implemented using the Visual Basic programming language and validated in a real application environment using configuration strategies, and the results were satisfactory.
\end{abstract}

Keywords: industrial automation, fieldbus networks, FOUNDATION FIELDBUS protocol, scheduling algorithm. 



\section{INTRODUÇÃO}

O avanço tecnológico no setor industrial trouxe novas técnicas de controle para os sistemas distribuídos, técnicas essas que alcançaram um nível considerável de desenvolvimento na tecnologia de chão de fábrica, cuja comunicação analógica, substituída pelo protocolo de comunicação digital, é conhecida como fieldbus.

O sistema fieldbus pode ser definido como:

[...] um sistema distribuído composto por dispositivos de campo e equipamentos de controle e de monitoramento integrados em um ambiente físico de uma planta ou uma fábrica. Os dispositivos do fieldbus trabalham em conjunto para realizar I/O e controle em operações e processos automáticos. (FIELDBUS FOUNDATION, 1999a, p.1).

Segundo Thomesse (1998), o fieldbus é "uma rede para conexão de dispositivos de campo, tais como, sensores, atuadores, controladores de campo como PLCs (Programable Logical Controller), reguladores, controladores de percursos e etc...”. Já para Tanembaum (1997), é um sistema de comunicação em tempo real, que se baseia na estrutura de camadas do modelo OSI (Open System Interconection).

Com estrutura semelhante às camadas de redes do modelo ISO/OSI (International Organization for Standardization/ Open System Interconection), o protocolo fieldbus utiliza apenas três camadas: a física, de enlace e de aplicação, e ao contemplar a norma IEC 61158, eliminou serviços como: os de correio eletrônico, mapeamento de servidores, roteamento de 
mensagens e outros, por não lhe serem úteis; essa eliminação agiliza o processo de comunicação, deixando-o mais rápido.

De forma amplamente difundida na literatura, a introdução da comunicação digital, encontrada na grande maioria dos sistemas fieldbus, bem como suas conseqüências diretas apresentam vantagens descritas de modo resumido nos parágrafos que se seguem.

De acordo com Henriques (2005), com a transmissão digital pode-se ter entre os dispositivos uma quantidade de informação trafegando no meio de comunicação, devido a uma multiplexação no tempo de transmissões entre os dispositivos, valida os dados que estão sendo transmitidos e ainda minimiza as distorções e possíveis variações indesejáveis do sinal.

Em relação aos custos de instalação de um sistema de controle distribuído, observouse redução dos mesmos, como também da complexidade relacionada à fiação e hardware frente à tecnologia convencional, como exemplo, o uso de PLC em determinadas aplicações (Cavalieri, 1998).

As funções de controle, aquisição (entrada) e atuação (saída) em processos ou plantas industriais são distribuídas nos dispositivos, permitindo redução da carga de processamento da sala de controle. Devido à distribuição de processamento, a sala de controle pode ficar integralmente responsável pelas atividades de supervisão, manutenção, gerenciamento e operação do sistema (Henriques, 2005), o que possibilita alto grau de compartilhamento de recursos não só para melhorar o aproveitamento dos recursos instalados, como também para simplificar as execuções de manutenção e documentação do sistema (Cavalieri, 1998).

A arquitetura fieldbus, no entanto, não apresenta somente vantagens, mas também dificuldades ou desvantagens, que merecem citação: 
- Maior preocupação com o gerenciamento do tráfego produzido pelos dispositivos, devido à necessidade da serialização do tráfego de informações produzida pelos dispositivos no barramento de comunicação (Cavalieri, 1998);

- A distribuição de recursos no fieldbus pode levar à perda do sincronismo existente entre os dispositivos, gerando, assim, a necessidade da existência de uma coordenação entre os mesmos para garantir a coerência de tempo (Sáenz e Thomesse, 1995);

- A complexidade para a garantia das restrições temporais do sistema (Henriques, 2005);

- Exigência de maior complexidade no software de configuração de aplicações, pois este deve possibilitar que os dispositivos trabalhem de forma cooperada e autônoma em uma arquitetura distribuída (Henriques, 2005).

Em oposição aos claros benefícios e avanços alcançados com o desenvolvimento de sistemas fieldbus eficazes, talvez a maior desvantagem deste tipo de sistema seja sua própria concepção baseada em barramentos de dados fato, que caracteriza todo fieldbus como um gargalo de comunicação, uma vez que um único canal de comunicação é compartilhado por todos os dispositivos e deve ser utilizado tanto para a transmissão de variáveis críticas de processo, informação de baixa prioridade e como também de monitoramento. Este compartilhamento do canal de comunicação, teoricamente, pode ocasionar um congestionamento na transmissão das mensagens e tarefas, causando atrasos na comunicação (Brandão, 2005).

Para sanar esta desvantagem, utilizam-se técnicas de escalonamento que atuam na rede como um agendamento das mensagens e tarefas a serem enviadas, de maneira a melhorar a 
transmissão e diminuir o congestionamento, mas respeitando sempre as prioridades de envio das mensagens.

Em sistemas distribuídos, o escalonamento é aplicado tanto na atribuição como na distribuição física e temporal de tarefas em recursos. Escalonar tarefas em um dispositivo ou equipamento significa organizar em seqüência seus processamentos; da mesma forma, podese entender o escalonamento de mensagens como o seu seqüenciamento no barramento.

Zweben e Fox (1994) assim definem o escalonamento:

"A seleção entre planos alternativos alocando recursos e atividades em cada instante de tempo, tal que esta designação obedeça às restrições temporais das atividades e as limitações de capacidade de um conjunto de recursos compartilhados".

De acordo com Pinedo (1995), a atividade de escalonamento objetiva alocar uma quantidade de recursos limitada para execução de uma tarefa no decorrer do tempo, de tal forma que um ou mais objetivos possam ser alcançados.

Pesquisas sobre o tema têm uma visão algorítmica e também apresentam fórmulas com estimativas para a solução do problema, como as de Xu \& Parnas (1990); Xu \& Lau (1997); Franco (1998), Henriques (2005) e SMAR EQUIPAMENTOS INDUSTRIAIS (2007e).

Em um sistema de controle distribuído em tempo real, as técnicas de escalonamento voltam-se para o atendimento dos requisitos temporais, restrições e ainda para alcançar os objetivos propostos, como ocorre nos métodos de escalonamento, mas não se envolvem diretamente com uma base de tempo.

Zweben e Fox (1994) definem escalonamento de produção como: "a seleção de seqüenciamento de atividades tais, que elas possam alcançar um ou mais objetivos e satisfazer um conjunto dominante de restrições". 
A localização de cada tarefa, na maioria dos sistemas fieldbus, é definida pelo usuário no momento do projeto ou da configuração do sistema de controle. Em grande parte dos casos esta definição baseia-se no tipo de malha de controle utilizado nos dispositivos livres e nas recomendações de segurança do sistema, isto é, nas condições seguras de funcionamento em caso de falha (Verhappen e Pereira, 2002).

Os algoritmos de escalonamento, em geral, são empregados na resolução das questões relativas à execução de cada tarefa ou mensagem, e se baseiam na configuração física e em restrições lógicas e temporais dos dispositivos e dos elementos de controle.

Os itens adiante são de extrema importância para a compreensão da funcionalidade de algoritmos no escalonamento de mensagens, bem como de suas tarefas (Cardeira e Mammeri, 1995).

\section{A. Aspectos temporais}

Os aspectos temporais caracterizam-se pelo instante de disparo, tempo de execução e tempo máximo de execução, como descritos a seguir:

- Instante de disparo: antes dele é impossível começar uma tarefa ou mensagem.

- Tempo de execução: prazo necessário para que uma tarefa ou mensagem seja executada sem interrupções.

- Tempo máximo de execução: intervalo máximo de tempo entre o início e o final da execução de uma tarefa ou mensagem.

\section{B. Prioridades}

Para iniciar o escalonamento das tarefas e mensagens, deve-se sempre levar em consideração a prioridade das mesmas, que se divide em dois conjuntos: prioridade de tarefas e de mensagens. 
Na primeira, as tarefas podem ser associadas de forma dinâmica ou estática, pelo próprio escalonador; já no caso das mensagens, a prioridade é definida pela aplicação.

\section{Preempção}

Preempção é o ato de interromper uma tarefa que está sendo executada para execução de uma segunda; somente após o término da execução da segunda, que se retorna a execução da primeira. Escalonadores de tarefas preemptivos têm melhor desempenho que os nãopreemptivos, apesar destes últimos serem usados na grande maioria dos casos, em razão de serem mais simples.

\section{Variação do tempo de execução das tarefas}

Para um número grande de escalonadores de tarefas, estas têm um tempo de execução finito, enquanto para os escalonadores de mensagens a condição de finitude é sempre verdadeira, pois toda mensagem tem um número finito de bytes.

\section{E. Restrições de precedência}

No caso de duas tarefas, há restrição de precedência, isto é, a execução de uma está condicionada ao término da execução de outra; também com as mensagens pode haver restrições de precedência.

\section{F. Restrições de recurso}

Uma tarefa pode necessitar de múltiplos recursos para ser executada, tais como: processador, memória, portas de $\mathrm{I} / \mathrm{O}$, porém a indisponibilidade de um deles impede a sua execução. Do mesmo modo, a transmissão de mensagens pode utilizar mais de um barramento 
(recurso) de comunicação, e caso isso ocorra, a transmissão de outras mensagens, ocasionalmente, em outros barramentos sofre bloqueio.

\section{G. Escalonamento on-line e off-line}

O escalonamento on-line é processado sempre que se requisitar a execução de uma tarefa; mais adequado no caso de tarefas ou mensagens aperiódicas. Já o off-line define a tabela de escalonamento das tarefas no sistema antes do início da operação, sendo mais utilizado quando tarefas ou mensagens são periódicas.

\section{H. Critérios de otimização}

A qualidade do resultado de um algoritmo de escalonamento é importante para garantir o atendimento de requisitos temporais de um sistema. Alguns algoritmos podem ser otimizados em função de certos critérios, como descrito a seguir:

- Minimizar o comprimento da tabela de escalonamento, isto é, o período de tempo compreendido entre o início da execução da primeira tarefa ou mensagem e o término da execução da última.

- Equilíbrio de carga: em redes com múltiplos barramentos, significa distribuir equilibradamente o tráfego de mensagens dentre os diversos barramentos.

- Minimizar o número de tarefas que não atendem a seus próprios requisitos temporais.

\section{Escalonamento de malhas de controle distribuídas em sistemas FOUNDATION FIELDBUS}

No protocolo FOUNDATION FIELDBUS, o escalonamento adotado é o do tipo offline, realizado pelo software configurador de redes de campo, no qual os elementos (tarefas) 
são alocados, escalonados e representados numa tabela de execução temporal (schedule table) assim que o usuário configura a malha de controle. Os elementos manipulados nesse tipo de escalonamento localizam-se no nível mais alto das camadas do protocolo FOUNDATION FIELDBUS, também chamado de camada do usuário (user layer) (Figura 1).

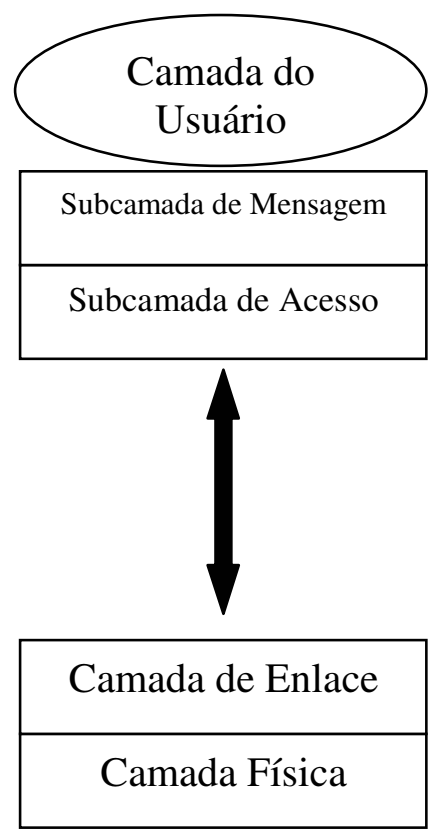

Figura 1 - Representação da estrutura em camadas do protocolo FOUNDATION FIELDBUS

As malhas de controle distribuídas em sistema FOUNDATION FIELDBUS configuram-se por meio de elementos denominados blocos funcionais, que nada mais são que softwares residentes nos dispositivos da rede. Estes blocos funcionais encapsulam funções e algoritmos básicos de automação e controle de processos, cujo tempo de execução é finito e previamente determinado. Distribuídos entre os transmissores, os blocos funcionais têm suas variáveis de entrada e saída conectadas a outros blocos, de forma a estabelecerem malhas de controle. Quando se conectam blocos funcionais de dispositivos distintos, estabelece-se e mapeia-se remotamente a uma mensagem periódica do sistema. 
Uma malha de controle SISO (Single Input, Single Output) com algoritmo PID (Proporcional Integral Derivativa), como ilustra a Figura 2, pode ser conectada a três blocos funcionais: Entrada Analógica (AI); Controlador PID; Saída Analógica (AO), conexão remota que é estabelecida entre os parâmetros OUT do bloco TT1-AI-1 (Transmissor de Temperatura) e o parâmetro IN do bloco FI1-PID-1 (Posicionador de Válvula), ambos situados em transmissores distintos.

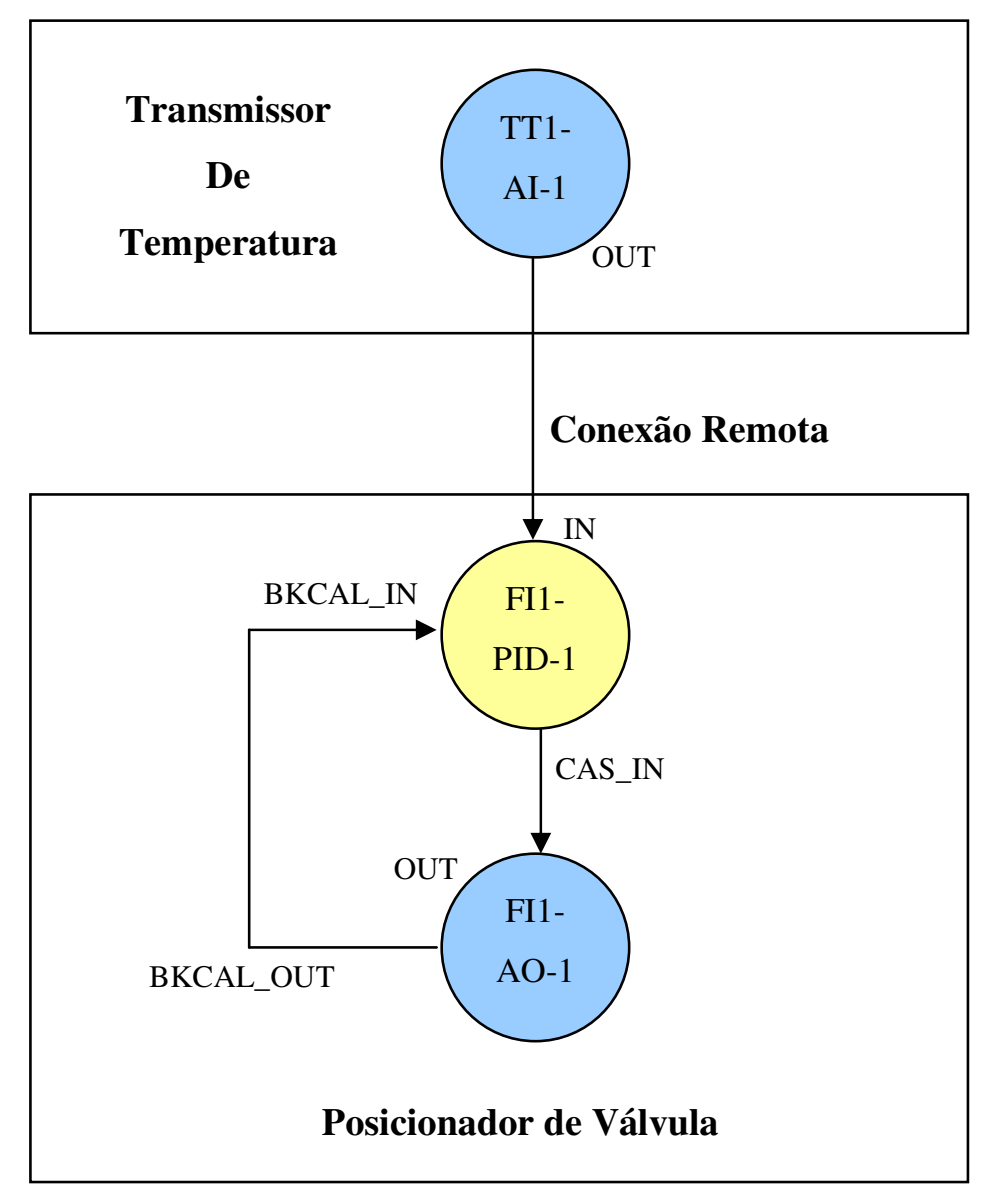

Figura 2 - Exemplo de malha de controle distribuída

Considerando que todas as mensagens periódicas devem ser enviadas em instantes predeterminados, já que carregam dados gerados por blocos funcionais, recomenda-se que a seqüência temporal de execução dos blocos funcionais e das suas conexões remotas sejam relacionadas ao instante de envio das mensagens periódicas. Tal seqüência de execução é 
definida por um algoritmo escalonador off-line, não-preemptivo, cujas restrições de recurso devem ser observadas. $\mathrm{O}$ algoritmo pode ou não levar em conta as restrições de precedência entre blocos funcionais e suas conexões remotas; como resultado dessa operação obtém-se uma tabela de escalonamento com instantes de disparo de cada bloco funcional e suas conexões remotas.

$\mathrm{O}$ acesso ao meio físico no protocolo FOUNDATION FIELDBUS é realizado por meio de algoritmos da camada de enlace e dividido em duas formas distintas, sendo que cada uma delas caracteriza uma banda ou fase de comunicação (Berge, 2002).

As duas bandas de comunicação são complementares e compartilham um único barramento: a primeira banda, destina-se à transmissão de mensagens periódicas ou cíclicas referentes as conexões remotas entre blocos funcionais; a segunda, fica reservada à transmissão de mensagens aperiódicas ou acíclicas, na qual incluem-se as mensagens de manutenção e gerência das estruturas do protocolo. Estas bandas alternam-se no barramento de dados de forma contínua e repetitiva, originando ciclos de períodos constantes, denominados macrociclos ou ciclos de comunicação (Figura 3).

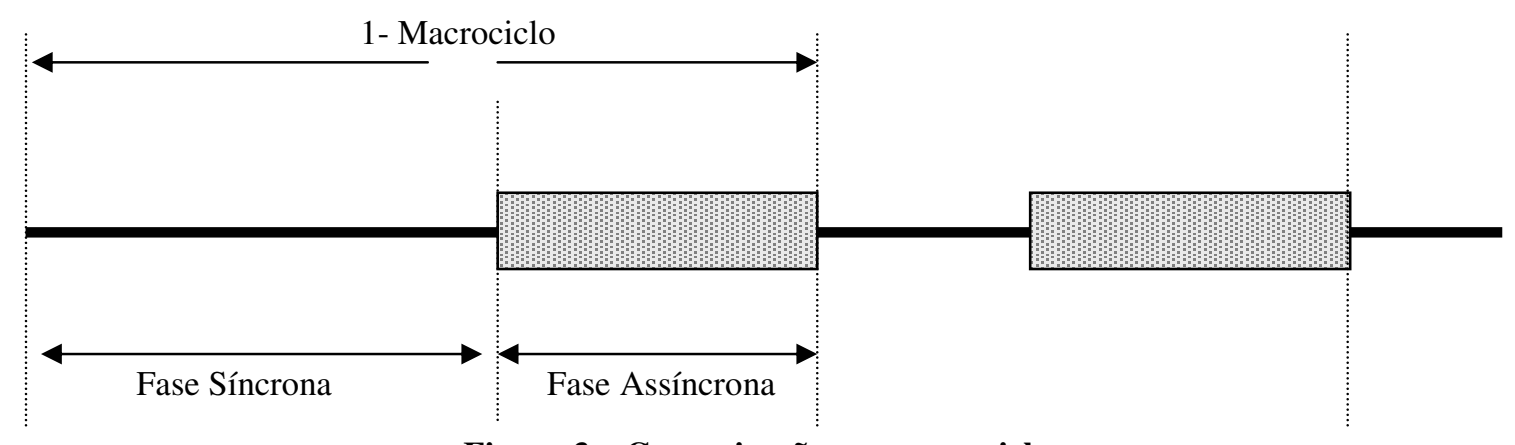

Figura 3 - Comunicação em macrociclos

O período do macrociclo em aplicações industriais típicas está entre alguns milisegundos (ms) e segundos (s), como também em outros sistemas fieldbus utilizados no 
controle de processos em tempo real; também determina a taxa de controle das malhas distribuídas em operação na rede.

Para a resolução do congestionamento e conseqüentemente do atraso em rede fieldbus, os algoritmos de escalonamento levam em consideração a integração entre os blocos funcionais, as restrições e as precedências das mensagens a serem transmitidas.

Como a linha de pesquisa sobre o assunto é vasta e as opiniões diversas, surgiu, então, a motivação do estudo deste tema aqui apresentado, acreditando que o seu desenvolvimento muito contribuirá para a ciência e para área de automação industrial.

\subsection{OBJETIVOS}

Os objetivos deste trabalho são:

1. Projetar e implementar um algoritmo de escalonamento para o protocolo FOUNDATION FIELDBUS, com base na estratégia de aplicação configurada pelo software SYSCON, pertencente à indústria SMAR EQUIPAMENTOS INDUSTRIAIS LTDA, visando a otimização do período do macrociclo para as mensagens cíclicas e o tempo de execução do processo.

2. Coletar os dados configurados na planta de processo industrial e gerar uma tabela com base nos elementos desta planta, destacando as prioridades dos blocos funcionais e das mensagens a serem transmitidas, com o fim de realizar o seu escalonamento.

3. Analisar os dados à validação e aos resultados do algoritmo comparando-os e observar o macrociclo do processo e o tempo de execução de cada bloco, assim como as respectivas mensagens a partir do algoritmo de escalonamento denominado FFSMART. 


\subsection{ORGANIZAÇÃO DO TRABALHO}

O presente trabalho está dividido em capítulos. No primeiro está o desenvolvimento da introdução; seguindo o Capítulo 2 destaca o protocolo FOUNDATION FIELDBUS e suas funcionalidades; o Capítulo 3 apresenta a Revisão Bibliográfica, com a teoria sobre Escalonamento e a fonte motivadora para o estudo deste tema. O Capítulo 4 contempla o desenvolvimento do trabalho, a implementação e as funcionalidades do algoritmo de escalonamento proposto; o Capítulo 5 traz os ensaios de campos e seus respectivos resultados, e, por fim, o Capítulo 6 apresenta as discussões e as conclusões. 


\section{FOUNDATION FIELDBUS}

\subsection{INTRODUÇÃO}

A evolução das interfaces de instrumentação iniciou-se a partir dos transmissores de 315 psi, passando pelas interfaces analógicas de 4-20 mA até chegar a tecnologia fieldbus (Scott e Buchanan, 2000). A Tabela 1 evidencia a evolução das tecnologias no mercado de instrumentação, no decorrer dos anos.

Tabela 1 - Evolução das tecnologias no mercado de instrumentação (Scott e Buchanan, 2000)

\begin{tabular}{c|c}
\hline ANO & TECNOLOGIA \\
\hline 1960 & $3-15$ Psi \\
1970 & $4-20$ mA analógico \\
1980 & Serial Links \\
1990 & Fieldbus \\
\hline
\end{tabular}

Para Regh, Swain e Yangula (1999), a arquitetura de controle dos processos industriais evoluiu a partir do Direct Digital Control (DDC) em 1962, passou pelos controladores lógicoprogramáveis (Programmable Logic Controllers - PLC) cuja origem data de 1970; estes foram seguidos pelo Sistema de Controle Distribuído - SCD (Distributed Control Systems DCS), em 1976, e deram origem ao Sistema de Controle Fieldbus - SCF (Field Control 
Systems - FCS), no ano de 1994. A Figura 4 representa o deslocamento das atividades de controle para os dispositivos em chão de fábrica.

O protocolo fieldbus surgiu na década de 90 , dada a necessidade do mercado ter acesso a um protocolo que funcionasse de maneira totalmente digital, uma vez que os transmissores inteligentes já faziam uso desta nova técnica, a tecnologia digital. Assim, o Fieldbus de posse desta característica digital, pôde transmitir dados serialmente através do meio de comunicação ou barramento e ainda possibilitar uma comunicação bidirecional (IEC, 2005).

\section{DDC}

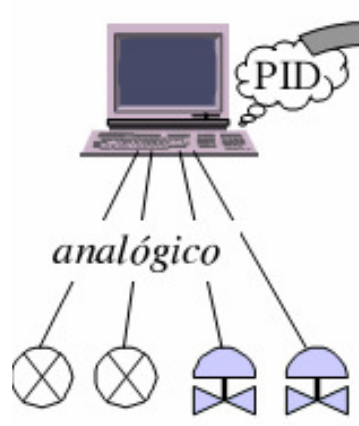

DCS

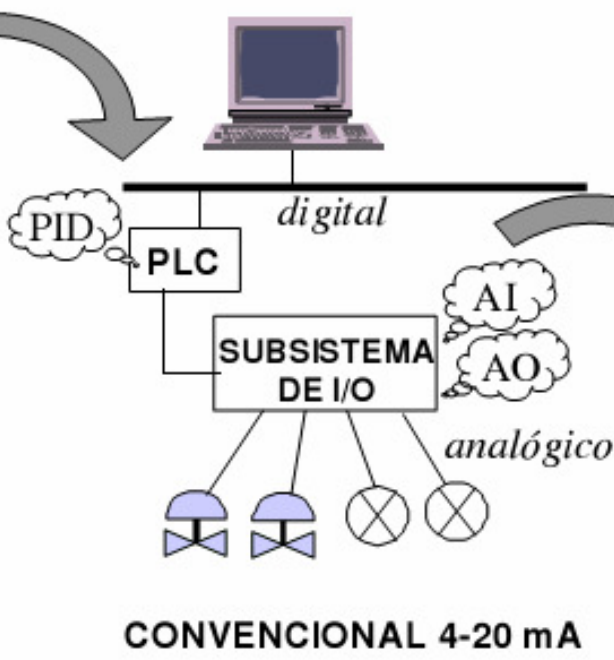

Legenda:

$\mathrm{AI}=$ Analog Input $\mathrm{AO}=$ Analog Output

Figura 4 - Arquitetura de controle (Regh, Swain e Yangula, 1999)

De acordo com a norma IEC (2005), a comunicação no fieldbus é digital e os serviços prestados pelo protocolo de comunicação deste sistema, quando bem elaborados, permitem melhor exploração do meio de comunicação, favorecendo que quantidade maior de 
informações trafeguem no barramento através do compartilhamento das informações transmitidas em ambas as direções, pelos dispositivos de campo.

Fieldbus é essencialmente uma arquitetura de comunicação de dados, plenamente adequada para instalação em ambientes agressivos, uma vez que propicia medições e controle em ambientes de chão de fábrica (IEC, 2005). É uma rede local utilizada tanto na indústria de automação de processos como de manufatura; favorece a distribuição da aplicação de controle nos dispositivos desta mesma rede, e ainda que as atividades de medição e controle de processos sejam efetuadas automaticamente pelos dispositivos sem qualquer intervenção humana, monitoradas e, se necessário, controladas remotamente (Thomesse, 1998).

O Fieldbus é um sistema de comunicação em tempo real, cuja configuração de protocolo de rede baseia-se no modelo ISO/OSI.

Neste trabalho, buscou-se evidenciar a camada de aplicação do usuário, responsável pelo tráfego de comunicação, e o escalonamento das mensagens no barramento FOUNDATION FIELDBUS.

\subsection{PROTOCOLO FOUNDATION FIELDBUS}

O FOUNDATION FIELDBUS é um dos protocolos que adotou a tecnologia digital, como também todos os padrões do fieldbus, descritos na introdução deste capítulo. O protocolo FOUNDATION FIELDBUS, além das camadas existentes, apresenta a camada do usuário, baseada em processos de aplicação de blocos funcionais; está situada hierarquicamente acima das camadas de rede, que compõem o chamado stack (pilha) de comunicação (Figura 5). 
O que são blocos funcionais? São módulos de programas que desempenham funções de controle, aquisição e atuação; eles requerem uma maior interação entre si, para que, através da troca de dados, seja possível controlar o sistema (FIELDBUS FOUNDATION, 1999b).

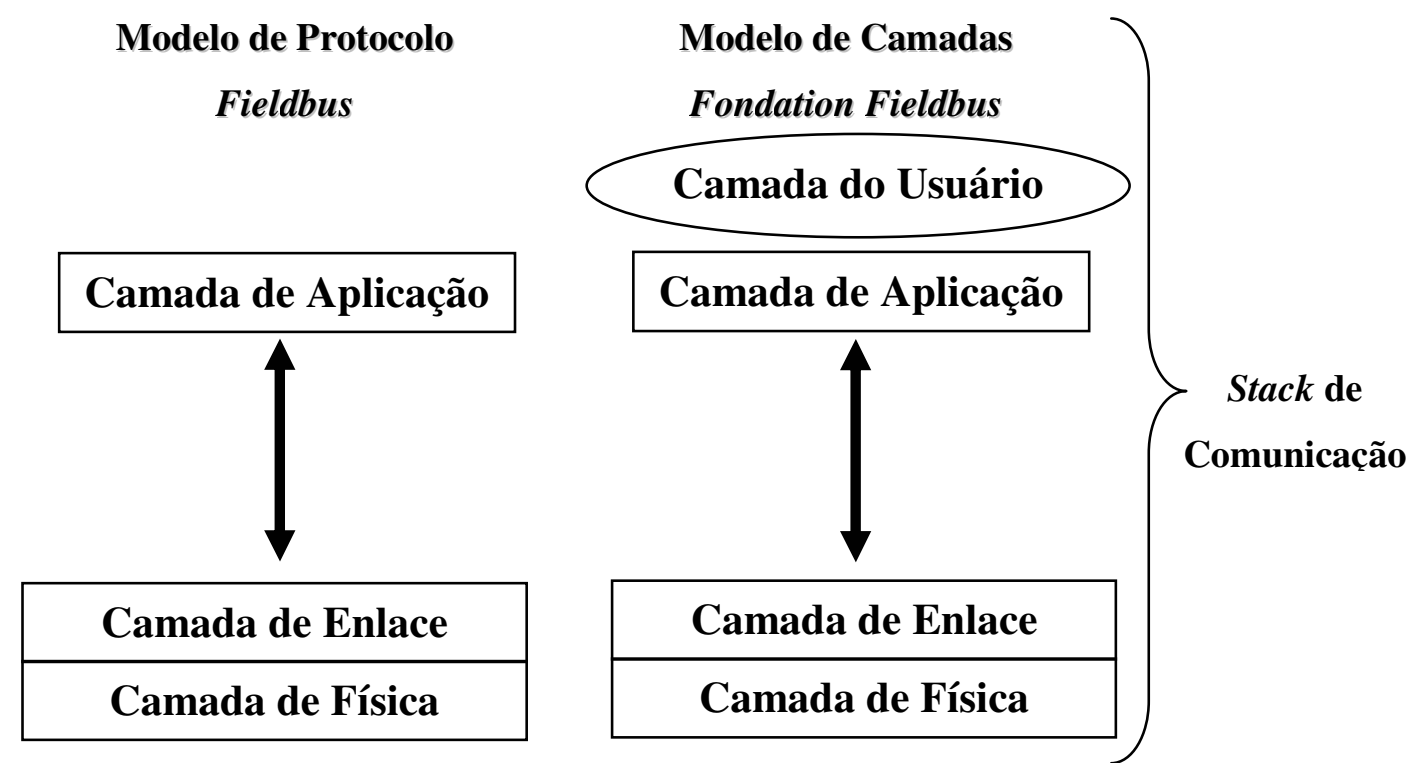

Figura 5 - Estrutura em camadas do protocolo FOUNDATION FIELDBUS

O FOUNDATION FIELDBUS é um protocolo de comunicação, com funcionalidades caracterizadas pelo fluxo de mensagens presente em um canal de comunicação, o stack ou barramento, que visa atender à demanda com troca de informações entre os dispositivos ativos na rede - informações provenientes tanto das estruturas das camadas de rede como das estruturas e funções da camada do usuário (Figura 5).

Com a utilização do protocolo FOUNDATION FIELDBUS, as necessidades do usuário final têm evoluído. Neste sentido almejam-se algumas melhorias, como proposto por Thomesse (1998):

"O maior requisito a ser alcançado é a confiabilidade, pois o medo de se perder o controle em casos de falha é grande. $\mathrm{O}$ sistema deve ser 
confiável, permitindo-se uma maior segurança e disponibilidade do sistema”.

\subsubsection{BLOCO FUNCIONAL}

A camada de aplicação do usuário é composta por blocos, representados por diferentes tipos de aplicação e função, daí o nome de bloco funcional (Figura 6).

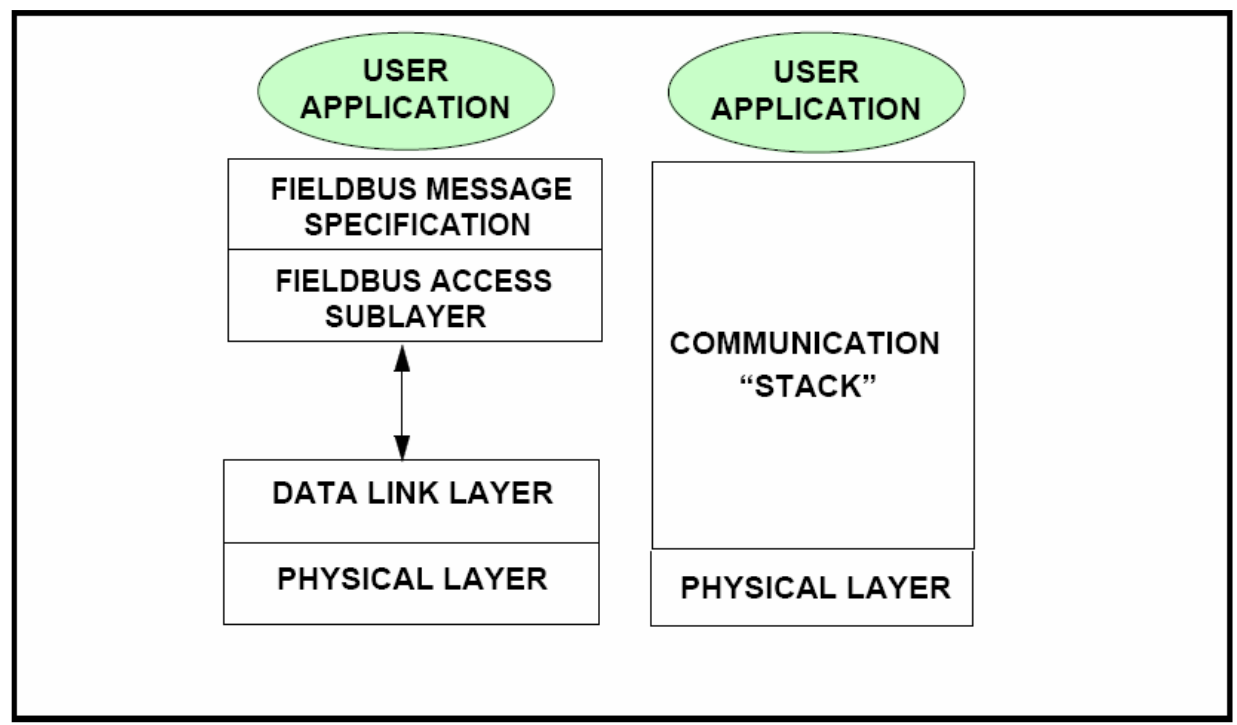

Figura 6 - Tipos de blocos da camada de aplicação do usuário (FOUNDATION FIELDBUS, 2003)

A norma define os blocos funcionais como elementos de software que modelam algoritmos paramétricos, os quais transformam os parâmetros de entrada nos de saída (FIELDBUS FOUNDATION, 1999b).

O protocolo FOUDANTION FIELDBUS realiza o controle do processo de modo distribuído, permitindo que cada bloco funcional que compõe a aplicação seja executado localmente nos dispositivos ou equipamentos de campo. A comunicação entre estes blocos 
funcionais é realizada por um barramento de comunicação compartilhado entre os dispositivos de campo; por meio de transferências de mensagens, os buffers de dados de entrada e saída de cada bloco funcional serão utilizados no decorrer do tempo (Zhou e Yu, 2002).

Os tipos de blocos usados na camada de aplicação do usuário estão descritos na Figura 7; no caso, os dispositivos são configurados com uso dos blocos Resource e Transducer (FIELDBUS FOUNDATION, 2003).

Os blocos funcionais processam parâmetros de entrada em função da sua configuração, e assim geram saídas que podem ser utilizadas por outros blocos. A norma os classifica em:

- Blocos de entrada: acessam medidas físicas e assim mantêm comunicação com blocos transdutores de entrada por meio de canais. Tais medidas são convertidas, linearizadas e disponibilizadas para outros blocos funcionais pelos parâmetros de saída;

- Blocos de saída: estes acionam blocos transdutores de saída pelos canais, a partir de um valor recebido pelos links estabelecidos com outros blocos nos seus parâmetros de entrada;

- Blocos de controle: realizam cálculos com parâmetros de blocos de entrada e enviam parâmetros para outros blocos de controle ou de saída;

- Blocos de cálculo: desenvolvem cálculos matemáticos sobre parâmetros de entrada, para gerarem parâmetros de saída. 


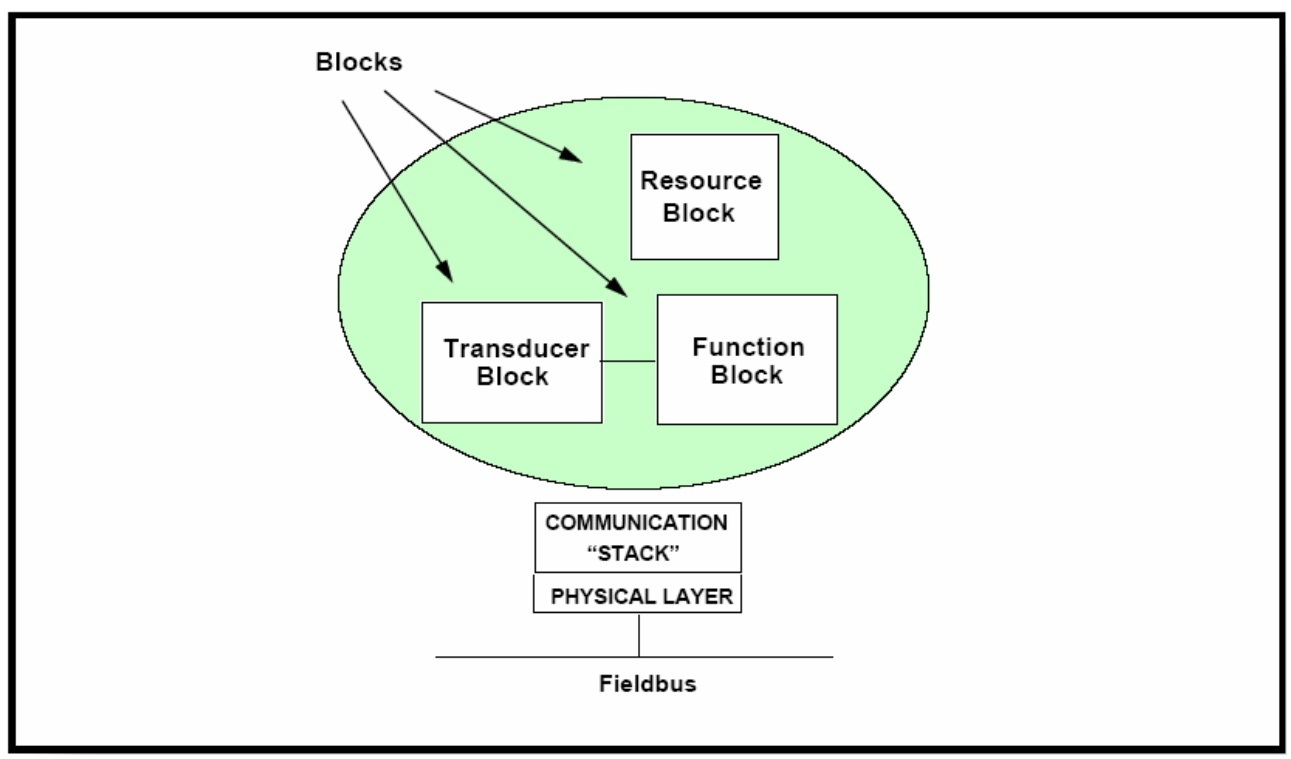

Figura 7- Tipos de blocos funcionais (FOUNDATION FIELDBUS, 2003)

Para construção do controle da estratégia de aplicação, utilizam-se os blocos funcionais. O desempenho de uma aplicação condiz com a execução precisa dos blocos funcionais em determinado período que, se respeitado garante a consistência temporal da aplicação. A complexidade da aplicação relaciona-se ao arranjo de blocos funcionais e suas ligações lógicas, que impõem os limites de tempo ao sistema.

Para que um ou mais objetivos possam ser alcançados, todas as restrições devem ser satisfeitas, com a adoção de propostas que visem a solução dos problemas de escalonamento, uma vez que o escalonamento de cada bloco de função deve ser executado de maneira precisa.

O escalonamento caracteriza no tempo qual bloco funcional ser á executado num dispositivo ou equipamento específico e quais mensagens serão transmitidas através do barramento. As mensagens transmitidas no instante de tempo afetam e são afetadas pelos blocos funcionais executados nos dispositivos de campo já configurados.

A comunicação de blocos funcionais ocorre quando se estabelece ligação lógica entre um parâmetro de saída de um bloco e um parâmetro de entrada de um outro bloco, ligação que pode ser local, estabelecida entre blocos de um mesmo dispositivo, ou remotamente, entre blocos de dispositivos distintos (BRANDÃO, 2005). 
No protocolo FOUDATION FIELDBUS, os blocos funcionais são de extrema importância, pois seu bom funcionamento favorece melhor desempenho da aplicação fator que garante consistência temporal na execução das tarefas.

O bloco resource ou de recurso (Figura 7), denominado bloco funcional, tem em sua configuração a descrição das características de hardware do dispositivo ou equipamento de campo. Já o bloco de recurso possui um algoritmo que é utilizado para monitorar o estado de operação do hardware e indicar possíveis alarmes neste aspecto. A execução do bloco de recurso não é escalonada, portanto ele não possui parâmetros de entrada ou de saída; tal execução segue as regras definidas pelo fabricante.

O bloco transducer ou bloco transdutor (Figura 7) é um bloco funcional e fica entre os blocos de I/O e o hardware de I/O. Como seu próprio nome diz, possui a função de transformar e traduzir sinais físicos em variáveis e vice-versa, de isolar os blocos funcionais dos dispositivos e hardware específicos de I/O, como sensores, atuadores e chaves de cada dispositivo. Seus algoritmos internos controlam os dispositivos I/O, apresentam uma interface padronizada para os blocos funcionais e ainda realizam funções, como calibração, filtragem de sinais e conversão de dados. Estes blocos seguem definições da norma, embora também possam ser de um tipo particular, definido pelo fabricante.

A comunicação entre os blocos transdutores e os funcionais de entrada ou de saída ocorre por meio de canais mapeados em parâmetros CHANNEL, podendo um bloco transdutor ter vários canais. Uma vantagem do isolamento do bloco funcional, em relação ao hardware, é a possibilidade da execução inexaurível do bloco transdutor no processamento de um dado de boa qualidade sem prejuízo de sobrecarga para os blocos funcionais (BRANDÃO, 2005).

A norma classifica os blocos transdutores em três tipos:

- Input - realizam a interface com sensores; 
- Output - executam a interface com atuadores ou dispositivos de saída;

- Display - operam dispositivos de interface local.

A execução dos blocos transdutores, assim como dos blocos de recurso, não possui parâmetros de entrada ou saída, e sua execução não é comandada por escalonamento, mas, sim, definida pelo fabricante.

\subsubsection{TRÁFEGO DE COMUNICAÇÃO}

Para desenvolver seu trabalho de maneira confiável, o fieldbus utiliza serviços que lhe garantam o atendimento das restrições temporais; assim, uma aplicação do sistema fieldbus requer o tratamento de dois tipos de tráfego de dados: o aperiódico ou acíclico e o periódico ou cíclico (Thomesse, 1998).

Segundo Thomesse (1998), as restrições temporais são essenciais para a operação em tempo real do sistema, pois a não-garantia destas restrições afeta o comportamento do mesmo. Para este autor as restrições temporais mais importantes são: periodicidade, jitters, tempo de resposta do processo de aplicação, e diferente simultaneidade ou coerência de tempo nas ações ou dados.

Thomesse (1998) assim define as restrições temporais:

- Periodicidade: tempo em que ocorre a transmissão de dados cíclicos e que deve ser respeitado;

- Jitters: são variações de tempo inseridas nas características temporais-padrão do sistema. Os jitters também ocorrem quando o sistema está em atividade, destoando do valor de período especificado em tempo de projeto; 
- Tempo de resposta: é aquele que está entre uma requisição e sua resposta;

- Coerência de tempo: propriedade associada a dois ou mais eventos; indica, ainda, se tais eventos ocorreram dentro de uma janela de tempo definida. Este conceito é utilizado para definir eventos simultâneos.

A literatura define como "acesso ao meio físico" a etapa do processo de comunicação regulamentada pela norma de camada de enlace, cuja comunicação em um barramento de dados ocorre quando a mensagem for produzida e transmitida por um dispositivo, e também recebida e decodificada com sucesso por outro(s) dispositivo(s). Dentro do processo de comunicação, o dispositivo que produz e transmite a mensagem deve, para esse fim utilizar o barramento de dados durante o tempo necessário para completar a transmissão da mensagem, sem entrar em conflito com outros dispositivos que porventura venham a utilizar o mesmo recurso, simultaneamente.

No protocolo FOUNDATION FIELDBUS, a comunicação de troca de dados se dá entre sensores e atuadores, controladores e atuadores, e também entre os próprios controladores. Os dados trocados entre estes elementos são definidos como tráfego de dados identificados, pois suas características temporais são conhecidas antes do sistema entrar em atividade, ou seja, no estágio de especificação da aplicação (Figura 8). De modo a garantir o acesso ao meio físico no protocolo FOUNDATION FIELDBUS, os itens de tráfego de comunicação citados por Thomesse (1998) são realizados por algoritmos da camada de enlace e divididos em duas formas distintas, sendo que cada uma caracteriza uma banda, tráfego, ou fase de comunicação. 


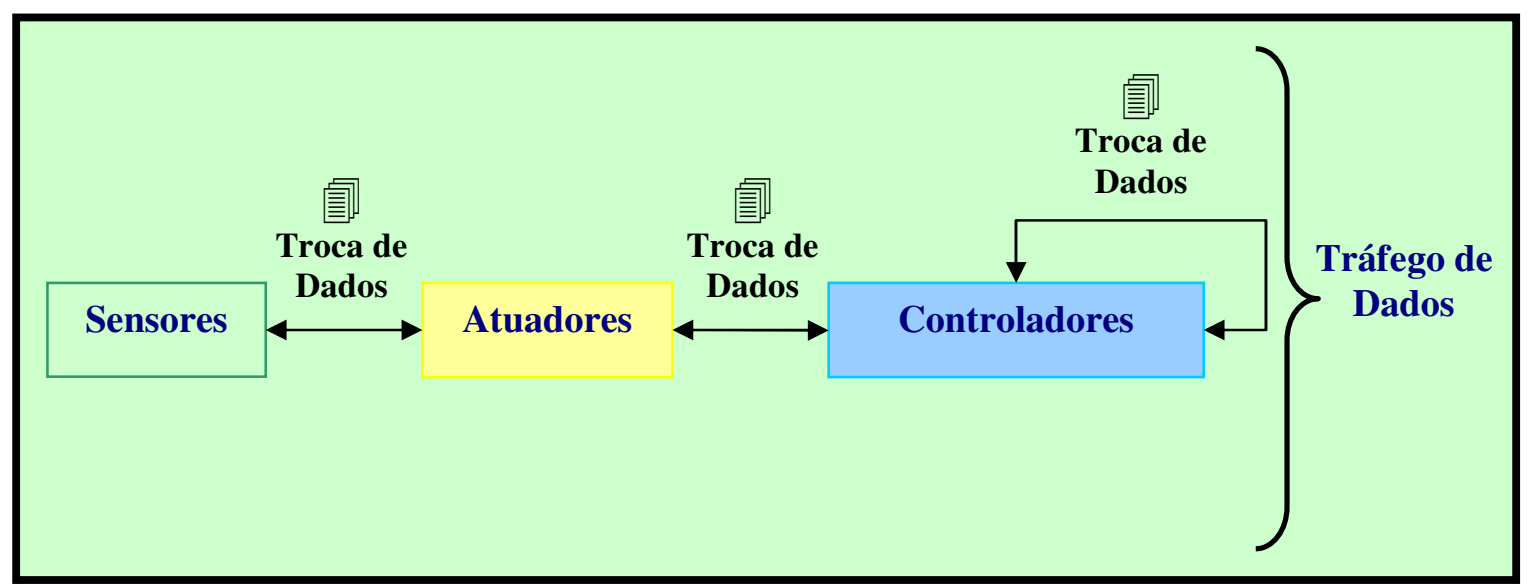

Figura 8 - Comunicação de troca de dados no protocolo FOUNDATION FIELDBUS

Os tráfegos de comunicação são complementares e compartilham um único barramento: um é destinado à transmissão de mensagens determinísticas e periódicas ou cíclicas de prioridade alta; o segundo tráfego de comunicação, de prioridade inferior, é reservado à transmissão de mensagens aperiódicas ou acíclicas, na qual se incluem as mensagens de manutenção e gerência das estruturas do protocolo. Estas fases, bandas ou tráfegos denominam-se cíclicos e acíclicos, e podem ser definidos como:

- Tráfego cíclico ou periódico: quando há troca de dados entre entidades de baixo nível (dispositivos de campo). As características dessa troca de dados ocorrem entre entradas e saídas dos algoritmos de controle que, transmitidos periodicamente, concedem a cada dado seu próprio período (Thomesse, 1998); tais dados são produzidos durante a troca de variáveis de medida e controle, e geralmente são caracterizadas como críticas em relação ao tempo (Franco, 1998). Os Jitters podem ou não ser aceitos pelos protocolos, que devem possuir regras mais rígidas para respeitar uma periodicidade de tempo, sem a presença dos mesmos (Thomesse, 1998). Os sistemas que contêm este tipo de tráfego baseiamse no estado do tráfego, geralmente denominados de sistemas disparados por tempo. 
- Tráfego acíclico ou aperiódico: composto por requisições feitas entre entidades de baixo nível (dispositivos de campo) e entidades de nível superior (sala de controle), expressa o modelo cliente-servidor. Neste caso, a transmissão de dados se dá de maneira aperiódica, com ocorrência aleatória no tempo, podendo ser liberados por meio de algum evento no sistema. Estas requisições estão associadas aos sistemas disparados por evento.

Os tráfegos de comunicação citados alternam-se no barramento de dados de forma contínua e repetitiva, originando ciclos de períodos constantes, denominados macrociclos ou ciclos de comunicação, como se observa na Figura 3. O período do macrociclo do FOUNDATION FIELDBUS, em aplicações industriais típicas, está entre alguns milisegundos e segundos, como também em outros sistemas fieldbus utilizados para controle de processos em tempo real, ou seja, encontra-se profundamente atrelado à taxa de controle das malhas distribuídas em operação na rede (Figura 9).

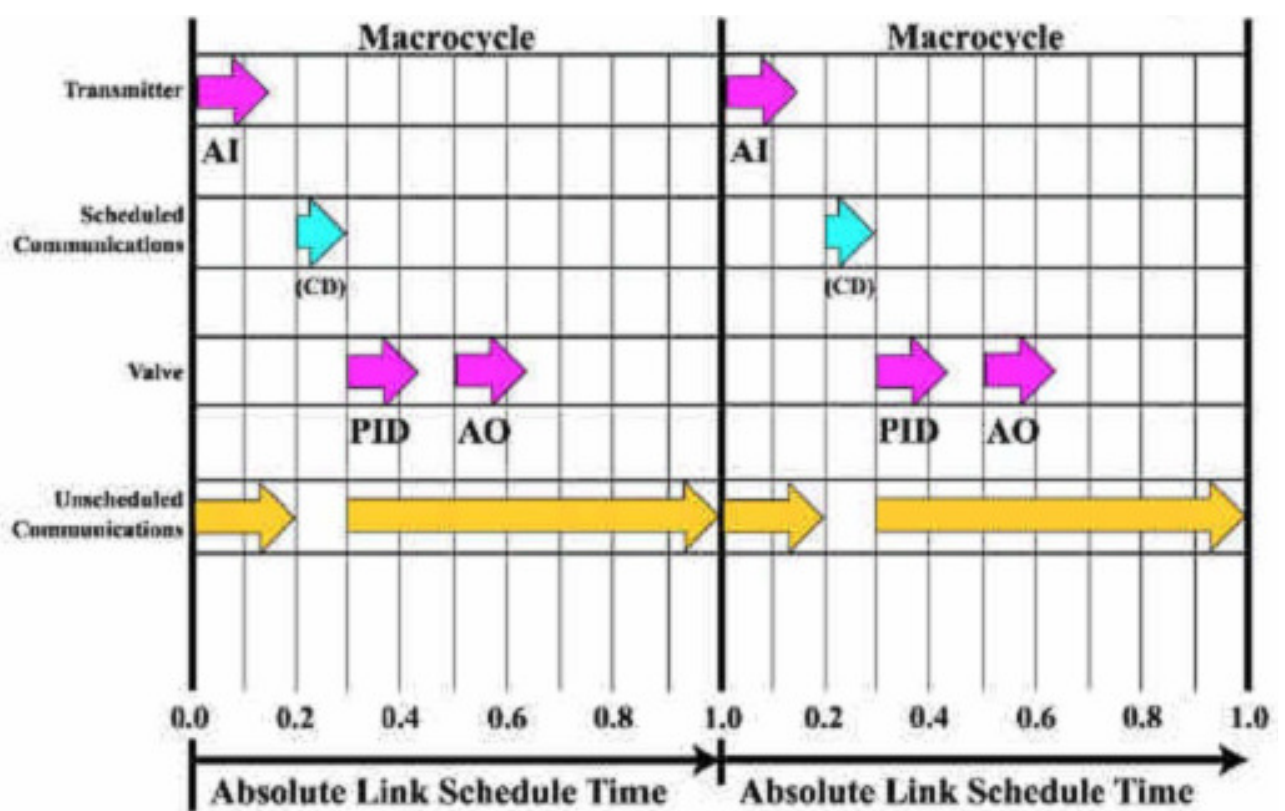

Figura 9 - Macrociclos e o escalonamento no barramento (FOUNDATION FIELDBUS, 2003) 


\subsubsection{CAMADAS, GERENCIAMENTO E SERVIÇOS DE REDE}

A camada do modelo OSI, usada no protocolo FOUNDATION FIELDBUS, possui uma funcionalidade no gerenciamento e no serviço de rede, e estas serão destacados a seguir. Como já foi descrito, o protocolo FOUNDATION FIELDBUS utiliza três camadas das sete existentes no modelo ISO/ OSI, assim neste trabalho serão descritas as camadas de nível 1, nível 2, nível 7 e a nível 8, existente no fieldbus, definida pela IEC 61158 e conhecida como camada de aplicação do usuário (Figura 10).

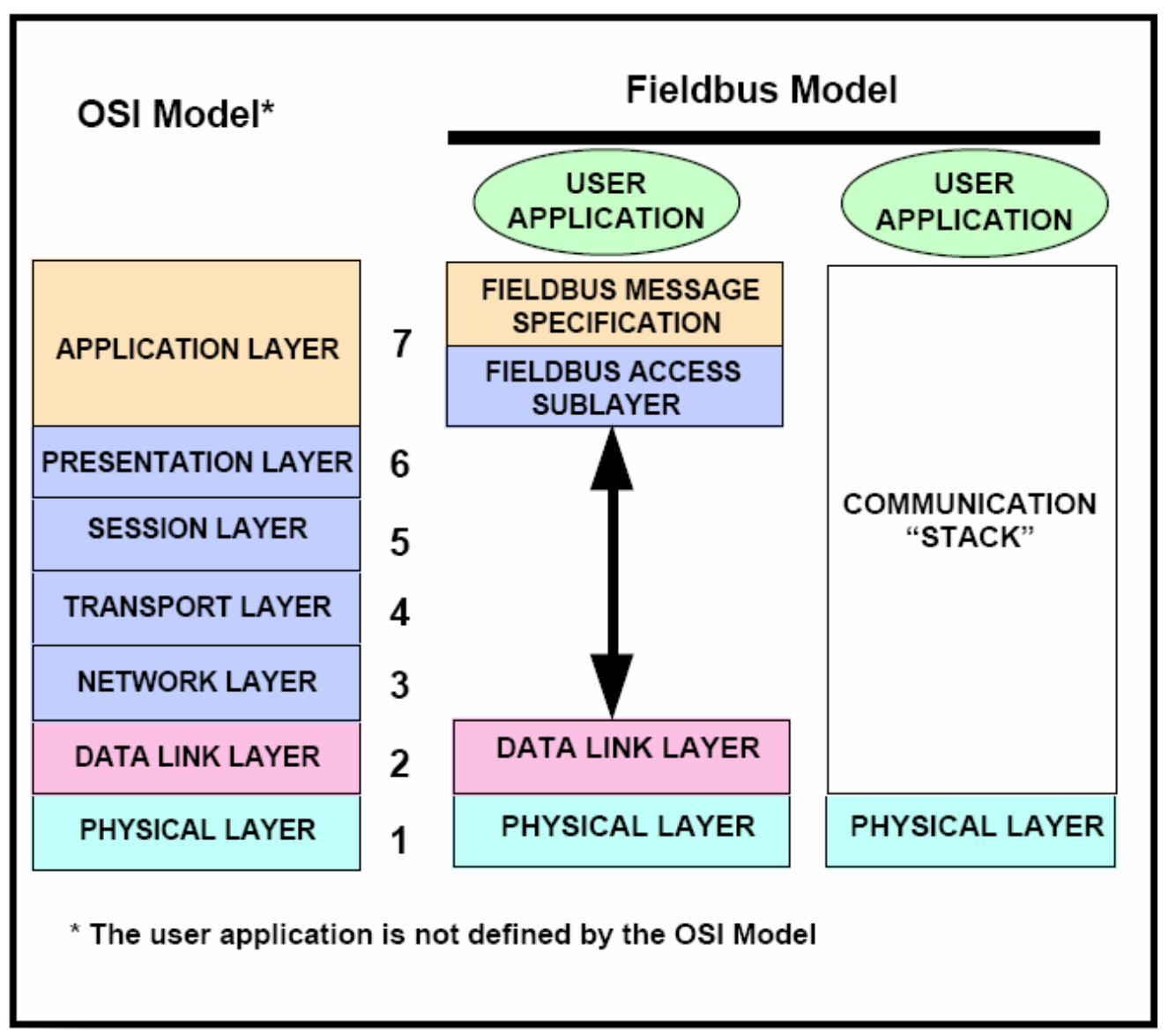

Figura 10 - Camada do modelo OSI no FOUNDATION FIELDBUS (FOUNDATION FIELDBUS, 2003)

A camada física ou nível 1, segundo a norma IEC (2005), é responsável pela transmissão de bits, características, especificações elétricas e mecânicas das interfaces e de dispositivo a serem instalados na rede. 
A camada de enlace de dados ou nível 2, também conhecida como DLL - Data Link Layer no protocolo FOUNDATION FIELDBUS, é dividida em duas subcamadas: MAC Medium Access Control e o LLC Logical Link Control, assim definidas segundo Henriques (2005) como:

- MAC: localizado na subcamada inferior da DLL, é responsável pela política de acesso ao meio físico, uma vez que a topologia adotada pelo protocolo é do tipo barramento, usualmente utilizada também em sistemas industriais;

- LLC: localizado na subcamada da parte superior da DLL; seu objetivo é definir alguns dos primeiros procedimentos de tolerância à falha do sistema, baseando-se na abertura e fechamento de conexões, fluxo de controle e gerenciamentos de erros; em outras palavras, diagnostica o que está acontecendo na rede.

Como este trabalho estuda o escalonamento no protocolo FOUNDATION FIELDBUS, é válido destacar que a atividade de escalonamento de mensagem no fieldbus localiza-se na subcamada MAC, que possui como referencial a garantia de ocorrer deterministicamente o acesso ao meio físico de comunicação, com destaque para MAC, a única responsável pela política de alocação de recursos compartilhados.

Continuando, no nível 7 situa-se a camada de aplicação, responsável pelo mapeamento das características da camada de aplicação do usuário para a subcamada MAC.

A camada de aplicação no FOUNDATION FIELDBUS se divide em duas subcamadas: FAS (Fieldbus Access Sublayer) e FMS (Fieldbus Message Specification), como exemplifica a Figura 11. 


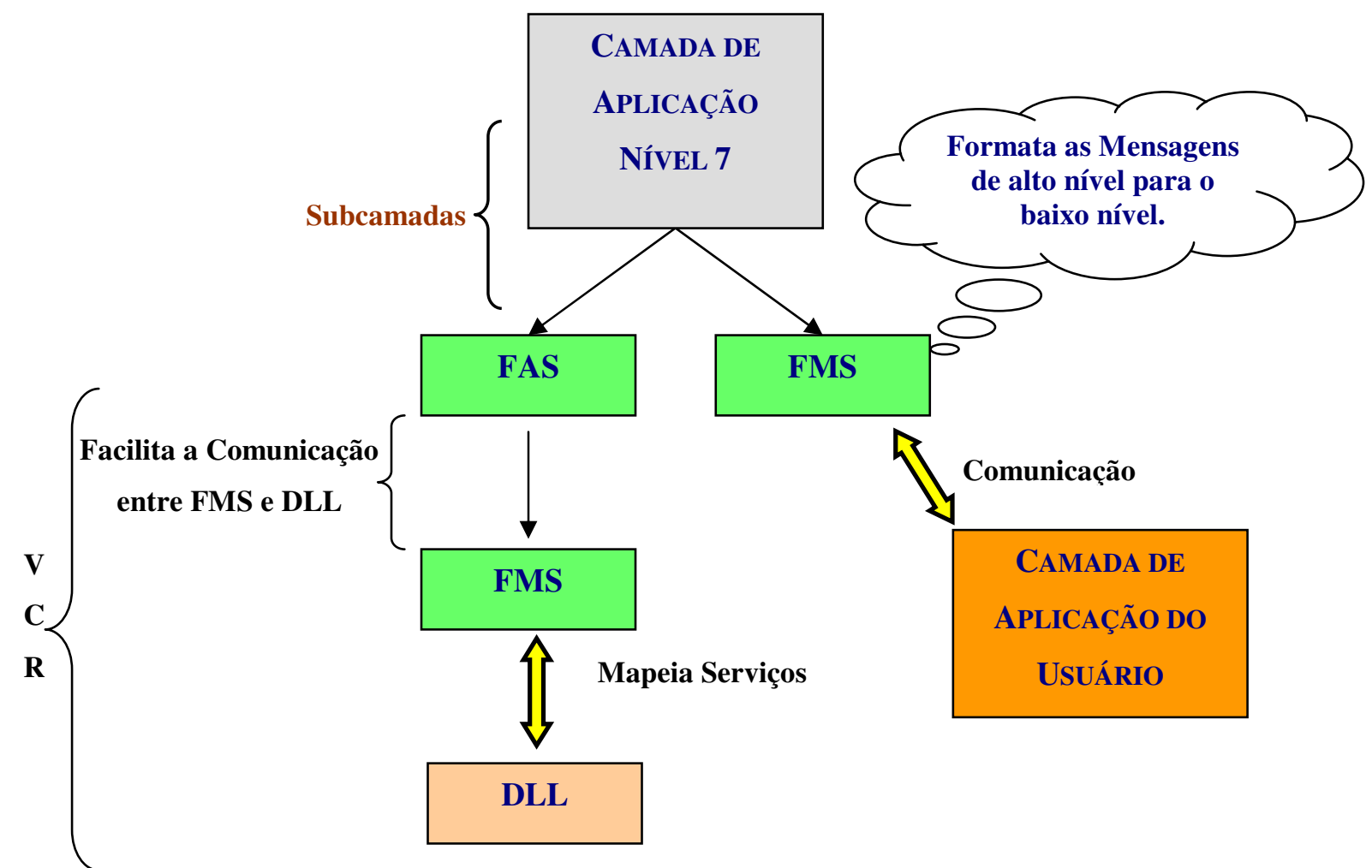

Figura 11 - Divisão da camada de aplicação e funcionalidades das subcamadas FAS e FMS

Como mostra a Figura 11, a subcamada FAS mapeia serviços da FMS para a camada DLL e vice-versa; a FAS ainda facilita a comunicação dos serviços da FMS com a DLL, através de atalhos simplificados. Os serviços oferecidos pela FAS são realizados pela VCR (Virtual Communication Relationships), que se constitui num relacionamento de comunicação virtual configurado depois que o usuário define sua aplicação.

Já a subcamada FMS, apresentada na Figura 11, está localizada entre FAS e a camada da aplicação do usuário; a primeira subcamada possui a funcionalidade de formatar mensagens e especificar o protocolo necessário para construção de mensagens da aplicação do usuário para as camadas inferiores, ou seja, formatar as mensagens de alto nível para baixo nível.

A camada do usuário, nível 8 como contempla a norma IEC 61158, presente no protocolo FOUNDATION FIELDBUS, é a aquela que possui os blocos funcionais padronizados e DD (Device Descriptions). 
O device descriptions descreve as características dos parâmetros e funções dos dispositivos de campo, permitindo que o host possa interoperar com os dispositivos sem que se efetue qualquer programação adicional.

Já os blocos funcionais, como citado, respondem pelo suporte de programação da aplicação, possibilitando que estratégias de controle sejam compreendidas e analisadas e ainda que as aplicações complexas possam ser desenvolvidas.

Neste trabalho, que propõe um algoritmo de escalonamento para o protocolo FOUNDATION FIELDBUS, a subcamada MAC destaca-se a camada DLL, onde ocorre o escalonamento e o acesso das mensagens no barramento, ou seja, ao meio físico.

A subcamada MAC executa um serviço de comunicação conhecido como LAS - Link Active Scheduler, e sua responsabilidade é garantir que somente um dispositivo de campo tenha acesso ao meio físico de comunicação, pois como o acesso é gerenciado pelo LAS, este impedirá a colisão de dados na comunicação. O LAS, o mestre de comunicação da rede, tem a responsabilidade de controlar o acesso do dispositivo no barramento de comunicação, de modo que esse controle seja feito somente quando o dispositivo possuir o token. O token acessa o meio físico autorizado pelo LAS que, baseado em prioridade, coordena as transmissões de dados aperiódicos ou acíclicos; o token pode ainda conter mensagens específicas como CD - Compel Data, PT - Pass Token, PN - Probe Node, DT - Data Transfer e TD - Time Distribution, caracterizadas pelos tipos de serviço usados no FAS, os quais estão apresentados a seguir.

A norma evidencia a possibilidade de redundância no dispositivo LAS, utilizando dispositivos do tipo "link master" ou "mestre backup". Os mestres backups comportam-se como dispositivos básicos (a definir), porém ao identificarem falha ou interrupção na atividade do LAS, assumem a função do LAS sem causar danos ao processo de comunicação; 
quanto aos demais dispositivos que na rede não possuem esta funcionalidade, são considerados escravos.

De acordo com a norma IEC 61158-2, o LAS controla a comunicação no barramento mantendo o tempo de sincronismo através de uma lista atualizada de dispositivos chamada de live list, que nada mais é que uma lista ativa dos dispositivos presentes na rede. A live list favorece o gerenciamento do tráfego na rede e também dá suporte à redundância de dispositivos e blocos funcionais.

O LAS garante que as mensagens contidas no tráfego periódico determinístico ou cíclico sempre serão escalonadas e transmitidas, em conformidade com as restrições de tempo, que são críticas.

Para as mensagens aleatórias, como definição de setpoints, parâmetros de configuração, diagnósticos etc, encontradas no tráfego aperiódico, acíclico ou estático, o LAS permite a sua transmissão conforme a disponibilidade de tempo no barramento de comunicação, desde que as aperiódicas sejam enviadas nos intervalos vagos entre as transmissões cíclicas.

Zhou e Yu (2002) definem o LAS, como:

"Um mecanismo de acesso ao meio de comunicação centralizado, que de acordo com uma lista pré-definida de tempo de escalonamento controla todas as mensagens remotas entre diferentes dispositivos de campo no barramento".

No tráfego periódico ou cíclico, o LAS trabalha com uma tabela de escalonamento para atender os dispositivos que terão permissão para atuar no barramento durante o macrociclo (release time). A cada macrociclo a tabela é verificada e, nos instantes de transferência de cada variável, o LAS envia ao dispositivo responsável uma mensagem do tipo Compel Data (CD), requisitando a publicação de variável, ao que imediatamente, o dispositivo destinatário do CD publica a variável da camada do usuário no barramento, utilizando uma mensagem do tipo Data Transfer (DT). Caso o dispositivo não responda ao 
CD imediatamente, o LAS aguarda um período de tempo configurado na variável da camada de enlace antes de retransmitir o CD.

O dispositivo com o $\mathrm{CD}$ é o produtor dos dados que alimenta o buffer, enquanto os dispositivos configurados para receber os dados são chamados consumidores (Figura 12).

\section{Scheduled Data Transfers}

The message in the data buffer is broadcast to all devices on the fieldbus when the LAS issues the compel data to the publisher. The subscribers listen to the message broadcast.
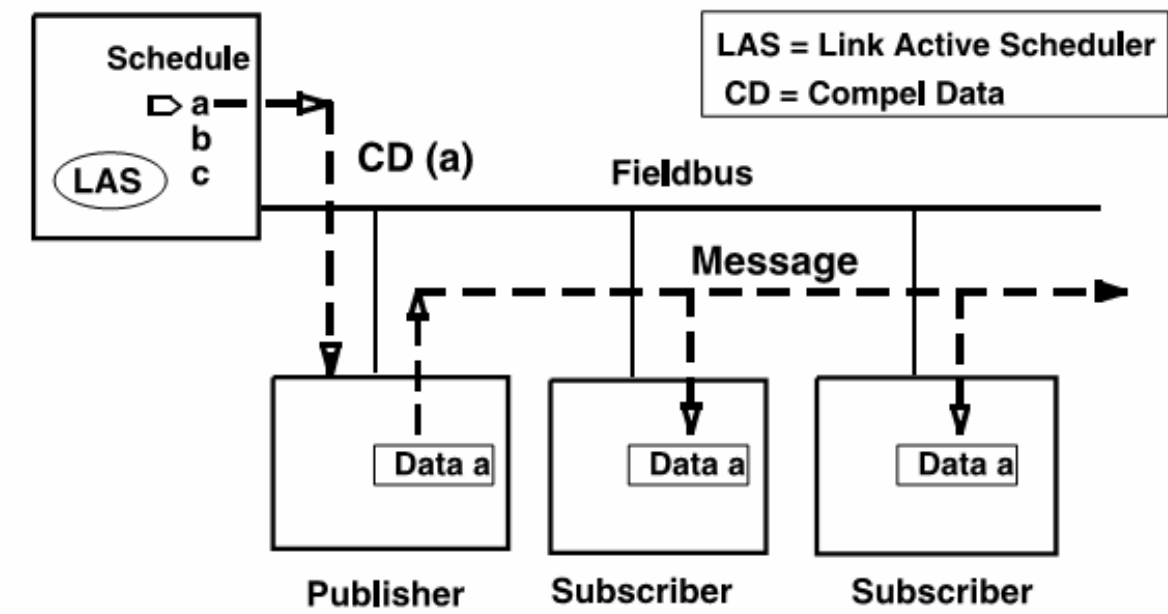

Figura 12 - Comunicação do LAS com o dispositivo ou equipamento através do compel data (FOUNDATION FIELDBUS, 2003)

Na subcamada FAS a norma IEC 61158 prevê que o tráfego periódico, através do serviço produtor - consumidor, utilize a comunicação cíclica ou escalonada de um endereço de origem para vários endereços de destino da rede, a fim de estabelecer uma comunicação orientada à conexão. Os dados transmitidos são sobrescritos nos buffers dos dispositivos, fazendo com que fique registrado na rede somente a última versão dos dados. Já na subcamada do FMS, as operações que adotam o serviço são as atividades de envio de variáveis entre blocos funcionais da aplicação de controle, os quais necessitam acessar o barramento. 
Para o tráfego aperiódico ou acíclico, o FAS disponibiliza dois tipos de serviços, tendo cada um suas próprias características: o serviço cliente-servidor e o serviço de distribuição de relatórios.

O serviço caracterizado como cliente-servidor estabelece uma conexão entre um endereço de origem e um outro de destino, para o envio da mensagem. Somente os endereços permanentes da rede podem fazer uso do serviço, assim a transmissão de dados se inicia quando a conexão se estabelece. Quanto à ordem das mensagens transmitidas, fica armazenada para que se respeitem as prioridades entre as mesmas. Na camada de enlace, o LAS dispara um serviço conhecido como Pass Token - PT ao dispositivo na live list, o qual responderá com a mensagem ou com uma requisição de uma mensagem para outro dispositivo (Figura 13). As operações do FMS, que adotam o serviço cliente - consumidor, englobam as seguintes atividades:

- Configuração;

- Supervisão;

- Upload/ Download de dispositivos;

- Read/Write;

- Diagnóstico remoto;

- Gerenciamento de alarme;

- Mudança de setpoints.

No serviço denominado de distribuição de relatório, utiliza-se a comunicação acíclica ou não-escalonada de um endereço de origem para vários outros endereços de destino da rede. Não existe o estabelecimento de uma conexão entre dispositivos de origem e destino para transmissão de mensagem como também não existe a confirmação da recepção da mensagem pelos dispositivos receptores, configurados na aplicação do usuário. Na camada de enlace, o 
LAS dispara um PT e o dispositivo que possui um relatório de evento ou de tendência envia a referida mensagem para vários endereços especificados pelo VCR. Imediatamente após a transmissão da mensagem, os dispositivos configurados para receber o relatório deste VCR armazenam as mensagens enfileirando-as sem sobrescrever as anteriores.

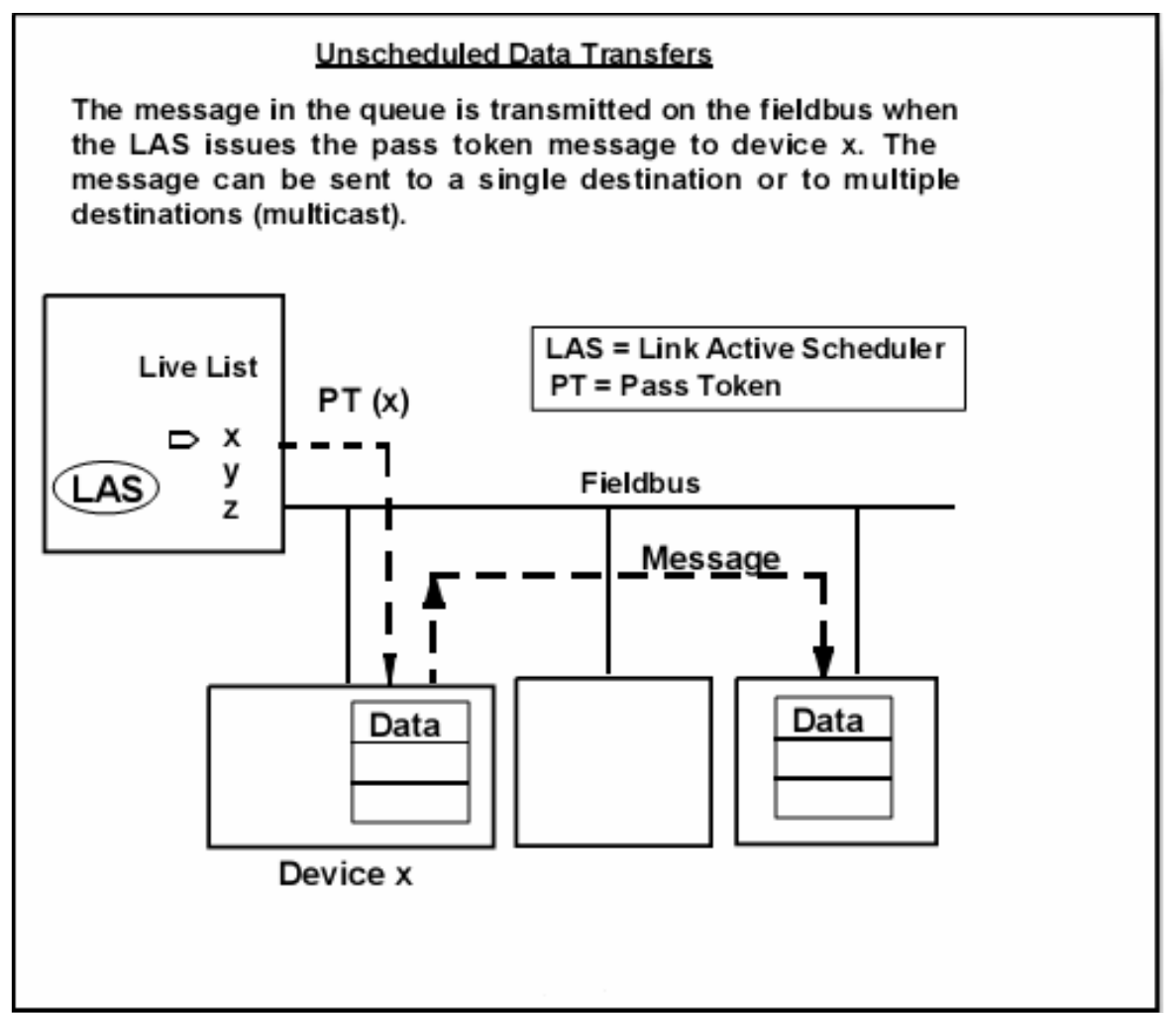

Figura 13 - LAS e o serviço do pass token (FOUNDATION FIELDBUS, 2003)

O protocolo FOUNDATION FIELDBUS mostra que toda comunicação deve ser sincronizada para que as restrições temporais sejam atendidas. Na primeira inicialização do LAS, define-se o tempo zero do segmento, porém todos os outros links masters do segmento continuarão com o tempo de segmento que tinham no momento do evento de transferência do LAS. Os dispositivos necessitam possuir a implementação de um timer, assim toda mensagem disparada pelo LAS deve ter uma sincronização em intervalos pré-configurados, realizada através do serviço Time Distribution - TD, que contem 55 bits e tempo de mensagem para o fieldbus $\mathrm{H} 1$ (31, $25 \mathrm{kbps})$ de 1,7 ms. 
Após os settings das mensagens citadas, o LAS envia um Probe Node (PN) para configurar os endereços não-utilizados, quando o dispositivo consultado deverá responder com o envio de Probe Response (PR); em seguida, o LAS envia um DT para que o dispositivo possa ser adicionado à live list, e finalmente o LAS envia um Live List Update para informar aos outros links masters do segmento de comunicação que o dispositivo consultado foi adicionado.

O funcionamento do algoritmo do LAS pode ser observado no fluxograma da Figura 14, onde as mensagens especiais disparadas estão agrupadas segundo o tipo de tráfego: cíclico ou acíclico.

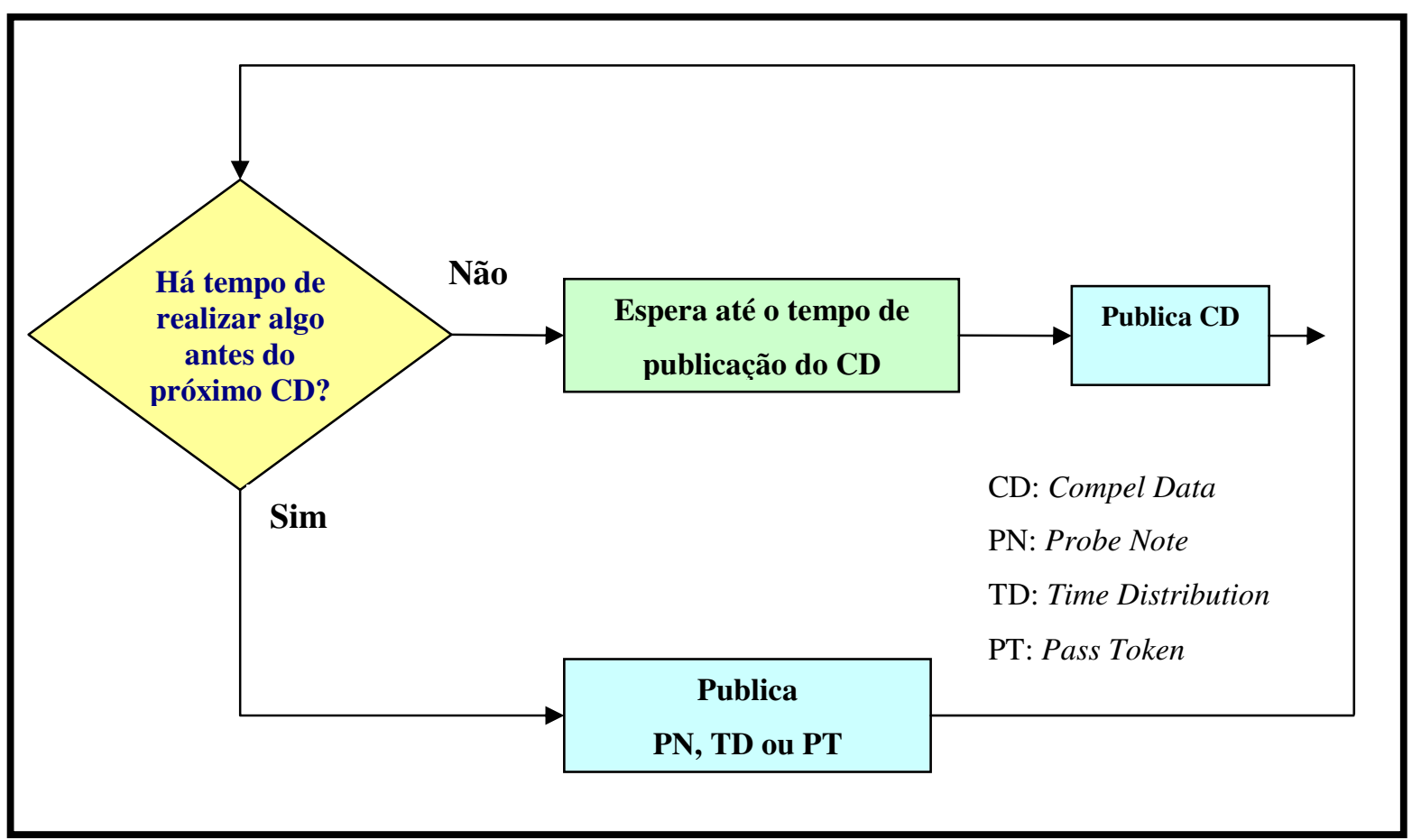

Figura 14 - Fluxograma do algoritmo do LAS - Link Active Schedule (IEC, 2005)

Para Hong e Choi (2001), os dispositivos de campo geram dados para o protocolo FOUNDATION FIELDBUS e podem ser divididos em três partes:

- Dados de tempo-crítico: estes são caracterizados como sinais de notificação de evento e alarme; devem ser transferidos em curtos intervalos de tempo, uma vez 
que são gerados esporadicamente numa ocorrência de freqüência relativamente baixa;

- Dados periódicos: aqueles produzidos por malhas de controle ou monitoração periódica dos processos; como os dados escalonados, são o atraso induzido pela rede não deve exceder às restrições temporais da mensagem.

- Dados de time-available: são gerados por programas de controle numérico e produzidos por um computador ou controlador; estes dados devem ser arquivados e as mensagens de gerenciamento do banco de dados enviadas por computadores ou controladores de supervisório.

Os atrasos no envio de dados, de acordo com Henriques (2005), referem-se ao tempo disponível, que não são considerados críticos como no caso de dados de tempo crítico e periódico. Observe na Figura 15 os serviços do LAS no barramento H1:

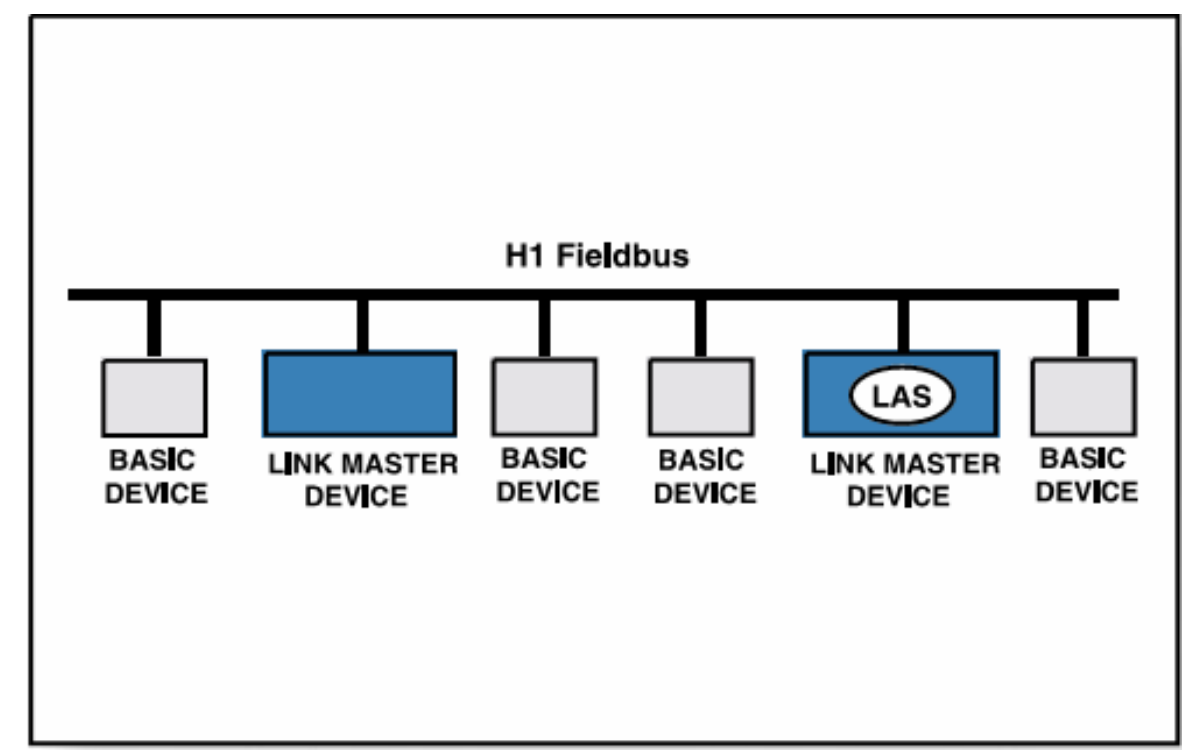

Figura 15 - Serviços do LAS no barramento H1 (FOUNDATION FIELDBUS, 2003)

Ainda na camada de enlace, há um modo de operação conhecido como Bridge que, quando configurado, o dispositivo em questão estabelece a comunicação entre dois ou mais 
links fieldbus (Figura 16). Além das tarefas normais executadas por um dispositivo Bridge, está o encaminhamento entre links de mensagens; mesmo quando o remetente e o destinatário não estão em um mesmo link, a redistribuição de mensagens ocorre de maneira sincronizada com o tempo interno dos dispositivos igual para todos os links.

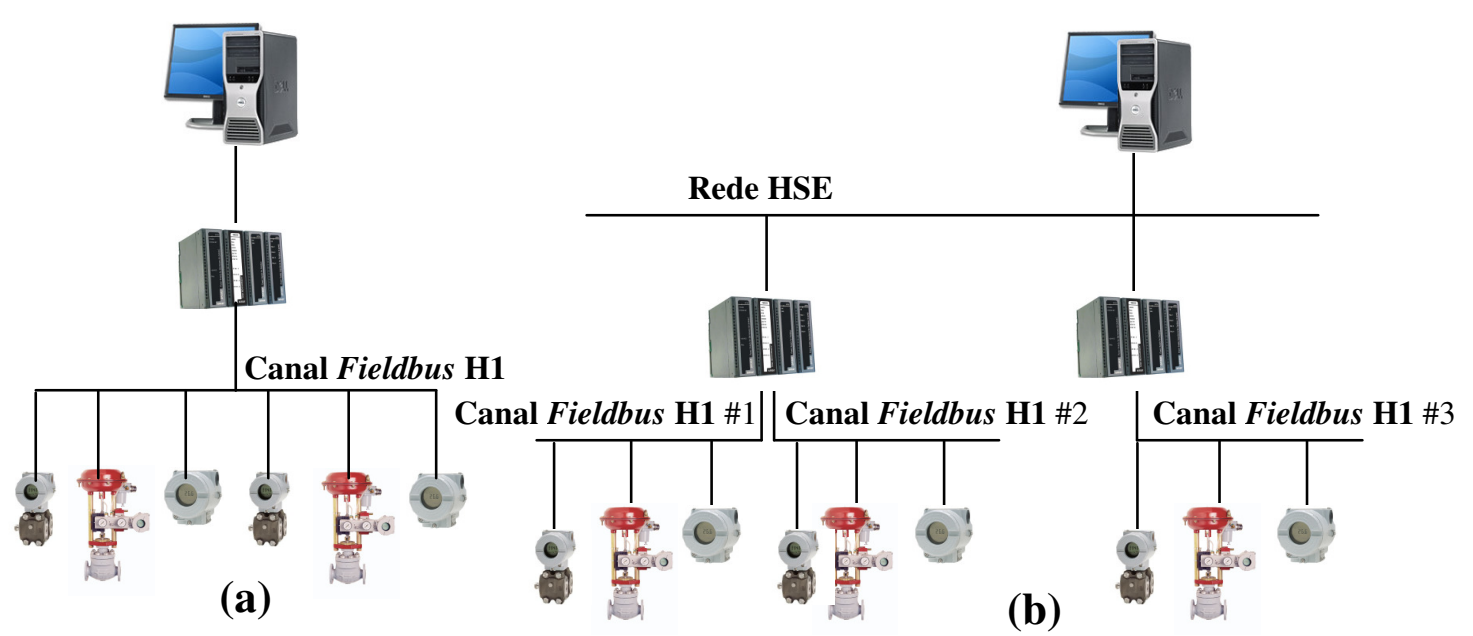

Figura 16 - (a) Topologia Single Link e (b) Topologia Bridged Network

\subsubsection{A CAMADA DE APLICAÇÃO DO USUÁRIO}

A camada de aplicação do usuário é composta pelas funções de aquisição conhecidas por entrada, atuação, também chamadas de saída e controle. Pela configuração e desenvolvimento efetuados pelo usuário na aplicação é que realizar-se-á a distribuição das atividades a serem executadas nos dispositivos de campo, os quais utilizam os serviços oferecidos pelo FMS.

No protocolo FOUNDATION FIELDBUS, os dispositivos de campo possuem características específicas de funções de controle, aquisição e atuação. Estas funções podem ser executadas e ativadas a partir do momento em que o download da aplicação for descarregado nos dispositivos, respeitando-se sempre as configurações feitas pelo usuário. 
Na camada de aplicação do usuário também encontram-se os blocos funcionais como já citados. Os blocos funcionais, segundo Henriques (2005,) são módulos de programas particionados de tal forma que cada uma das partes tem a função de realizar determinada atividade localmente no dispositivo.

A camada de aplicação do usuário é configurada por blocos funcionais alocados em dispositivos de campo especificados pelo próprio usuário, através de ligações lógicas que permitirão a ativação de tal aplicação. Assim, o controle automático da planta ou processo industrial é feito com a interligação entre os blocos funcionais.

A aplicação do usuário pode ser composta por uma ou mais malhas ou estratégias de controle (Figura 17), sendo esta ultima caracterizada por um conjunto de blocos funcionais, que objetiva o controle de uma ou mais variáveis do processo.

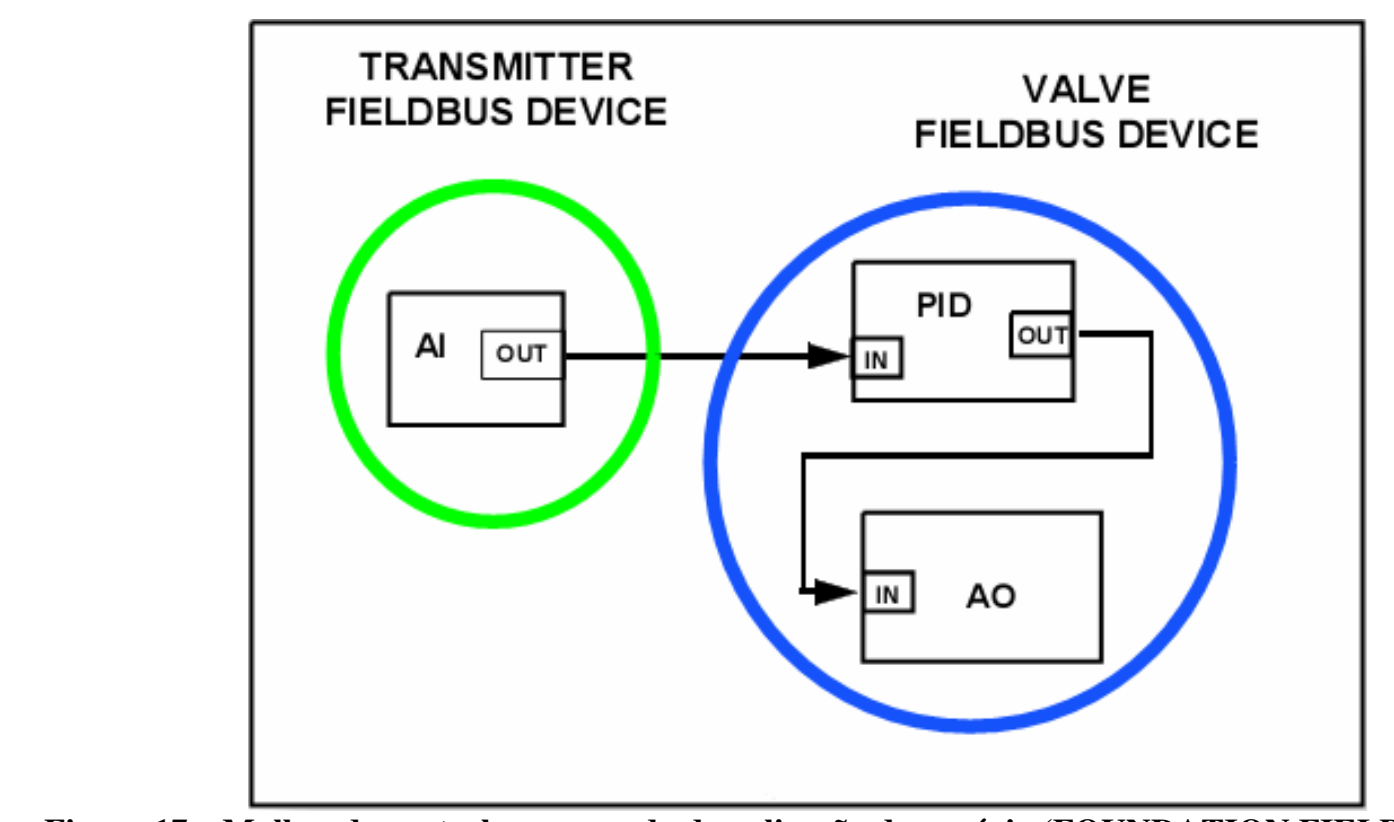

Figura 17 - Malhas de controle na camada de aplicação do usuário (FOUNDATION FIELDBUS, 2003)

Para a execução dos blocos funcionais, é necessário ter uma sequiência de aplicação que dependa da estratégia de controle determinada pelo próprio usuário, porém sabe-se que as funções de aquisição normalmente são executadas antes do início das funções de controle, 
seguidas pela execução das funções de atuação, cujo papel é finalizar a estratégia para que ela haja sobre a planta ou processo industrial.

Assim que a aplicação do usuário é concluída, o configurador (software) utilizado gera uma tabela de escalonamento que será armazenada nos dispositivos de características link master, e estes irão conter a função de LAS nos tráfegos periódicos. Conforme a abordagem adotada pelo configurador (software), o LAS terá ou não as informações essenciais sobre a aplicação do usuário para o escalonamento do tráfego aperiódico.

Neste capítulo, constam as características mais relevantes do sistema fieldbus, para a devida compreensão da sua funcionalidade e do seu comportamento, especificamente o protocolo FOUNDATION FIELDBUS. Portanto, é de extrema importância o entendimento dos serviços de comunicação, blocos funcionais, camadas de gerenciamento de rede, inclusive da transmissão de mensagens e tarefas que estão no barramento de comunicação, para que nos capítulos seguintes haja melhor percepção da utilização deste protocolo. 



\section{REVISÃO BIBLIOGRÁFICA}

Como descrito no Capítulo 2, o protocolo FOUNDATION FIELDBUS, é uma tecnologia complexa, com muitas funcionalidades e vantagens, mas também desvantagens, e entre estas cita-se a que todo fieldbus trabalha com um único barramento de comunicação, fato que pode ocasionar atraso na transmissão das mensagens e nas tarefas no decorrer do processo.

Para evitar as desvantagens, utilizam-se algumas linhas de pesquisas direcionadas à aplicação de escalonamento através de um algoritmo. Assim, esta revisão bibliográfica, além das definições de escalonamentos e técnicas usadas sobre este protocolo, cita trabalhos da área.

No trabalho de Zweben e Fox (1994), escalonamento é definido como:

[...] "A seleção entre planos alternativos alocando recursos e atividades em cada instante de tempo, tal que esta designação obedeça às restrições temporais das atividades e as limitações de capacidade de um conjunto de recursos compartilhados".

Neste trabalho, consideram-se as características de tempo e concorrência entre as tarefas para que o comportamento do sistema em tempo real seja encontrado, e, para este fim, utiliza-se a previsibilidade gerada pela técnica de escalonamento (Farines; Fraga; Oliveira, 2000).

Brandão (2005) relata que o escalonamento no protocolo FOUNDATION FIELDBUS é executado periodicamente em um espaço de tempo denominado macrocycle; para tanto, 
deve-se sincronizar com precisão de $1 \mathrm{~ms}$ cada dispositivo do barramento e obedecer a um escalonamento predeterminado.

Assim, pode-se dizer que uma atividade de escalonamento tem como objetivo alocar uma quantidade de recursos limitados para a execução de tarefas, no decorrer do tempo, de tal forma que um ou mais objetivos possam ser alcançados (Pinedo, 1995).

Henriques (2005) refere que para se idealizar um problema de escalonamento é imprescindível caracterizar conceitos essenciais para o tratamento dos elementos escalonáveis que retratam o sistema. Ainda Henriques (2005) define elementos como processos e tarefas que expressam, ao longo do tempo, uma atividade ou ação a ser executada, processada ou transmitida em algum recurso concorrente disponível no sistema.

Para a realização de um escalonamento de tarefas no sistema, seguem definições de alguns termos abordados ao longo deste estudo:

- Release ou Tempo de Liberação - é o instante inicial em que uma tarefa poderá ser executada em algum recurso do sistema.

- Tempo de Execução - em sistema fieldbus, é o tempo necessário para processamento dos blocos funcionais (Henriques, 2000).

- Tempo de Transmissão - em sistema fieldbus, para Franco (1998), é o tempo necessário para transmissão das mensagens no barramento de comunicação compartilhado.

- Jitter - Para Cavalieri et al. (1996), a diferença de tempo entre release e arrival time expressa uma variação denominada release jitter variação que determina o tempo, a partir do release (tempo de liberação), que o escalonador necessitará para atender à tarefa.

- Deadline - é o instante de tempo que uma tarefa deve respeitar, caso sua execução termine ou seja concluída (Xu; Parnas, 1990); é, pois, o instante máximo de tempo 
desejado para a conclusão da tarefa. O deadline pode ser classificado em dois tipos: Soft deadline e Hard deadline (Farines; Fraga; Oliveira, 2000).

- Soft Deadline ou Deadline Não-Crítico - é o instante de tempo desejado para se finalizar uma tarefa em execução; quando este deadline não for atendido, a atividade operacional do sistema não será afetada drasticamente (Sprunt; Sha; Lehoczky, 1989).

- Hard Deadline ou Deadline Crítico - é o instante de tempo no qual a execução de uma tarefa deve ser completamente finalizada; o não-atendimento deste deadline pode levar o sistema a uma condição crítica, que afetará drasticamente sua atividade operacional (Sprunt; Sha; Lehoczky, 1989).

Os sistemas de tempo real, segundo Jonsson e Shin (1997), são definidos como aqueles que envolvem um ou mais computadores, nos quais a correção do sistema depende não só dos resultados da computação, mas também do instante de tempo em que são produzidos os resultados. Assim como há dois tipos de deadline, também se podem classificar os sistemas de tempo real em duas categorias: Hard Real-Time e Soft Real-Time.

- Hard Real-Time ou Sistema de Tempo Real Crítico - neste sistema é necessário que se garanta a execução de todos os requisitos temporais dos projetos, e quando ocorrer uma falha temporal em sistemas desta categoria, as consequiências serão catastróficas. Utiliza este tipo de sistema as usinas nucleares, mísseis e usinas petroquímicas (Farines; Fraga; Oliveira, 2000).

- Soft Real-Time ou Sistema de Tempo Real Não-Crítico - neste sistema o requisito temporal descreve apenas o comportamento desejado, um bom exemplo é a multimídia (Farines; Fraga; Oliveira, 2000). 
Os sistemas de tempo real também realizam tarefas, que se dividem em dois tipos: Tarefas Periódicas e Tarefas Aperiódicas. De acordo com Sprunt, Sha e Lehoczky (1989), estas tarefas podem ser definidas da seguinte maneira:

- Tarefas Periódicas ou Síncronas - são aquelas ativadas em períodos regulares e que possuem o hard deadline.

- Tarefas Aperiódicas ou Assíncronas - são aquelas com tempo de chegada irregular; convencionalmente possuem o soft deadline.

Para uma tarefa ser escalonada é preciso que esteja agendada numa tabela predefinida, cujo tempo é limitado pelo release e deadline. As tarefas periódicas em sistemas Hard RealTime sempre têm prioridades sobre as demais na hora da execução.

Segundo Blazewicz (1996), a prioridade impõe uma importância relativa a uma tarefa, que é determinada na tomada de decisão, quando ocorre a atividade de escalonamento.

Ao se escalonar uma tarefa deve-se levar sempre em consideração, além da sua prioridade, se existe precedência. Segundo Cardeira e Mammeri (1993), duas tarefas têm restrições de precedência quando a execução de uma delas estiver condicionada ao término da execução da outra tarefa.

\subsection{ESCALONAMENTO}

Com os escalonamentos empregados em diversos sistemas utilizam termos especiais, neste estudo eles merecem não só destaque, mas também o registro de suas definições, segundo alguns pesquisadores. No trabalho de Henriques (2005), há definições, como: 
- Escalonamento Ótimo - neste tipo, pesquisaram-se todas as opções possíveis para o escalonamento de tarefas no sistema, de tal forma que a atividade de escalonamento só será interrompida quando a melhor solução for encontrada, principalmente após considerar que foi definido pelo escalonador, como restrições temporais e critérios predefinidos.

- Escalonamento Realizável (Factível) - este escalonamento satisfaz todas as restrições temporais do sistema e garante sempre o seu cumprimento.

- Escalonamento Preemptivos - Preempção é o ato de interromper uma tarefa que está sendo executada para execução de uma outra. Somente após o término da execução da segunda tarefa é que a da primeira será retomada. Escalonadores de tarefas preemptivos têm melhor desempenho que os não-preemptivos, apesar de os não-preemptivos serem usados na maioria dos casos, em razão de serem mais simples (Cardeira e Mammeri, 1993).

A teoria de escalonamento de tarefas em processadores teve seu marco com a publicação do trabalho de Liu e Layland (1973). Os autores mostraram que os algoritmos RM (Rate Monotonic) e EDF (Earliest Deadline First) serviram como base para o desenvolvimento das futuras técnicas de escalonamento de mensagens em redes digitais. $\mathrm{Na}$ técnica RM, as prioridades de transmissão de cada mensagem cíclica são atribuídas estaticamente, tanto que não mudam durante o processo. No caso, o algoritmo escalonador impõe a cada tarefa uma prioridade proporcional à sua taxa de execução.

A técnica EDF baseia-se em atribuição de prioridades dinâmicas, na qual a prioridade de cada tarefa varia no tempo e cresce na medida em que se aproxima o instante deadline, definido como o instante da próxima execução da tarefa em questão. Com base nos aspectos apresentados e na definição de Hard Real-Time de Liu e Layland (1973), num ambiente Hard 
Real-Time todas as tarefas devem ser completadas dentro de um intervalo de tempo logo após a requisição de sua execução, consideram possível também a realização de uma revisão sobre o escalonamento de blocos funcionais e mensagens periódicas em sistemas fieldbus.

Como todo sistema de controle distribuído em tempo real, o FOUNDATION FIELDBUS requer um algoritmo de escalonamento no qual todos os requisitos temporais relacionados à camada de aplicação sejam garantidos (Hard Real-Time). Neste protocolo, tanto a execução dos blocos funcionais quanto a transmissão de mensagens periódicas são processos críticos e não-preemptivos.

A investigação do escalonamento de sistemas Hard Real-Time não-preemptivos foi realizada por Xu e Parnas (1990), que propuseram um algoritmo para o escalonamento de tarefas com restrições de precedência, o instante de disparo e deadlines. Neste algoritmo, Xu e Parnas (1990) propuseram, ainda, a possibilidade da automação completa de uma tarefa no processo de escalonamento pré-run-time, desde que se respeitassem a precedência e as relações de exclusão ${ }^{1}$.

O algoritmo usa uma técnica de branch-and-bound, que percorre toda árvore e procura nos ramos os nós da raiz, aplicando, assim, a estratégia Earliest Deadline First, de Liu e Layland (1973), para computar o tempo e o escalonamento válidos das soluções inicialmente apresentadas. Este processo deve satisfazer o tempo previsto e todas relações de exclusão e preempção inicial. Os autores chamam os algoritmos de prioridade fixa de Rate Monotonic RM ou Taxa Monotônica ou Deadline Monotônico, e os algoritmos de prioridade dinâmica, de Earliest Deadline First - EDF.

Num sistema monoprocessado, o algoritmo RM - Rate Monotonic é de fácil implementação, uma vez que atribui altas prioridades às tarefas com menores períodos.

\footnotetext{
${ }^{1}$ Relações de exclusão - Exclusion Relations podem existir quando alguns segmentos do processo excluem a interrupção através de outros segmentos de processo, e prevêm erros causados por acesso simultâneo aos recursos compartilhados, como dados, dispositivos de I/O, etc, (Xu e Parnas 1990).
} 
Para Baruah e Goossens (2004), esta técnica é ótima para sistemas periódicos síncronos com deadline implícito, ou seja, para tarefas independentes; também a consideram ótima para os outros tipos de sistemas.

Para as estratégias dinâmicas, Henriques (2005) apresenta duas regras existentes de escalonamento: Earliest Deadline Frist (EDF ou Deadline Driven Scheduler - DDS ou Earliest Deadline Scheduler - EDS) e Least Laxity First (LLF ou Least Slack Time - LST). No algoritmo EDF a prioridade da tarefa é especificada segundo o deadline relativo; no entanto tarefa eleita pelo algoritmo de escalonamento dinâmico indica a primeira tarefa da fila pelo seu deadline mais próximo. Já no caso do LLF, a tarefa é selecionada segundo a folga expressa pelo deadline relativo subtraído pelo instante de tempo atual caracterizado no momento da ação de seleção adotada pelo escalonador.

No trabalho de Baruah, Goossens e Funk (2003a), os algoritmos EDF e LLF são classificados como ótimos para ambientes que possuem sistemas monoprocessados, pois caso haja existir escalonamento factível, os algoritmos permitirão que as tarefas atendam a seus respectivos deadlines. Porém, nos sistemas multiprocessados, os algoritmos empregados em tempo de execução não são classificados como ótimos, uma vez que as restrições são desconhecidas num primeiro momento.

Henriques (2005), ao estudar os escalonamentos de sistemas monoprocessados e multiprocessados através de escalonamentos distribuídos, esclarece que em sistemas que possuem recursos distribuídos faz-se necessário a adoção de um recurso de comunicação para troca de informações entre os processadores, porém como os recursos são escassos no sistema, eles devem ser compartilhados entre as tarefas contidas no mesmo sistema. Assim, sistemas distribuídos são aqueles monoprocessados que trocam dados através de meios de comunicação, meios estes considerados em escalonamentos como processadores adicionais, que têm como tarefas não-preemptivas as mensagens transmitidas entre os processadores com 
atrasos de transmissão de pior caso. A comunicação, então, é caracterizada pelas restrições de precedência; assim em ambientes multiprocessados com recursos de comunicação, uma tarefa pode ser um programa a ser executado em algum processador do sistema, ou um dado enviado entre os processadores.

No caso do fieldbus, além das características apresentadas acima por Henriques (2005), há também um modelo estendido caracterizado, o qual contém tarefas dependentes entre si; estas impõem que a execução de uma tarefa não seja definida de forma arbitrária, mas que siga uma ordem predefinida (Farines, Fraga e Oliveira, 2000), o que acarreta restrições ou relações de precedência entre tarefas que determinam uma ordenação parcial, a ser respeitada durante a atividade de escalonamento.

O algoritmo RM - Rate Monotonic, proposto por Liu e Layland (1973), não é considerado ótimo para múltiplos processadores, porém Baruah e Goossens (2003b) tentam refinar a atribuição das prioridades definidas estaticamente para as tarefas, visando delimitar um RM-factível em função da quantidade de processadores. Estes últimos autores consideram que um RM é factível se ele atender a todos os deadlines das tarefas para qualquer sistema de tarefas, quando a soma da utilização das mesmas for menor que m, onde m é igual a:

$$
\left(\frac{\text { número_de_processadores }}{3}\right)
$$

Ainda segundo Baruah e Goossens (2003b), a utilização máxima do conjunto de tarefas deve ser menor ou igual a 1/3 para que se obtenha um RM-factível. O interesse destes autores não é comprovar estas considerações e, sim, melhorar os testes que determinarão se um sistema de tarefas é RM-factível, através das utilizações das tarefas e de seu particionamento. $\mathrm{O}$ trabalho destes autores também expõe a existência de um algoritmo que torna mais eficiente a atribuição de prioridades das tarefas, quando o RM for não-factível.

Almeida (1999), em seu trabalho, relata que os escalonadores executados em tempo de projeto (escalonadores pré-run-time) produzem um escalonamento denominado de estático, 
também caracterizado por uma tabela de escalonamento implementada antes do sistema entrar em atividade (off-line). Esta tabela, num primeiro momento, de acordo com seu conhecimento de todo o comportamento temporal do sistema, provê os tempos de liberação (release) futuros das tarefas a serem escalonadas perante as operações do sistema. No fieldbus as tarefas são caracterizadas como mensagens no barramento e nos programas, enquanto os blocos funcionais, nos processadores e dispositivos.

Almeida (1999), propôs em seu trabalho, um algoritmo de escalonamento denominado estático, onde o escalonador é executado em tempo de projeto, quando o sistema não estiver em atividade (off-line). Este escalonador baseado nas informações futuras operacionais do sistema (tabela de requisitos) cria uma tabela de escalonamento a ser utilizada quando o mesmo entrar em atividade (on-line) (Figura 18).

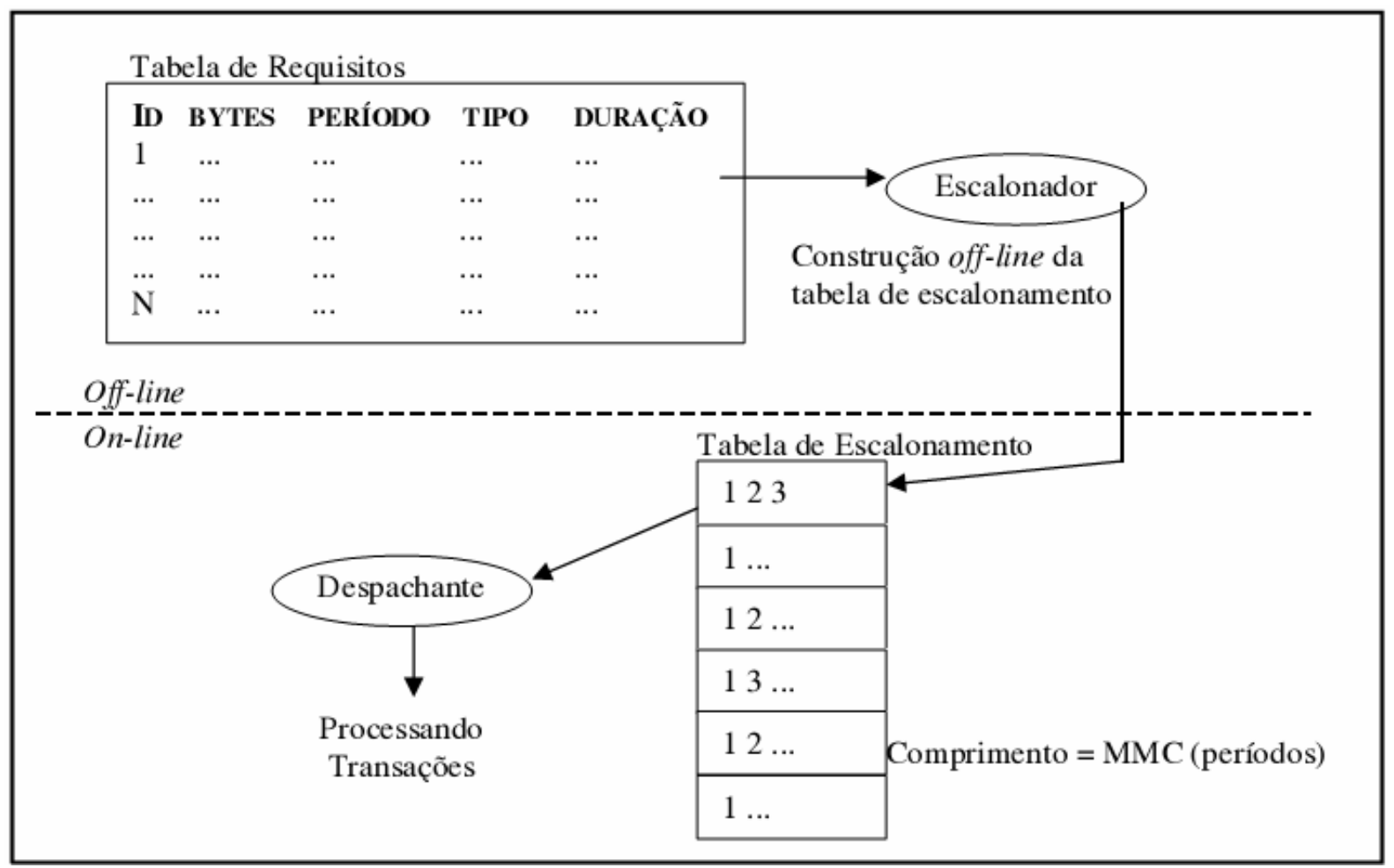

Figura 18 - Exemplo do escalonamento pré-run-time de Almeida (1990)

Para o autor, os escalonadores em tempo de projeto (pré-run-time) possuem alto determinismo, menor quantidade de informações no cabeçalho da mensagem, baixa 
flexibilidade operacional e largos requisitos de consumo de memória. O alto determinismo é imposto pelo conhecimento de todo o comportamento temporal do sistema, no primeiro instante. A previsibilidade mostrada pelo aspecto discutido anteriormente é obtida em função do comportamento do sistema, representado pelas necessidades temporais em regime de pior caso, quando o sistema não estiver ativo. O segundo aspecto, de menor tamanho de cabeçalho em tempo de execução, expressa que o despachante em tempo de execução somente verificará a tabela para a execução das transações, sem providenciar a criação de um cabeçalho que contenha extensas informações sobre a transação a ser executada. A baixa flexibilidade operacional é evidenciada através de mudanças efetuadas na tabela de escalonamento, pois sua viabilidade depende novamente da execução do escalonador, que criará uma nova tabela de escalonamento com as mudanças necessárias. Os largos requisitos de consumo de memória são condizentes com os valores atribuídos aos períodos das tarefas, uma vez que o tamanho da tabela de escalonamento está condicionado ao desmembramento dos períodos das tarefas, em números primos, para o cálculo do período comum (mínimo múltiplo comum - MMC), o que pode gerar um valor grande para MMC, e conseqüentemente maior tamanho da tabela de escalonamento para armazenamento dos dados das transações.

Almeida (1999) também é apresentada um escalonamento realizado em tempo de execução (escalonadores run-time), o qual não possuem qualquer conhecimento sobre as requisições futuras, por isso produzem um escalonamento dinâmico que muda constantemente em função da alteração das prioridades das requisições, quando o sistema estiver em atividade. Por se tratar de um escalonamento dinâmico, é mais flexível do que os escalonadores pré-run-time, devido às constantes mudanças de requisitos comportamentais do sistema. Como os escalonadores run-time não precisam da tabela de escalonamento, eles dispõem de maior capacidade para a disponibilidade da memória durante seu processamento, já que as mensagens ficam enfileiradas ao chegarem para o escalonamento. Para o autor, o 
analisador de escalonabilidade nem sempre consegue ter um desempenho satisfatório, em tempo hábil, para o atendimento das requisições feitas ao escalonador em tempo de execução (escalonadores run-time).

Raja e Noubir (1993) estudaram a composição de tabelas de escalonamento sob a hipótese harmônica, para a qual sempre vale a relação de multiplicidade entre os períodos de execução das tarefas a serem escalonadas. Assim propôs duas formas de escalonamento: MoPS (Monocycle Polling Scheduling) ou monociclo e MuPS (Multicycle Polling Scheduling) ou multiciclo. No MoPS, todas as tarefas são disparadas em cada ciclo de execução da tabela, enquanto no MuPS os ciclos são diferenciados, em função do período de execução das tarefas, e a execução se dá em forma de diversos microciclos que, somados, resultam em um macrociclo. Para resolver o problema de escalonamento MuPS, Raja e Noubir (1993) propuseram dois algoritmos: o RMM (Rate Monotonic Multicycle) e o EDFM (Earliest Deadline First Multicycle), ainda sob a hipótese harmônica baseada no trabalho de Liu e Layland (1973).

Raja e Noubir (1993) também constataram que a forma de escalonamento baseada no MoPS, adotada pela norma FOUNDATION FIELDBUS, tem a desvantagem de apresentar um baixo índice de utilização da rede; eles não se dedicaram aos estudos de algoritmos de escalonamento com base em monociclo (MoPS).

Porém Raja e Ulloa (1993) propuseram ainda um algoritmo dinâmico, compatível com o RMM e o EDFM, utilizado para expandir o domínio de transmissões cíclicas sobre a janela de tempo acíclica, em caso desta estar ociosa. Este algoritmo identifica lacunas na fase acíclica e escalona transmissões cíclicas no período do macrociclo.

Nos casos reais, a hipótese harmônica, ditada por estes últimos autores, não pode ser adotada, pois os períodos de execução de mensagens e processos periódicos são arbitrários, o que limita o uso dos algoritmos RMM e EDFM. Mesmo quando os períodos de execução de 
mensagens e processos não são periódicos, a execução da tabela de escalonamento deve ser periódica. Este caso é referenciado por ciclo de escalonamento harmônico generalizado, uma vez que o período mínimo de execução da tabela de escalonamento (utilizando-se a política MuPS) e os períodos das tarefas e mensagens não possuem um mínimo múltiplo comum.

Em geral, neste tipo de problema, a construção do escalonador baseia-se no máximo divisor comum e no mínimo múltiplo comum entre os períodos das mensagens e tarefas a serem escalonadas, respectivamente para o projeto da tabela de escalonamento do microciclo e do macrociclo de comunicação. É importante salientar que o tamanho da tabela de escalonamento é um fator complicador em redes fieldbus, devido aos recursos do dispositivo, principalmente memória e tempo de processamento.

Uma alternativa para diminuir o tamanho da tabela de escalonamento, neste caso, é não limitá-la pelo mínimo múltiplo comum dos períodos das mensagens. Esta solução faz surgir variações no instante de transmissão das mensagens periódicas (jitter), porque a tabela de escalonamento não mais é múltipla do período das mensagens. Como afirmam Koller, Sauter e Rauscher (2003), o jitter é um fator que pode provocar perda de informações ao processo de aplicação.

Para otimizar a tabela de escalonamento sem considerar a hipótese harmônica, Cavalieri, Stefano e Mirabella (1995) identificaram condições teóricas que permitiram redução no comprimento da tabela de escalonamento às custas de modificações na sua estrutura, mas mantendo um alto nível de garantia das transmissões. Esta solução impõe um escalonamento on-line e, que deve ser usado de modo ponderado nas aplicações dos sistemas com recursos escassos.

Abdelzaher e Shin (1999) inseriram no campo de pesquisa do escalonamento de tarefas a questão da comunicação, o que resultou na elaboração de um algoritmo combinado 
que atendesse tanto ao escalonamento de mensagens como ao de tarefas; ressaltam, porém a hipótese da presença de jitter fixo e conhecido.

Já Franco (1998) propôs um algoritmo que objetivasse gerar uma tabela de escalonamento, em conformidade com a norma IEC 61158, a fim de atender às restrições temporais de comunicação entre os dispositivos num mesmo segmento fieldbus, após o usuário fazer a configuração da estratégia de controle.

Como as mensagens cíclicas e suas restrições de tempo são especificadas pelo usuário antes da execução, este algoritmo tem a condição de gerar a tabela de escalonamento em tempo anterior à sua execução (pré-run-time); ele se encaixa na definição de escalonamento Hard Real Time, que se aplica às restrições de releases, precedências e deadlines.

Percebe-se, então, que neste algoritmo proposto em Franco (1998) aplica-se a teoria EDF e a estratégia de busca, chamada de "ramificar-e-podar". Trata-se de uma técnica baseada na idéia da enumeração inteligente de todos os pontos factíveis de um problema de combinação. Com isso, a ramificação baseia-se no particionamento sucessivo do espaço de solução, e a poda refere-se aos limites mínimos usados para construir uma função de custo, como fim de evitar a busca exaustiva nos ramos e em nós da árvore a ser percorrida. Portanto, este algoritmo destina-se ao escalonamento de mensagens cíclicas, de processos com tempos de release, tempo de computação, deadline e restrições de precedência, preempção e ainda à exclusão de tarefas em processadores. Escalonando as mensagens no primeiro momento possível e acomodando-as sempre no início do macrociclo, seu critério de otimização é alcançar um atraso em todas as mensagens menor ou igual a zero.

Neste algoritmo, Franco (1998) apresenta também duas limitações; a primeira referese ao número de mensagens de entrada, ou seja, limita as mensagens de entrada que devem ser escalonadas uma após a outra, sem intervalo, para satisfazer o tempo de correlação. A 
segunda limitação relaciona-se ao escalonamento de mensagens dependentes de estratégias de controle, usadas como mensagens de entradas de outra estratégia.

O trabalho de Henriques (2005) mostra dois algoritmos de escalonamento; um que possui o escalonador em tempo de projeto ou pré-run-time, e o outro que possui o escalonamento em tempo de execução ou run-time. $\mathrm{O}$ autor relata que, no momento em que o engenheiro de aplicações define a aplicação em um sistema de configuração do protocolo FOUNDATION FIELDBUS, o escalonador em tempo de projeto (pré-run-time) deverá, através das informações conhecidas, especificar as restrições temporais dos blocos funcionais e as mensagens que compõem a aplicação do usuário. Assim, de posse destas informações, a ação do escalonador é criar um escalonamento realizável ou factível a ser utilizado depois pelo algoritmo run-time. A dificuldade em se obter um escalonamento realizável varia em função da complexidade do comportamento temporal da aplicação; neste caso, o comportamento temporal para a ação do escalonador é expresso pelas restrições temporais do protocolo FOUNDATION FIELDBUS, tais como: respeitar o deadline, restrições de precedência e de exclusão, restrições de recursos e as de fim-a-fim.

O algoritmo pré-run-time, apresentado por Henriques (2005), pode ter todo o seu funcionamento analisado, a começar pelos blocos funcionais e suas ligações lógicas, restrições de precedência e temporal, como também pelo macrociclo da configuração (Figura 19).

Na Figura 19 observa-se que os parâmetros Id e It são definidos pelo usuário ou engenheiro de aplicação, variáveis estas que guardam o valor da ordem da prioridade entre as estratégias de controle. Na etapa seguinte realiza-se a heurística de escalonamento, a ser escolhida entre os seguintes programas EDF (Earliest Deadline First), ERF (Earliest Release First), LST (Least Slack Time), RM (Rate Monotonic) ou DM (Deadline Monotonic), para ativar o escalonamento. 
O algoritmo de escalonamento em tempo de execução ou run-time, segundo Henriques (2005), deve atender às requisições aperiódicas com ocorrência incerta no tempo, pois o sistema não consegue adquirir qualquer conhecimento futuro sobre a chegada deste tipo de requisição. Assim este algoritmo deve administrar as requisições aperiódicas a serem atendidas e descartar as que não poderão ser absorvidas pelo sistema. A Figura 20 mostra também a descrição do escalonador run-time para o protocolo FOUNDATION FIELDBUS, proposto pelo autor. 


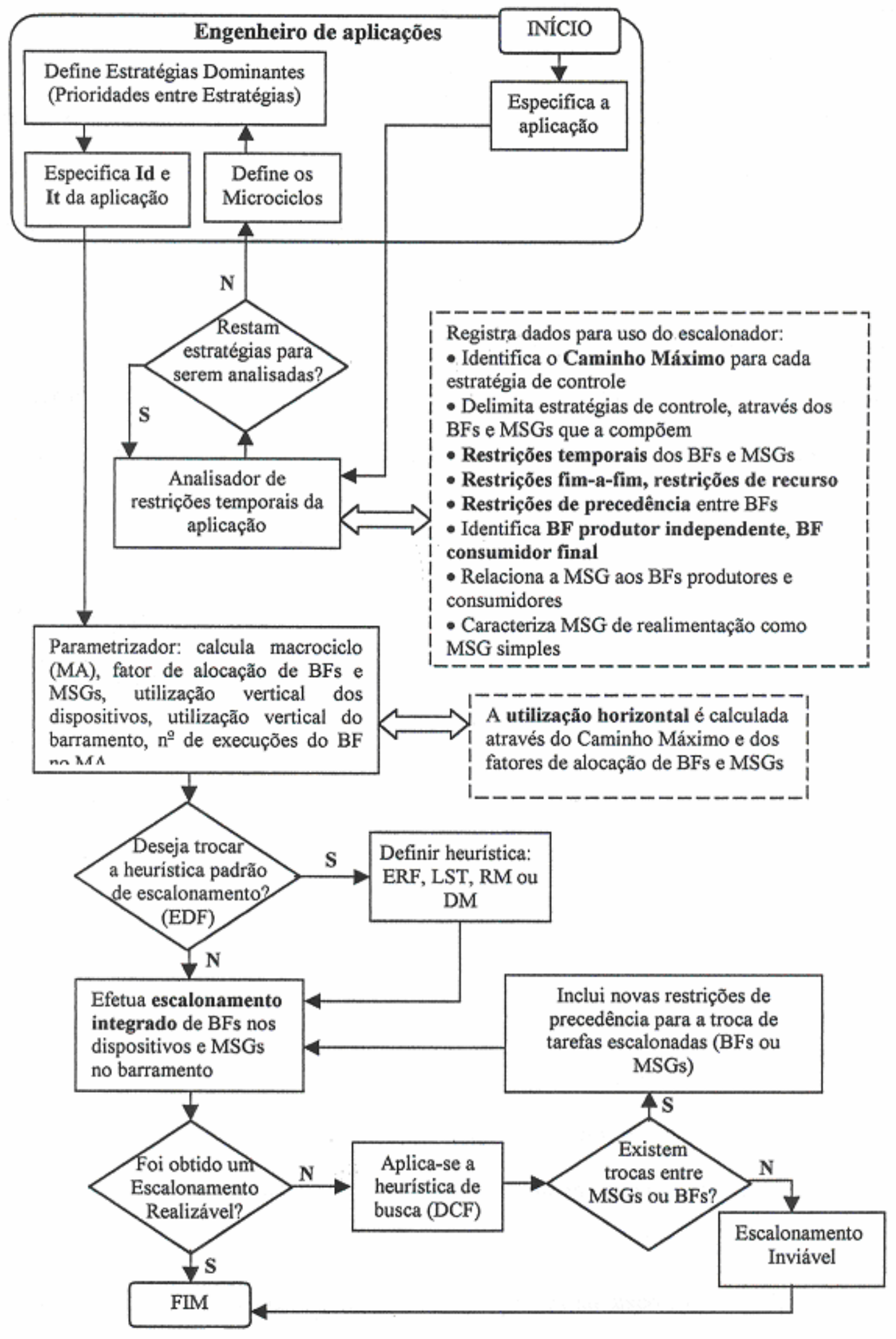

Figura 19 - Algoritmo de escalonamento pré-run-time, segundo Henriques (2005) 


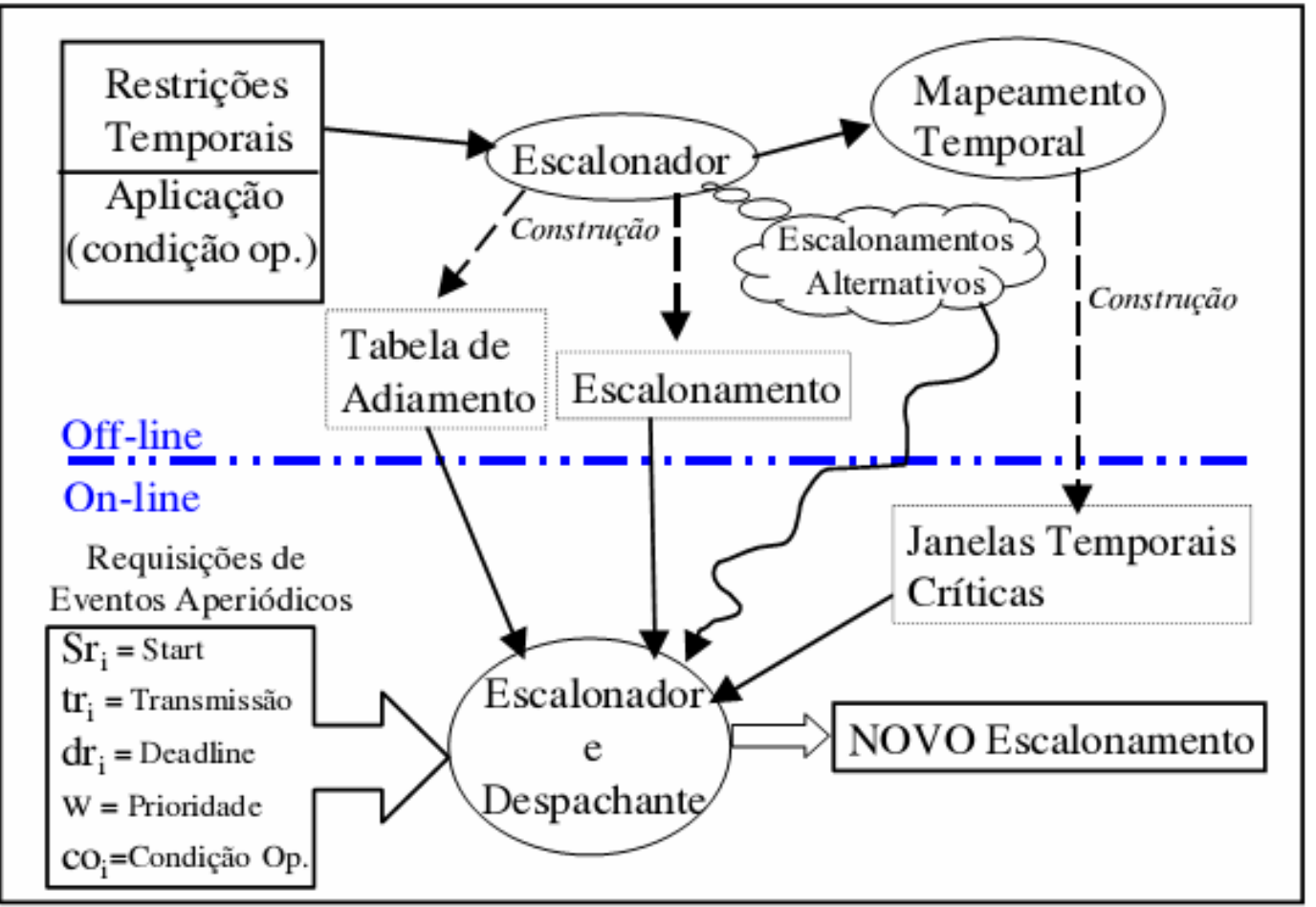

Figura 20 - Descrição do algoritmo de escalonamento run-time de Henriques (2005)

O escalonamento em tempo de projeto contém alguns critérios temporais e de desempenho para sistemas que utilizam o protocolo FOUNDATION FIELDBUS, os quais vêm detalhados a seguir.

O protocolo FOUNDATION FIELDBUS possui uma ação de controle distribuído, o que permite que um ou mais dispositivos interajam. Essa distribuição é feita pelos blocos funcionais executados localmente em cada dispositivo e são configurados para desempenharem alguma funcionalidade no sistema. Os blocos funcionais estabelecem ligações internas ou externas que também recebem o nome de mensagem (FIELDBUS FOUNDATION, 2003). A ligação ou mensagem é interna quando os blocos funcionais de um mesmo dispositivo trocam dados entre si; já a ligação externa ocorre quando há troca de dados entre blocos funcionais de dispositivos diferentes. Assim, uma aplicação é composta por um conjunto de blocos funcionais agrupados em estratégias de controle, com a função de controlar objetos do sistema. Conclui-se, então, que uma aplicação pode ser composta por 
uma ou mais estratégias de controle independentes entre si, configuradas nos dispositivos, desde que não existam ligações entre seus blocos funcionais (Franco, 1998).

Uma aplicação é considerada complexa devido sua configuração e quantidade dos blocos funcionais e ligações; estas configurações impõem à aplicação restrições temporais ao sistema (Franco, 1998).

Para que os objetivos possam ser alcançados, as restrições exigem a adotação de soluções propostas para os problemas de escalonamento e ainda impõem necessidades que devem ser atendidas na alocação de recursos, que limitam o espaço para busca de um problema de escalonamento.

Segundo Henriques (2005), as unidades escalonáveis, durante a ação de escalonamento para um sistema FIELDBUS FOUNDATION, são denominadas tarefas, e para se identificarem as características da tarefa a ser escalonada, os passos são:

- Dispositivos ou devices: as tarefas escalonáveis são blocos funcionais.

- Barramento de Comunicação: as tarefas escalonáveis são mensagens.

- Deadline: as tarefas são periódicas, com: deadline rígido, restrições de precedência, restrições de exclusão, restrições de recursos e restrições de fim-afim.

A restrição de precedência é um conjunto de tarefas dependentes entre si sendo assim as estratégias de controle são classificadas em composta e simples. Ela é composta quando há precedência entre as mensagens, e de controle simples quando não existe esta restrição.

Henriques (2005) considera que a estratégia de controle composta possui mensagens de entrada e saída relacionadas à precedência, e que estas devem aguardar o processamento dos blocos funcionais. Quando estes blocos estiverem sendo processados, o barramento fica ocioso, por isso chamado de tempo ocioso (Franco, 1998), o que possibilita assim que outras 
estratégias façam uso do barramento de comunicação. Figura 21 traz exemplo, segundo de Henriques (2000), de uma aplicação que utiliza estratégias de controle simples e composta.

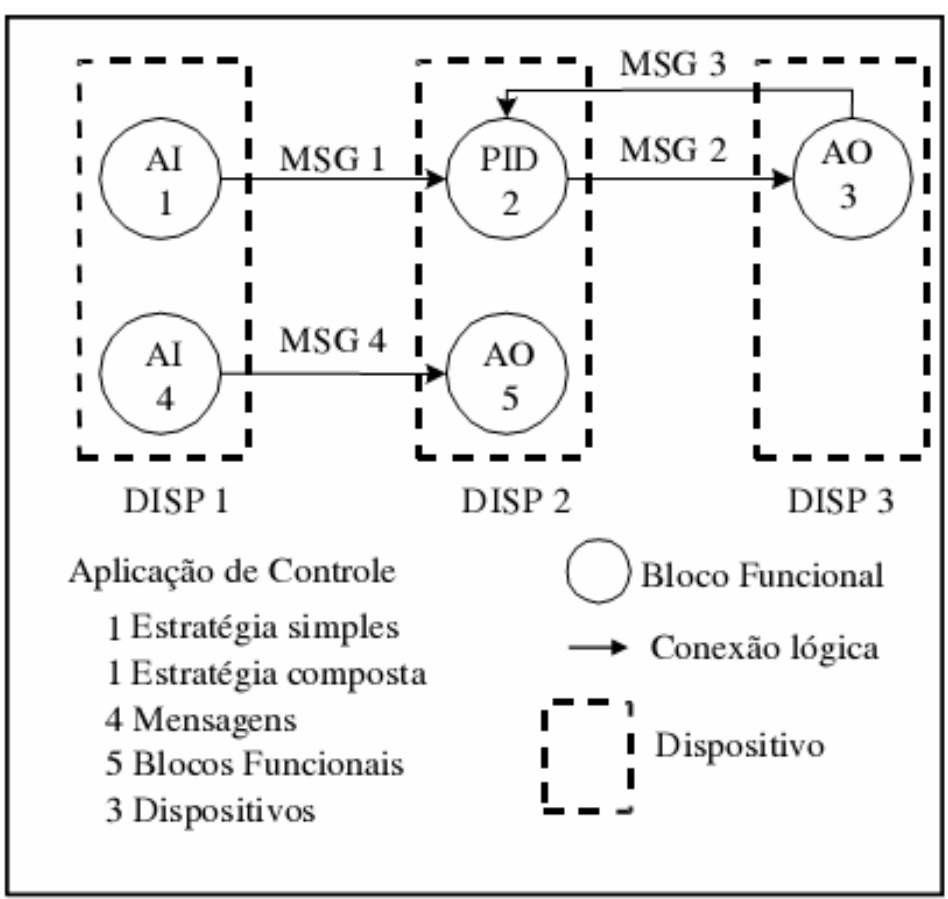

Figura 21 - Estratégia de controle simples e composta (Henriques, 2000)

Merece destaque o fato de cada recurso poder alocar em um mesmo instante de tempo somente um bloco funcional para cada processador contido no dispositivo fieldbus, ou uma mensagem no barramento de comunicação. Então, para que não haja sobreposições adotam-se as restrições de exclusão, as quais não permitem que dois ou mais blocos funcionais sejam executados ou transmitidos um mesmo intervalo de tempo em recurso compartilhado.

As restrições fim-a-fim especificam que todos os blocos funcionais e mensagens das estratégias de controle deverão estar contidos dentro do microciclo especificado para eles, na estratégia de controle.

Este capítulo mostrou os conceitos essenciais para o entendimento da área de escalonamento, como também descreveu conceitos sobre o assunto, segundo alguns pesquisadores, o que levou à melhor compreensão que os comportamentos do ambiente de escalonamento têm grande impacto sobre as características temporais das tarefas. 



\section{DESENVOLVIMENTO}

O algoritmo de escalonamento denominado FFSMART tem seu desenvolvimento divido em dois módulos. A função do primeiro módulo é ler as informações do arquivo de configuração da planta, que possui dados da estratégia da aplicação. Este arquivo possui o formato da extensão XML e é gerado pelo configurador SYSCON, um software da empresa SMAR EQUIPAMENTOS INDUSTRIAIS. Nos itens a seguir serão explicados de maneira breve, a tecnologia XML e também o configurador SYSCON.

No segundo módulo, encontra-se a maneira como o algoritmo trabalha e organiza as informações geradas pelo arquivo XML e como as classifica em uma tabela antes de iniciar o escalonamento. Após a execução desta funcionalidade, o algoritmo FFSMART realiza o escalonamento das informações coletadas.

\subsection{CONFIGURADOR SYSCON}

$\mathrm{Na}$ tecnologia fieldbus é comum os sistemas utilizarem um software que realiza a configuração da planta; estes softwares chamados de configuradores são executados em computadores e em dispositivos móveis (SMAR EQUIPAMENTOS INDUSTRIAIS, 2007b).

Um das vantagens de se utilizar um software de configuração é que ele auxilia na estratégia de controle de forma remota e também na automatização da configuração. Devido à 
complexidade do protocolo FOUNDATION FIELDBUS, e por se tratar de um protocolo específico, obrigatoriamente ele precisa de um configurador para auxiliar o usuário responsável pela planta a fazer uma automatização da configuração e também da documentação.

O configurador SYSCON da SMAR EQUIPAMENTOS INDUSTRIAIS é um software utilizado em computadores que realizam todo o trabalho de automatização para o protocolo FOUNDATION FIELDBUS. Este software também configura a estratégia de controle de processos reais em dispositivos FOUNDATION FIELDBUS, que permitem a geração de um arquivo com as informações em extensão XML, a ser utilizado pelo algoritmo na segunda parte do seu funcionamento.

Como todo o software, o SYSCON também realiza operações básicas e essenciais de funcionamento, assim, neste trabalho merece destaque como se configura uma estratégia de controle e também se como gera o arquivo XML. Para maior conhecimento sobre o modo de usá-lo e as funcionalidades do configurador SYSCON, recomenda-se buscar o manual do produto que está disponível na página da internet da empresa SMAR EQUIPAMENTOS INDUSTRIAIS LTDA (SMAR EQUIPAMENTOS INDUSTRIAIS, 2007c).

Para se criar no configurador SYSCON uma estratégia de controle para diagrama de blocos no modo off-line ${ }^{2}$, primeiramente elabora-se um projeto como mostra a Figura 22.

\footnotetext{
${ }^{2}$ Modo off-line ocorre quando o configurador não está conectado à rede, neste caso a rede física FOUNTATION FIELDBUS.
} 


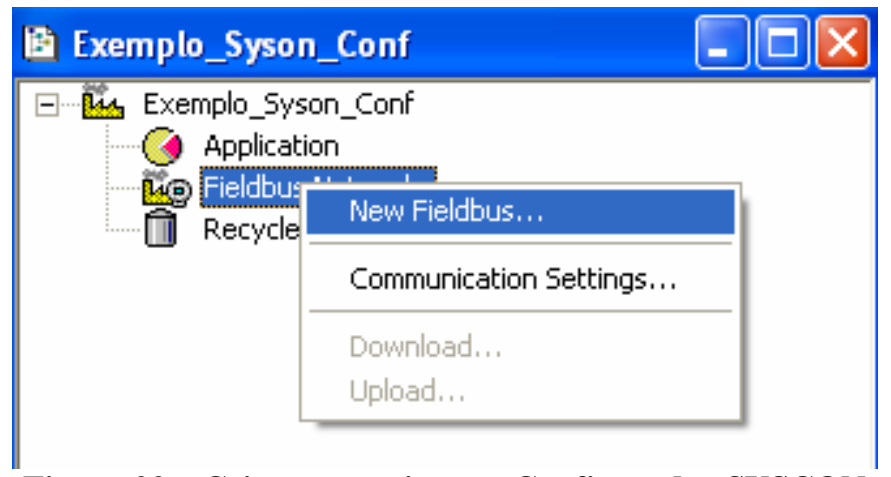

Figura 22 - Criar um projeto no Configurador SYSCON

Após criar o projeto e inseri-lo na rede fieldbus, cria-se a estratégia para a configuração. As Figuras 23, 24, 25 e 26 mostram a sequiência de passos a serem percorridos para acessar o ambiente de configuração da estratégia.

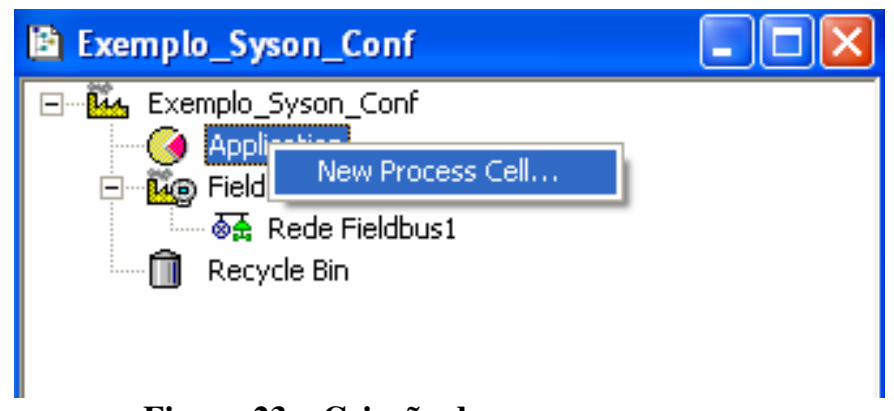

Figura 23 - Criação de um novo processo

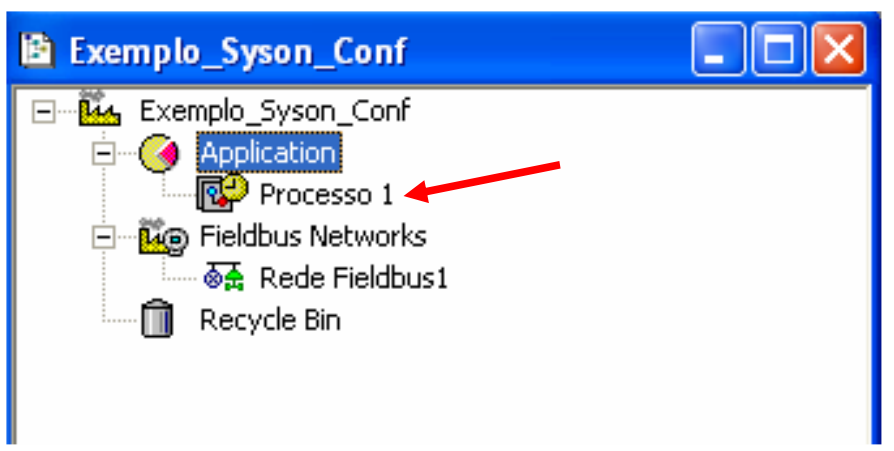

Figura 24 - Processo criado 


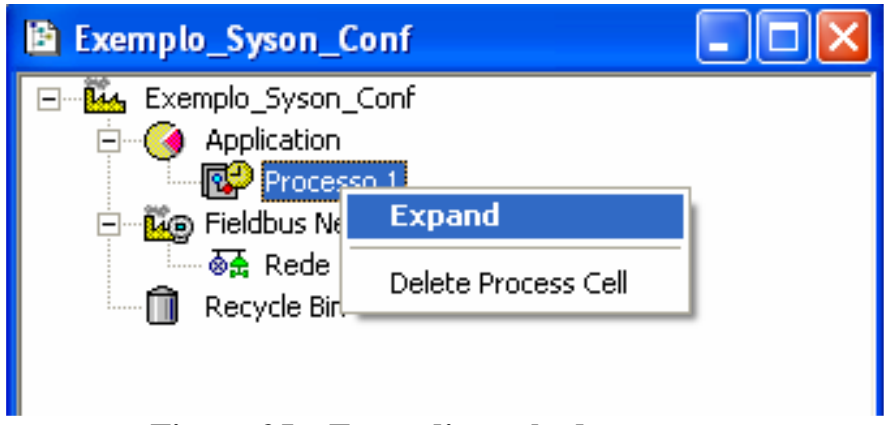

Figura 25 - Expandir a tela do processo

\section{[3. Processo 1}

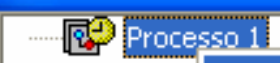

New Control Hodule

Attributes...

Figura 26 - Criação no novo módulo para, a seguir, acessar o ambiente da estratégia

Somente após criar um novo módulo no processo, pode-se acessar o ambiente de configuração de estratégia para os diagramas de bloco, como se observa na Figura 27.

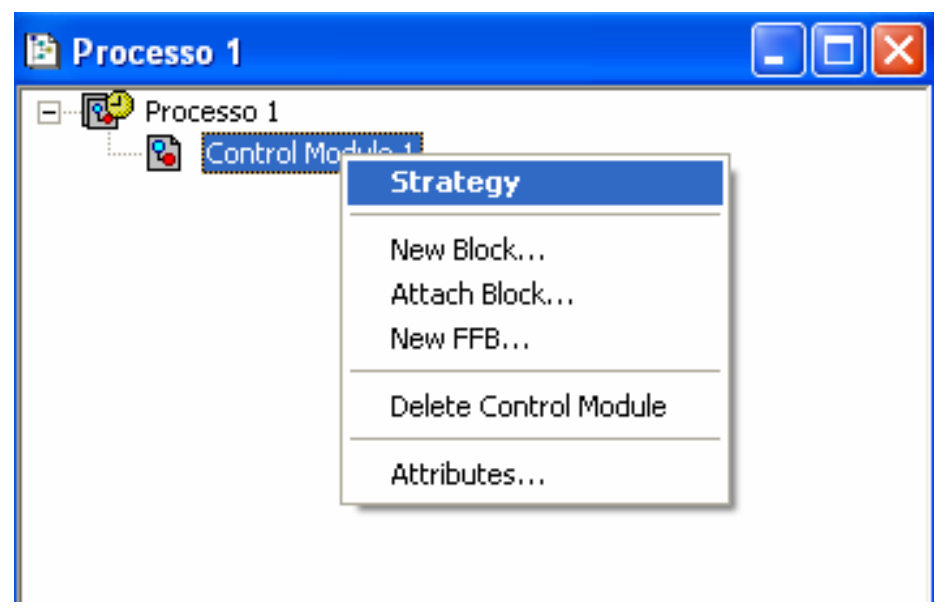

Figura 27 - Início do ambiente de configuração de estratégia para os diagramas de bloco

Após a execução de cada passo descrito, deve-se abrir o ambiente de configuração de estratégia para os diagramas de bloco, quando inclui-se o equipamento de campo ou device, 
juntamente com o seu bloco funcional, que permite a criação dos $l i n k s^{3}$. A Figura 28 mostra a inserção de um equipamento de campo, seguida da escolha do fabricante (manufacter) do equipamento, e, posteriormente, o tipo de equipamento de campo (device type) a ser utilizado, quando também se escolhe o bloco para o equipamento.
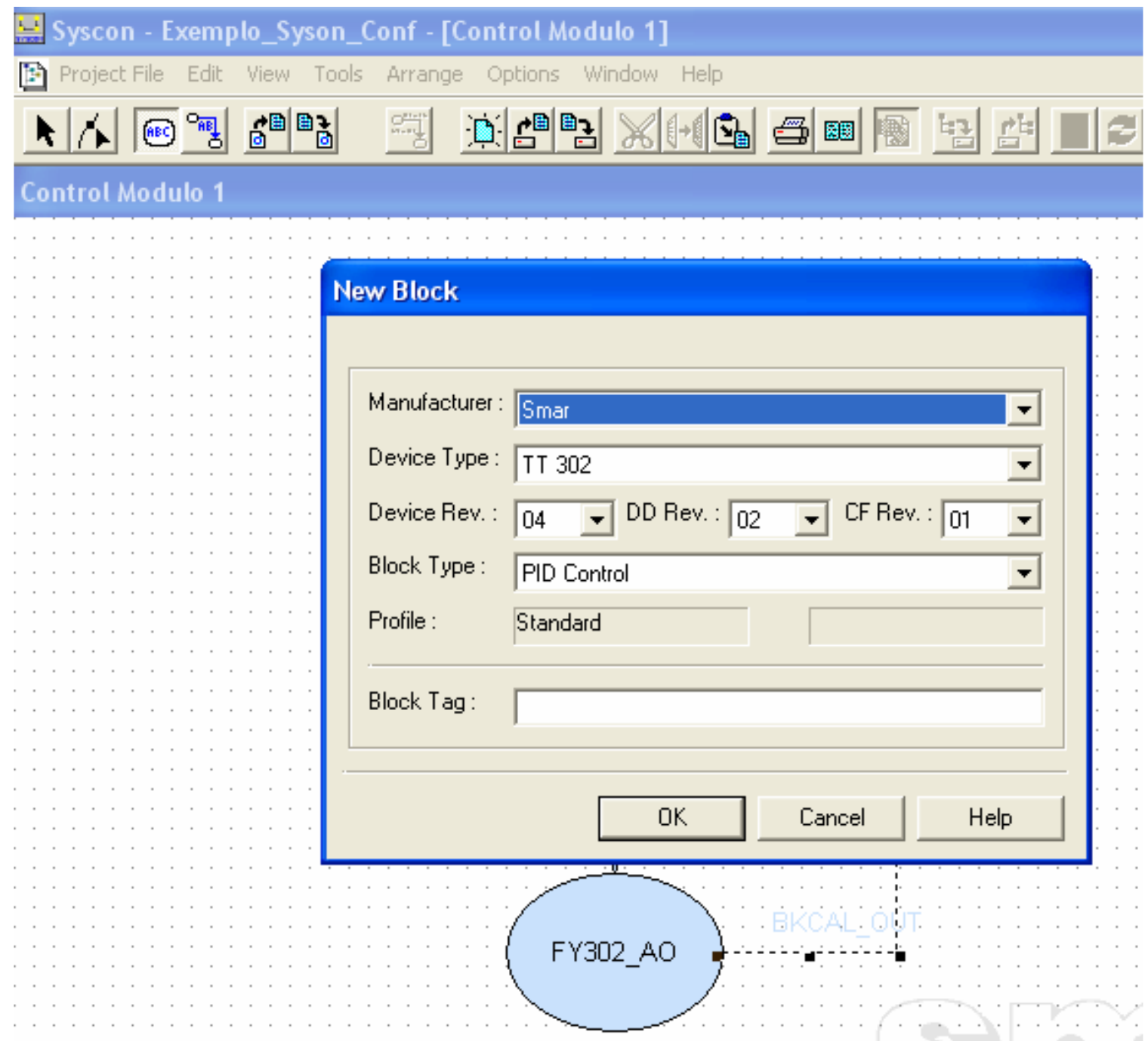

Figura 28 - Inserção do equipamento de campo juntamente com o bloco

Assim que se insere o diagrama gráfico, com as informações já especificadas pelo usuário, representado por círculos, pode-se criar as ligações, ou seja, os links entre os parâmetros de entrada e saída dos blocos, representados por setas, que nada mais são que a conexão entre os blocos.

\footnotetext{
${ }^{3}$ Links: No SYSCON links são as ligações que ocorre nos blocos funcionais entre dois dispositivos.
} 
Para se criar um link entre os blocos, o SYSCON mostra uma tela com a lógica de cada um deles especificada, bem como suas entradas e saídas (Figura 29).

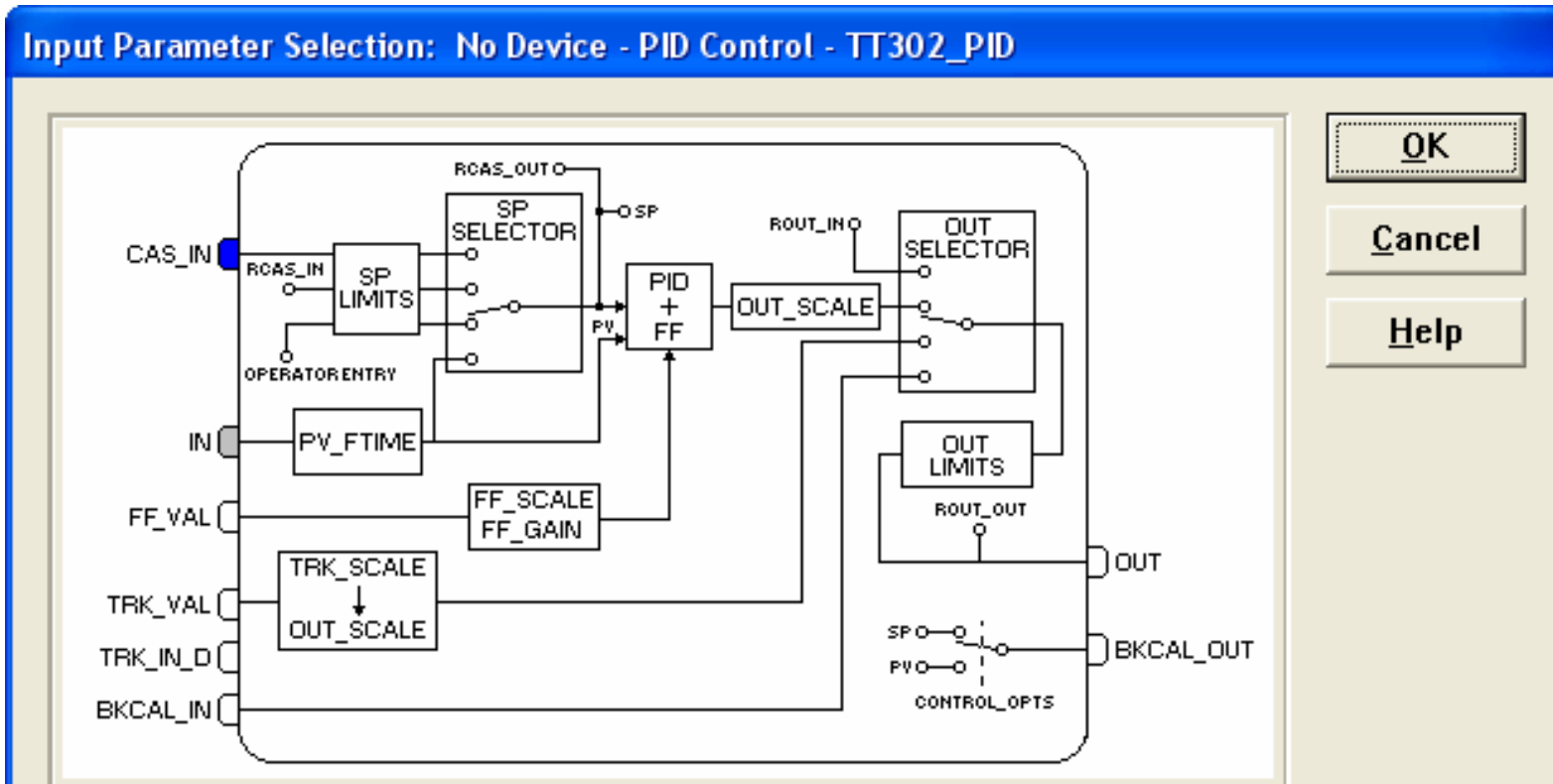

\section{Parameter Description:}

This parameter is the remote setpoint value, which must come from another Fieldbus block, or a DCS block through a defined link.

Figura 29 - Diagrama da lógica do bloco de controle PID (Proporcional Integral Derivativo) e suas entradas e saídas

Por fim, a Figura 30 mostra a estratégia de controle do diagrama gráfico de bloco desenvolvida de modo off-line. Depois que todos os elementos foram criados, o SYSCON permite a geração, a partir deste ponto, do arquivo XML (Figura 31). 


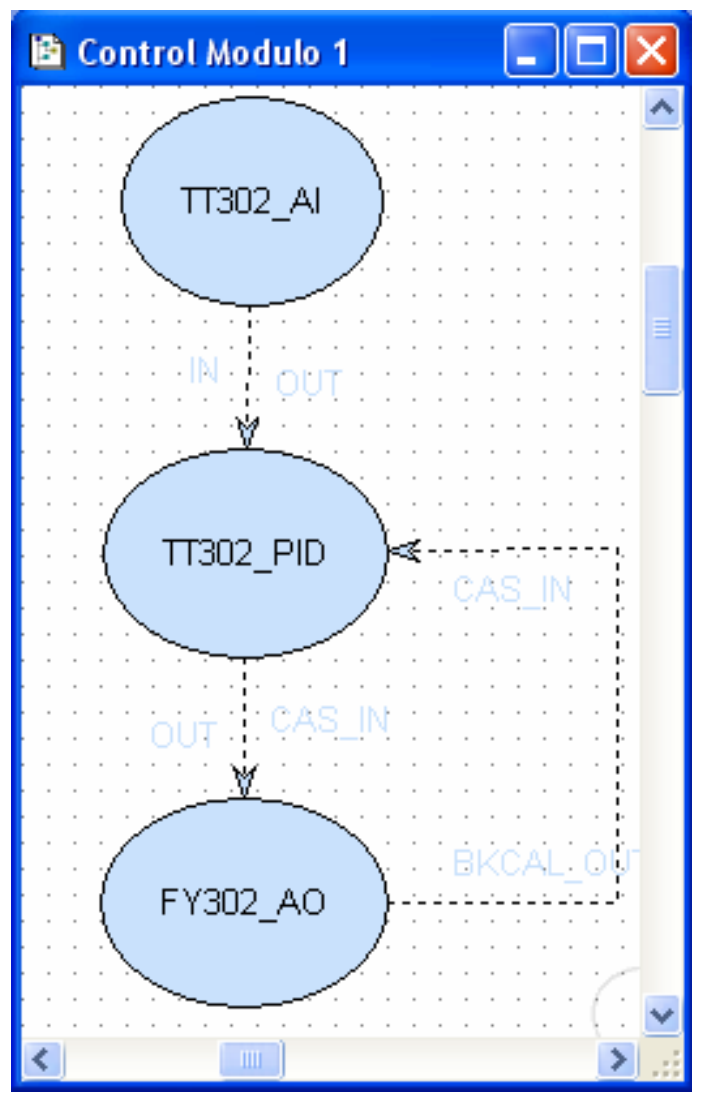

Figura 30 - Estratégia de controle

Syscon - Exemplo_Syson_Conf
Project File Edit View Tools Arrange Options Window Help
New
Open...
Open Default Template...
Close
Save
Save Ás...
Save Ás Default Template

Printer Setup...

Print...

Print to File...

Print Preview...

Security...

\begin{tabular}{llll} 
Export & Configuration as XML... \\
\hline Import &
\end{tabular}

Figura 31 - Geração do arquivo XML 


\subsection{TECNOLOGIA XML}

A sigla XML, abreviação de EXtensible Markup Language (Linguagem Extensível de Formatação), refere-se a uma tecnologia criada inicialmente com o propósito de trocar informações via internet ou em sistemas distribuídos. Foi criada em 1998, pela World Wide Web Consortium (W3C) para desenvolvimento da World Wide Web (WWW), entidade responsável pela definição da área gráfica da internet.

A linguagem XML é definida como o formato universal para dados estruturados na Web, dados estes que consistem em tabelas, desenhos, parâmetros de configuração etc. Esta linguagem, então, trata de definir as regras que permitem escrever documentos de forma adequadamente visíveis para o computador (Pantoni, 2006).

\subsubsection{CARACTERÍSTICAS DO XML}

O princípio do projeto era criar uma linguagem que pudesse ser lida por software, para ser integrada às demais (Pantoni, 2006). São suas principais características:

- Separação do conteúdo da formatação;

- Simplicidade e legibilidade, tanto para humanos quanto para computadores;

- Possibilidade de criação de tags sem limitação;

- Criação de arquivos para validação de estruturas (Chamados DTDs ${ }^{4}$ );

- Interligação de bancos de dados distintos;

- Concentração na estrutura da informação, e não na sua aparência.

${ }^{4}$ DTDs - Document Type Definition, ou simplesmente DTD, contém as regras que definem quais tags podem ser usadas em um documento XML e quais os valores válidos. 
O XML tem um bom formato para a criação de documentos com dados organizados de forma hierárquica, como se vê freqüentemente em documentos de texto formatados, imagens vetoriais ou bancos de dados (Pantoni, 2006).

\subsubsection{TAG}

As tags, são estruturas de linguagem de marcação, consistem de breves instruções, com duas marcas, uma de início e outra de fim. Há uma tendência nos dias atuais para se usar as tags apenas como delimitadoras de estilo ou como conteúdo, tanto em HTML (Hypertext Markup Language) quanto em XML (Pantoni, 2006).

O XML baseia-se em linguagens de marcadores denominados separadores de conteúdo. A sintaxe de um marcador é sempre precedida do sinal menor $(<)$, e finalizada com o sinal maior (>). O HTML também pode ser uma linguagem de marcadores (Pantoni, 2006) (Figura 32).

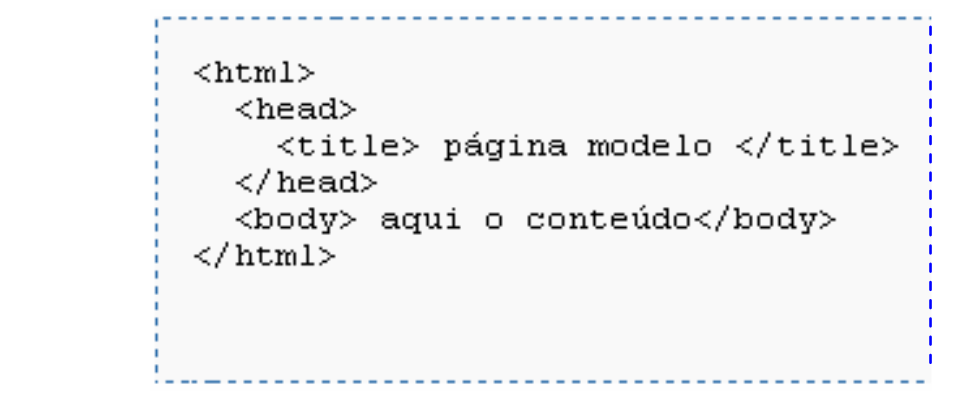

Figura 32 - Exemplo de um código em HTML com a utilização de tags

As marcações na tabela representam as tags, a palavra head indica o início do cabeçalho, que contém o título title (Pantoni, 2006). A Figura 33 mostra um exemplo do XML com a utilização de tags. 


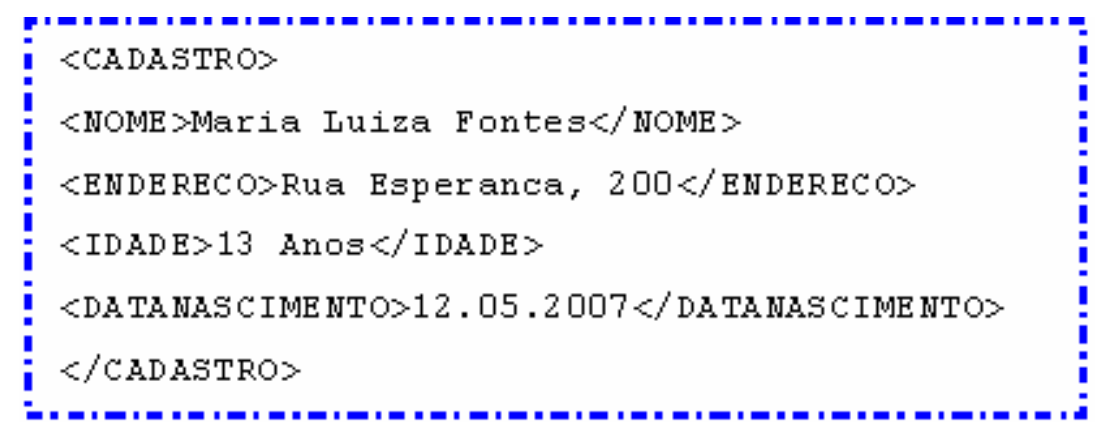

Figura 33 - Exemplo de um código em XML com utilização de tags

O XML é tido com uma tecnologia simples, não-proprietária, ou seja, não necessita do uso de licença e é também aberta. A simplicidade do XML se baseia em arquivos-textos estruturados; é aberta porque indica caminho para diferentes sistemas se comunicarem em uma linguagem comum, independentemente da sua plataforma (Pantoni, 2006).

A Figura 34 mostra uma parte do código do arquivo XML, gerado pelo SYSCON, na estratégia configurada de acordo com a Figura 30.

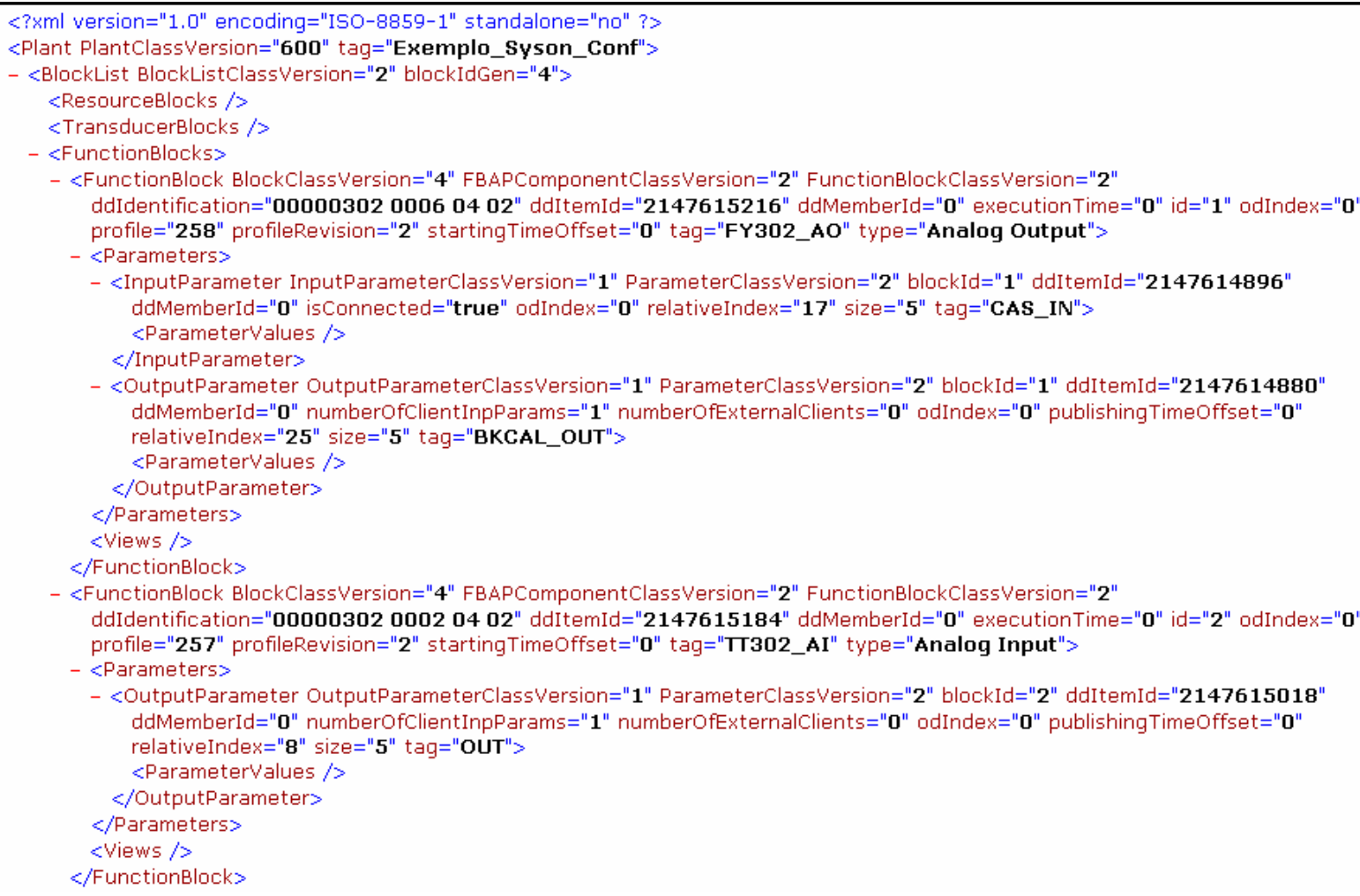

Figura 34 - Exemplo do código do arquivo XML gerado no SYSCON 


\subsection{ALGORITMO FFSMART}

O algoritmo de escalonamento proposto como estudo para este trabalho, denominado FFSMART, foi implementado na linguagem VB (Microsoft Visual Basic) versão 6.0. O FFSMART é um algoritmo de escalonamento estático, pré-run-time que, segundo Almeida (1999), tem como característica organizar os dados em uma tabela de escalonamento antes do sistema entrar em atividade (off-line).

É composto por dois módulos, no primeiro destaca-se a função do algoritmo de ler e interpretar os dados armazenados no arquivo XML, gerados através do configurador SYSCON, que tem em seu poder as informações da estratégia de controle da configuração da planta. Na Figura 34, vê-se como o arquivo XML expõe essas informações; após o FFSMART executar o primeiro módulo, tem início o segundo.

No segundo módulo, por se tratar de um algoritmo de escalonamento estático, o FFSMART trabalha com a tabela de escalonamento gerada a partir das informações obtidas no primeiro módulo. Assim, o algoritmo organiza as informações na tabela de escalonamento dividindo-as da seguinte maneira: Tarefa, Pré-requisitos, Recurso Utilizado, Tempo de Execução e Prioridade, onde:

- Tarefa: Nesta coluna ficam os blocos funcionais e as mensagens a serem escalonados;

- Pré-requisitos: São os links que fazem a ligação entre o recurso e a tarefa;

- Recurso utilizado: Compreende os dispositivos de campo ou devices, que fazem parte da configuração do processo;

- Tempo de execução: É quanto cada bloco funcional e as mensagens demoram para executar suas funcionalidades; 
- Prioridade: Como o próprio nome diz, classifica a prioridade de uma tarefa em relação à outra. O FFSMART assim define as prioridades em seu trabalho:

○ Link Local: É um link local que faz a ligação entre as entradas e as saídas dos blocos funcionais de um mesmo dispositivo no barramento. A tarefa que tem como precedência um link local é classificada pelo algoritmo como prioridade número um;

○ Link Remoto: É um link remoto que faz a ligação entre as entradas e as saídas de blocos funcionais de dispositivos de campos diferentes no barramento. Para este caso, o algoritmo classifica a prioridade da tarefa como número dois;

- Bloco Funcional: Uma tarefa cuja prioridade é a execução de um bloco funcional; o algoritmo a classifica como prioridade número três;

○ Link BKCAL: O link BKCAL é como um link de realimentação para blocos funcionais dos dispositivos de campo. BKCAL é a sigla de Back Calculation. A tarefa que possui como precedência um link BKCAL classifica-se como prioridade número quatro;

Observa-se que na Figura 35 as informações ficam armazenadas na tabela de escalonamento, após o algoritmo FFSMART executar a funcionalidade do segundo módulo. 


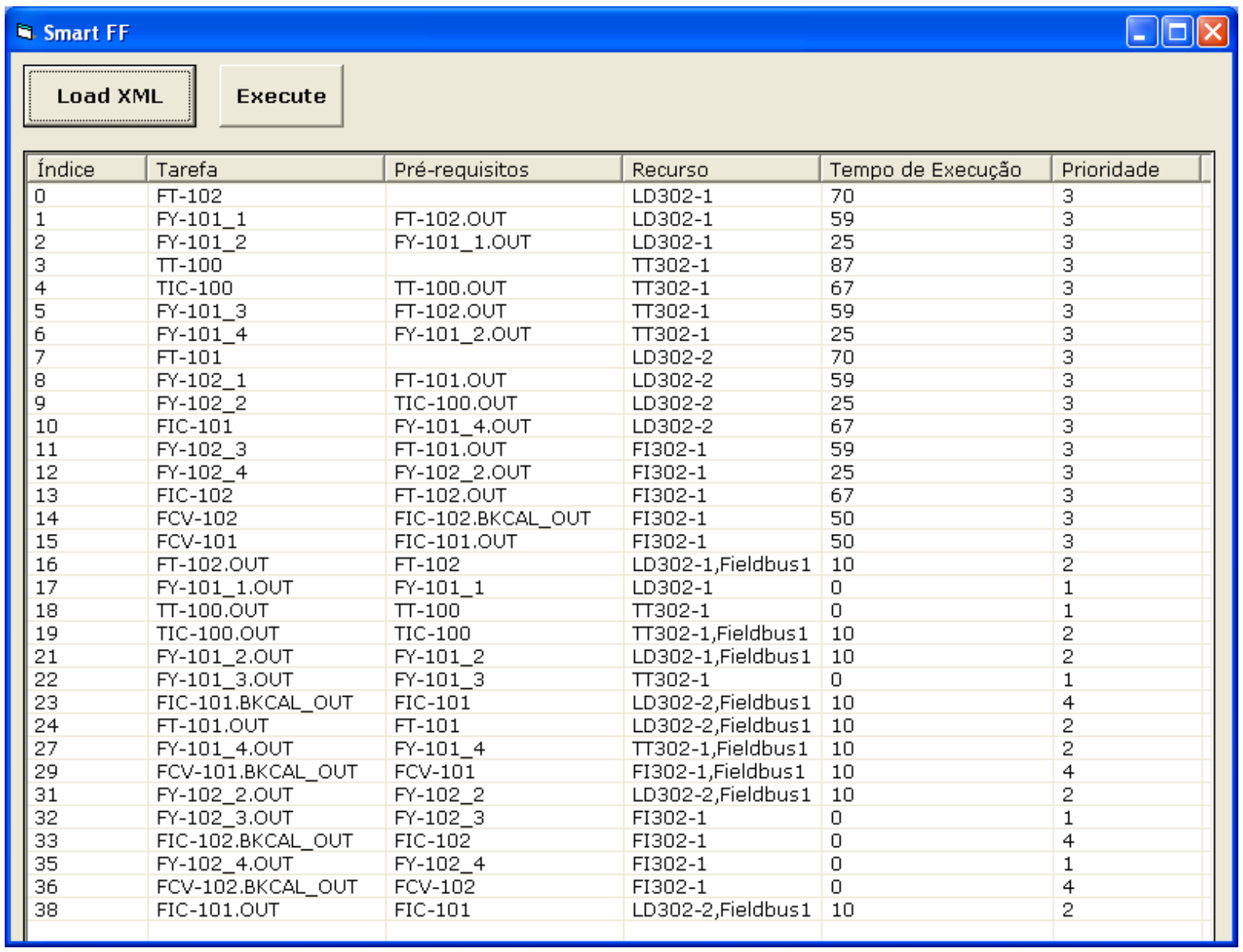

Figura 35 - Informações do arquivo XML armazenadas na tabela de escalonamento

O algoritmo dá início à execução do escalonamento a partir das informações contidas na tabela (Figura 35).

Para cada recurso ou device da estratégia, cria-se uma variável com o nome de "Relógio do Recurso", responsável por guardar o tempo de execução gasto em cada tarefa. Há também a variável "Relógio Global”, responsável por registrar o tempo gasto na execução de toda a tabela. Analisam-se as tarefas para verificar quais estão prontas para o início da execução. Para a tarefa estar pronta e ser executada, ela deve possuir todos os recursos utilizados livres, sem a presença de qualquer pré-requisito, após as verificações em cada uma das tarefas prontas, inicia-se sua execução, caso em que a variável "Tempo de Disparo" recebe o valor da variável do "Relógio Global". 
A variável "Relógio do Recurso" utilizada na tarefa executada deve ser atualizada pelo tempo de execução de cada tarefa. Vale a pena ressaltar que em caso de duas tarefas prontas para serem iniciadas no mesmo recurso, o desempate se dá pela prioridade.

Quando uma tarefa tem a sua execução concluída, é inserida em uma nova tabela, chamada "Tabela de Resultados", que contém "Nome da Tarefa", "Tempo de Disparo" e o “Tempo de Execução", que significam:

- Nome da Tarefa: denominação da tarefa que foi executada no escalonamento;

- Tempo de Disparo: valor total do tempo da execução de todas as tarefas escalonadas;

- Tempo de Execução: tempo gasto em cada uma das tarefas para serem concluídas.

Na Figura 36 observa-se o fluxograma do algoritmo de escalonamento FFSMART. 


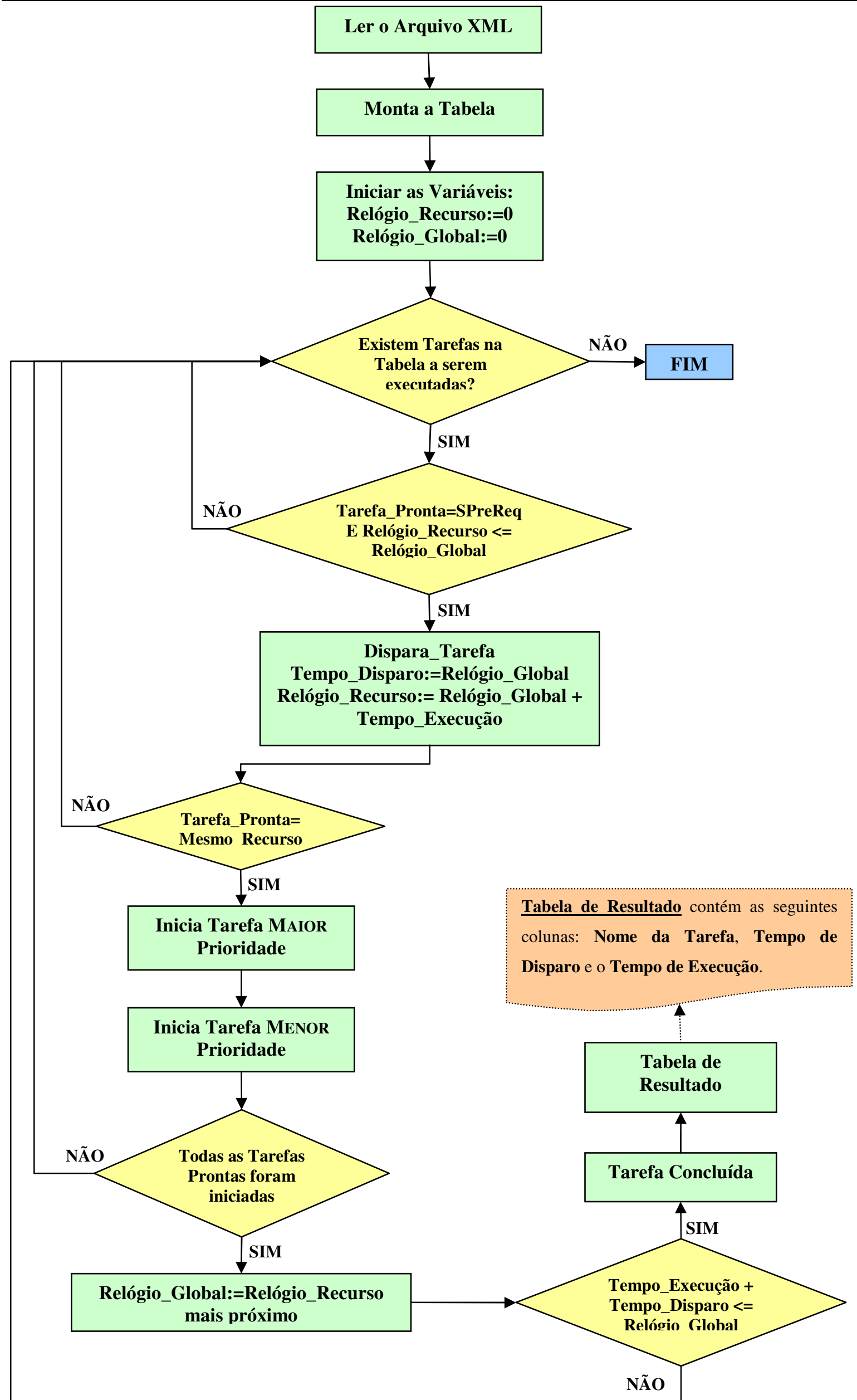

Figura 36 - Fluxograma do algoritmo FFSMART 
A Figura 37 expõe como as informações são concentradas na "Tabela de Resultados", após o escalonamento das mensagens.

\begin{tabular}{|c|c|c|c|}
\hline \multicolumn{3}{|l|}{ E Results } & \multirow{2}{*}{$\square \square$} \\
\hline Tarefa & Tempo de Disparo & Tempo de Execução & \\
\hline FT-102 & 0 & 70 & \\
\hline$\pi-100$ & 70 & 87 & \\
\hline FT-101 & 157 & 70 & \\
\hline FY-101_1 & 227 & 59 & \\
\hline $\mathrm{TIC}-10 \overline{0}$ & 286 & 67 & \\
\hline FY-101_3 & 353 & 59 & \\
\hline FY-102_1 & 412 & 59 & \\
\hline FY-102_3 & 471 & 59 & \\
\hline FIC $-10 \overline{2}$ & 530 & 67 & \\
\hline FT-102.OUT & 597 & 10 & \\
\hline FT-101.OUT & 607 & 10 & \\
\hline FY-101_2 & 617 & 25 & \\
\hline FY-102_2 & 642 & 25 & \\
\hline FCV $-10 \overline{2}$ & 667 & 50 & \\
\hline TIC-100.OUT & 717 & 10 & \\
\hline FY-101_4 & 727 & 25 & \\
\hline$F Y-102-4$ & 752 & 25 & \\
\hline FY-101_2.OUT & 777 & 10 & \\
\hline FY-102_2.OUT & 787 & 10 & \\
\hline FIC -101 & 797 & 67 & \\
\hline FY-101_4.OUT & 864 & 10 & \\
\hline FCV-101 & 874 & 50 & \\
\hline FIC-101.BKCAL_OUT & 924 & 10 & \\
\hline FIC-101.OUT & 934 & 10 & \\
\hline FCV-101.BKCAL_OUT & 944 & 10 & \\
\hline
\end{tabular}

Figura 37 - Tabela de resultados do escalonamento das mensagens 


\section{RESULTADOS}

Neste capítulo estão os resultados obtidos com os três experimentos realizados com o algoritmo de escalonamento FFSMART, os quais continham estratégias diferentes para análise do desempenho do algoritmo.

No primeiro experimento, utilizou-se uma aplicação para controlar a temperatura de saída do produto, valendo-se do vapor para aquecê-lo. Esta aplicação de controle simples foi composta por uma entrada e uma saída independentes, 3 dispositivos de campo e 5 blocos funcionais. No segundo experimento, utilizou também uma aplicação de duplo limite cruzado, tipo de controle que tentou manter a razão ar/combustão numa aplicação de controle da temperatura de um forno industrial (SMAR EQUIPAMENTOS INDUSTRIAIS, 2007d). Neste experimento a aplicação de controle é complexa, ou seja, é composta por 4 dispositivos de campo e 16 blocos funcionais. Já o terceiro experimento tratou de uma aplicação já utilizada no trabalho de Henriques (2005), parcialmente implementada por uma empresa que fez a fundição de ferro. Nesta aplicação o autor usou 4 dispositivos de campo e 21 blocos funcionais.

Os experimentos foram processados em uma rede FOUDATION FIELDBUS, e para sua realização a pesquisadora contou com os seguintes equipamentos:

- Um microcomputador Intel Core Duo 1.6 GHz com memória 1GB;

- Configurador SYSCON da SMAR EQUIPAMENTOS INDUSTRIAIS para Windows NT, 2000 e XP versão 06.01.00.079. 
- Equipamentos de campo FOUNDATION FIELDBUS Smar, sendo eles: LD302 (Transmissor de Pressão), TT302 (Transmissor de Temperatura), FY302 (Posicionador), FI302 (Conversor de Corrente Fieldbus).

\subsection{EXPERIMENTO 1 - CONTROLE DA TEMPERATURA DE SAÍDA DO PRODUTO COM UTILIZAÇÃO DO VAPOR PARA AQUECÊ- LO}

A aplicação de controle do experimento 1 serviu para controlar a temperatura de saída do produto, com uso do vapor para aquecê-lo. A Figura 38 exemplifica este experimento, de aplicação simples, mas composta por 3 dispositivos de campo, 5 blocos funcionais e 6 links. Os equipamentos utilizados no experimento pertencem à empresa SMAR EQUIPAMENTOS INDUSTRIAIS, e estes estão demonstrados na Tabela 2.

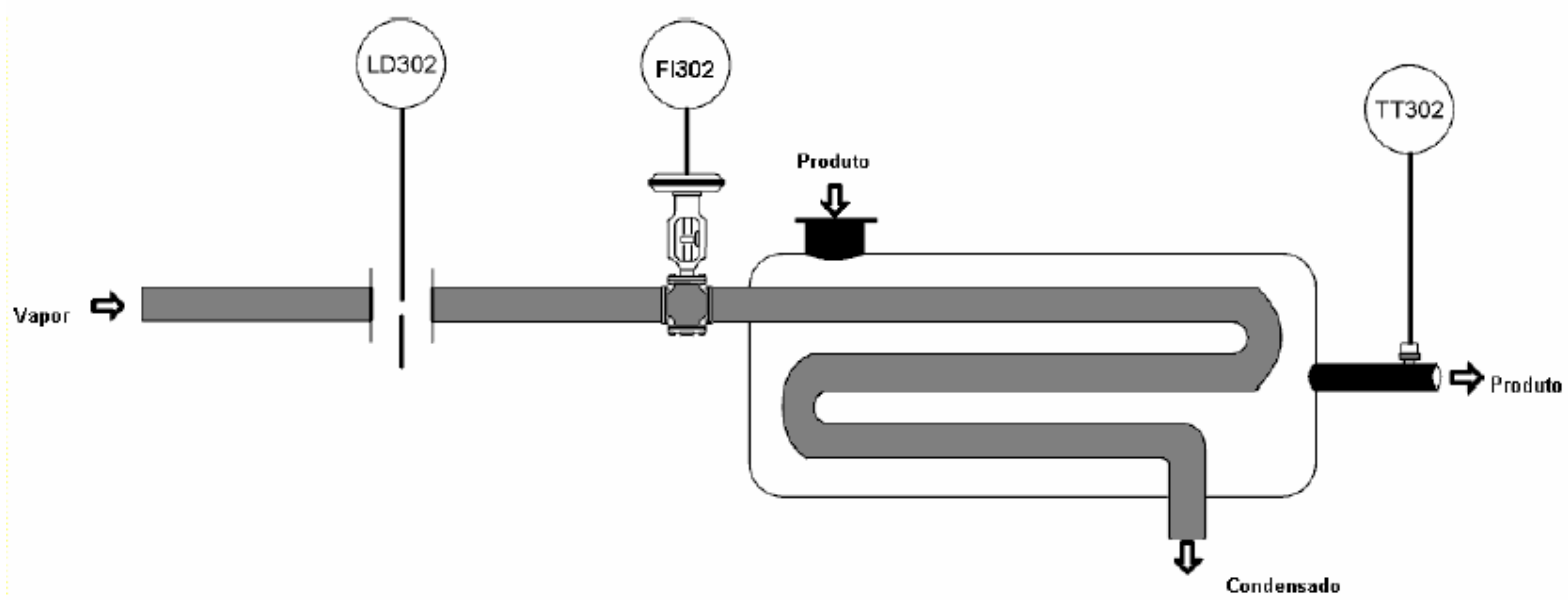

Figura 38 - Estratégia do controle de temperatura 
Tabela 2 - Dispositivos e Blocos Funcionais da SMAR utilizados no experimento 1

\begin{tabular}{cc}
\hline DISPOSITIVOS & BLOCOS FUNCIONAIS \\
\hline TT302 & AI - Analog Input \\
(Transmissor de Temperatura) & PID - Proporcional Integral \\
LD302 & Derivativo \\
AI - Analog Input \\
(Transmissor de Pressão) & PID - Proporcional Integral \\
FI302 & Derivativo \\
(Conversor de Corrente & \\
Fieldbus $)$ & Ao - Analog Output \\
\hline
\end{tabular}

Com base na Tabela 2, montou-se a estratégia para aplicação no configurador SYSCON, como mostra a Figura 39.

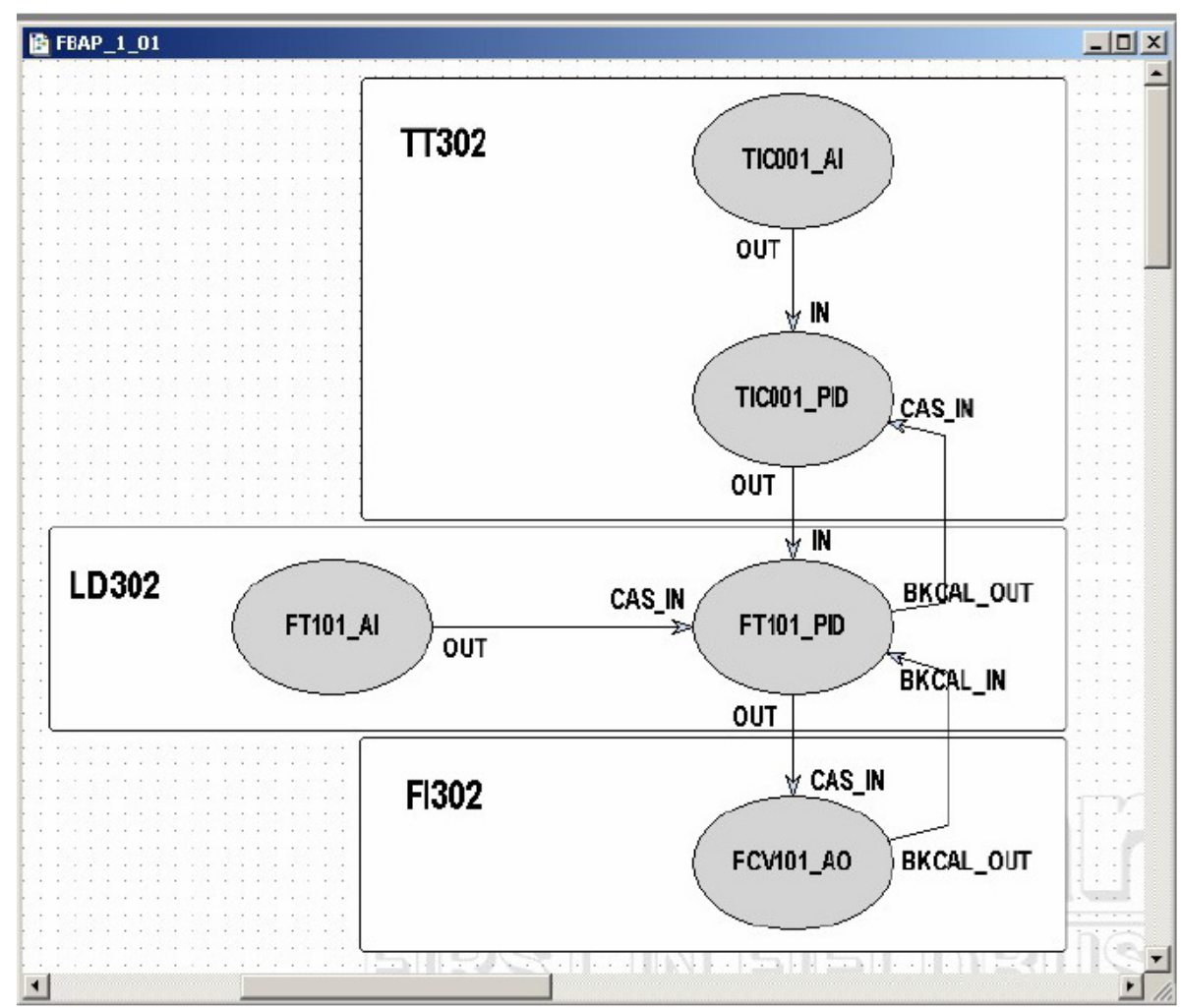

Figura 39 - Estratégia de blocos configurada no SYSCON para o experimento 1 
Com a estratégia de blocos pronta foi possível gerar o arquivo XML e iniciar o escalonamento. A Figura 40 expõe as informações da aplicação abstraídas do arquivo XML. Com base nestas informações, o FFSMART executou o escalonamento, gerando a tabela de resultados (Figura 41). A Figura 42 ilustra gráfico com as informações sobre o escalonamento da tabela de resultados.

\begin{tabular}{|c|c|c|c|c|c|}
\hline \multicolumn{3}{|c|}{ Smart FF } & & & $-\square x$ \\
\hline Load XML & \multicolumn{5}{|l|}{ Execute } \\
\hline Índice & Tarefa & Pré-requisitos & Recurso & Tempo de Execução & Prioridade \\
\hline$\overline{0}$ & TICO01 AI & & TICOO1 & 87 & 3 \\
\hline 1 & TIC001_PID & TIC001_AI.OUT & TICO01 & 67 & 3 \\
\hline 2 & FIT101_AI & & FIT101 & 70 & 3 \\
\hline 3 & FIT101_PID & TIC001_PID.OUT & FIT101 & 67 & 3 \\
\hline 4 & FIT101_PID & FIT101_AI.OUT & FIT101 & 67 & 3 \\
\hline 5 & FCV101_AO & FIT101_PID.OUT & FCV101 & 50 & 3 \\
\hline 6 & TICOO1_AI.OUT & TICOO1_AI & TICOO1 & 0 & 1 \\
\hline 7 & TIC001_PID.OUT & TICO01_PID & TIC001,Fieldbus1 & 10 & 2 \\
\hline 8 & FIT101_PID.OUT & FIT101_PID & FIT101,Fieldbus 1 & 10 & 2 \\
\hline 9 & FCV101_AO.BKCAL_OUT & FCV101_AO & FCV101,Fieldbus1 & 10 & 4 \\
\hline 10 & FIT101_PID.BKCAL_OUT & FIT101_PID & FIT101,Fieldbus1 & 10 & 4 \\
\hline 11 & FIT101_AI.OUT & FIT101_AI & FIT101 & 0 & 1 \\
\hline
\end{tabular}

Figura 40 - Tabela de informações da configuração do experimento 1

\begin{tabular}{|c|c|c|c|}
\hline E Results & & & $\square \square$ \\
\hline Tarefa & Tempo de Disparo & Tempo de Execução & \\
\hline TICO01_AI & 0 & 87 & \\
\hline FIT101_AI & 0 & 70 & \\
\hline TIC001_PID & 70 & 67 & \\
\hline FIT101_PID & 137 & 67 & \\
\hline TIC001_PID.OUT & 204 & 10 & \\
\hline FIT101_PID.OUT & 214 & 10 & \\
\hline FIT101_PID & 224 & 67 & \\
\hline FIT101_PID.BKCAL_OUT & 281 & 10 & \\
\hline FCV101_AO & 291 & 50 & \\
\hline FCV101_AO.BKCAL_OUT & 341 & 10 & \\
\hline
\end{tabular}

Figura 41 - Tabela de resultados do escalonamento do experimento 1

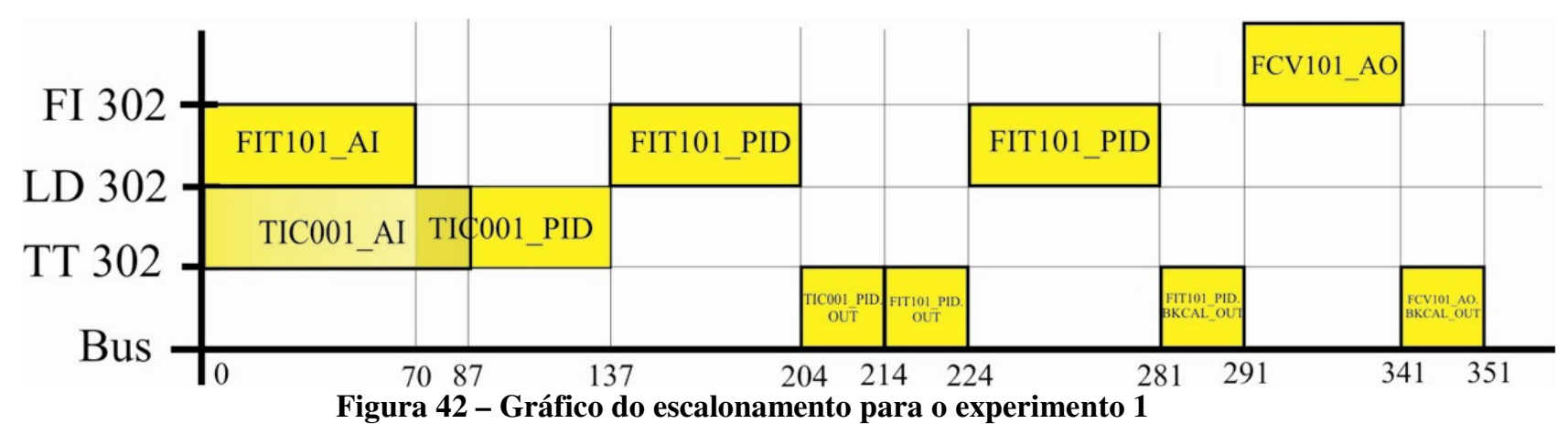


O gráfico presente na Figura 42 mostra que o macrociclo da aplicação foi de $351 \mathrm{~ms}$, porém SMAR EQUIPAMENTOS INDUSTRIAIS (2007e) referiu que o macrociclo de cada canal é dependente da configuração, podendo ser estimados através de dados, como número de links, dispositivos de campo e número de blocos. Neste trabalho empregou-se esta estimativa para comparar e analisar a eficácia do algoritmo de escalonamento FFSMART.

Para se entender a estimativa do cálculo do macrociclo da aplicação, SMAR EQUIPAMENTOS INDUSTRIAIS (2007e) dispõe das seguintes definições:

- Background Traffic: foi o tempo usado para supervisão e mensagens assíncronas, cuja sua estimativa foi calculada com base na seguinte fórmula:

$$
(\mathrm{BT}=(\text { NúmerosDispositivos } * \text { NúmerosBlocos }) * 30 \text { ms }) \quad(5.1)
$$

Para variável "NúmerosBlocos" considerou-se uma estimativa de 2 blocos por dispositivos de campo (SMAR EQUIPAMENTOS INDUSTRIAL, 2007e).

- Foreground Traffic: tempo utilizado para links e controle. Sua estimativa foi analisada pela quantidade de links; assim, neste caso a fórmula foi:

$$
(\text { FT = (NúmerosLinks* } 30 \text { ms) })
$$

- Macrociclo: calculou-se a estimativa do macrociclo pela somatória do Background Traffic e Foreground Traffic mais a soma de uma margem de segurança de $20 \%$.

$$
(\text { Macrociclo }=(\mathrm{BT}+\mathrm{FT})+20 \%)
$$


Para executar este experimento classificado como tráfego baixo, SMAR EQUIPAMENTOS INDUSTRIAL (2007e) realizou a estimativa seguindo os cálculos dos macroclicos, ou seja:

- Background Traffic

$$
\begin{gathered}
(\mathrm{BT}=(\text { NúmerosDispositivos } * \text { NúmerosBlocos }) * 30 \mathrm{~ms}) \\
((\mathrm{BT}=(3 * 2) * 30 \mathrm{~ms})) \\
\mathbf{B T}=\mathbf{1 8 0} \mathbf{~ m s}
\end{gathered}
$$

- Foreground Traffic:

$$
\begin{gathered}
(\mathrm{FT}=(\text { NúmerosLinks*30 ms })) \\
(\mathrm{FT}=(6 * 30 \mathrm{~ms})) \\
\text { FT }=\mathbf{1 8 0} \mathbf{~ m s}
\end{gathered}
$$

- Macrociclo

$$
\begin{gathered}
(\text { Macrociclo }=(\mathrm{BT}+\mathrm{FT})+20 \%) \\
(\text { Macrociclo }=(180+180)+20 \%)
\end{gathered}
$$

\section{Macrociclo $=432 \mathrm{~ms}$}

Ao se analisar a Figura 42, observou-se que o macrociclo da aplicação levou um tempo de $351 \mathrm{~ms}$ para a transmissão das mensagens e informações no barramento, enquanto a estimativa de tempo para o cálculo do macrociclo, segundo SMAR EQUIPAMENTOS INDUSTRIAL (2007e), foi de 432 ms. Percebe-se, então, que no método para estimar o macrociclo o algoritmo FFSMART apresentou uma otimização de $81 \mathrm{~ms}$ para sua aplicação. Nos sistemas de comunicação em redes este resultado foi considerado como um ganho satisfatório para a aplicação. A Figura 43 evidencia o gráfico da análise do resultado. 


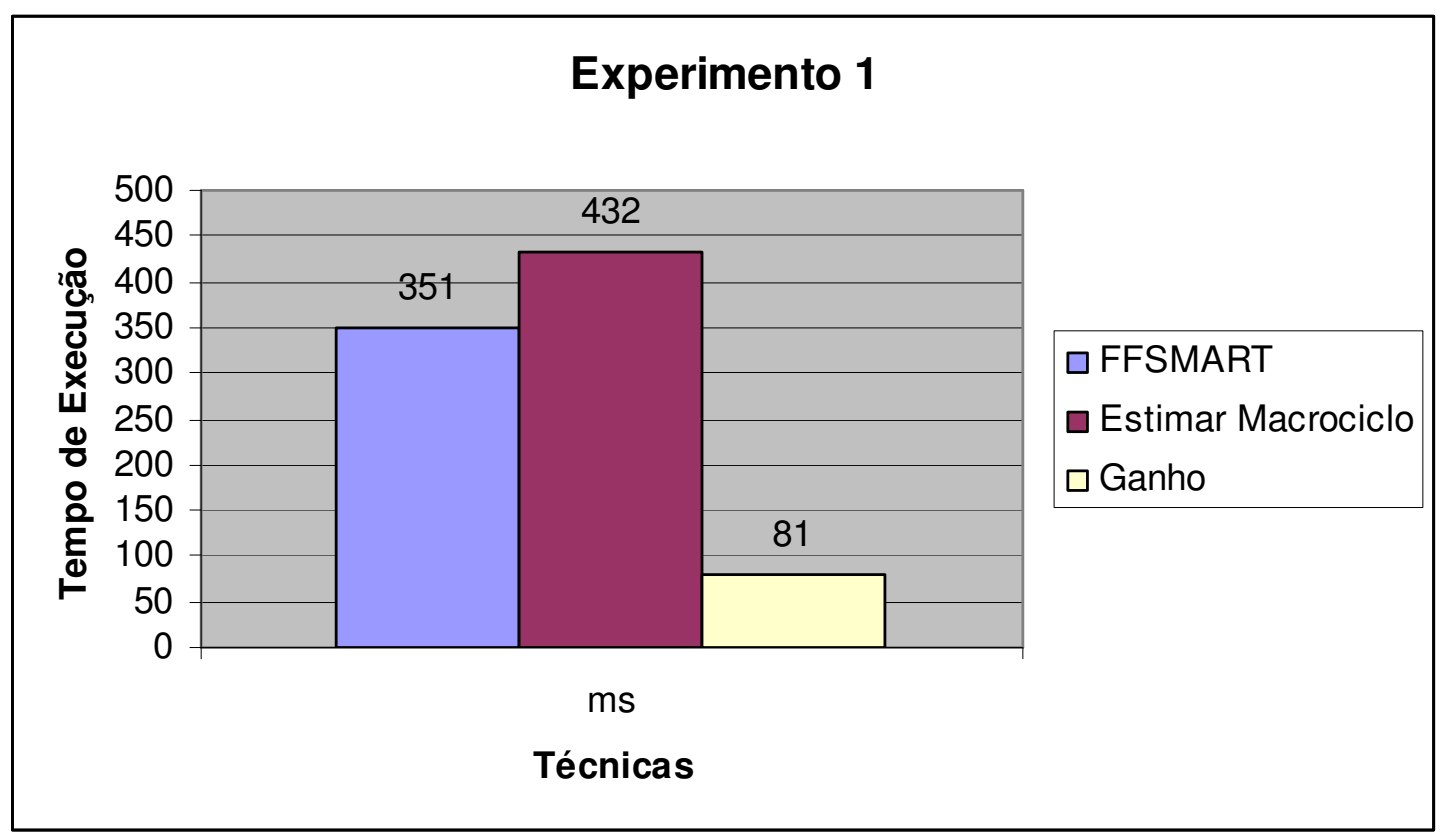

Figura 43 - Análise e otimização do resultado do algoritmo FFSMART para o experimento 1

\subsection{EXPERIMENTO 2 - DUPLO LIMITE CRUZADO}

O segundo experimento trouxe a aplicação de controle chamada de duplo limite cruzado, a qual tentou manter a razão entre os elementos químicos ou naturais existentes na planta que estava sendo controlada pelo sistema (SMAR EQUIPAMENTOS INDUSTRIAIS, 2007d).

A aplicação do experimento 2 foi utilizada para controlar a temperatura de um forno industrial. A Figura 44 exemplifica esse experimento de controle complexo, composto por 4 dispositivos de campo, 16 blocos funcionais e 23 links. 


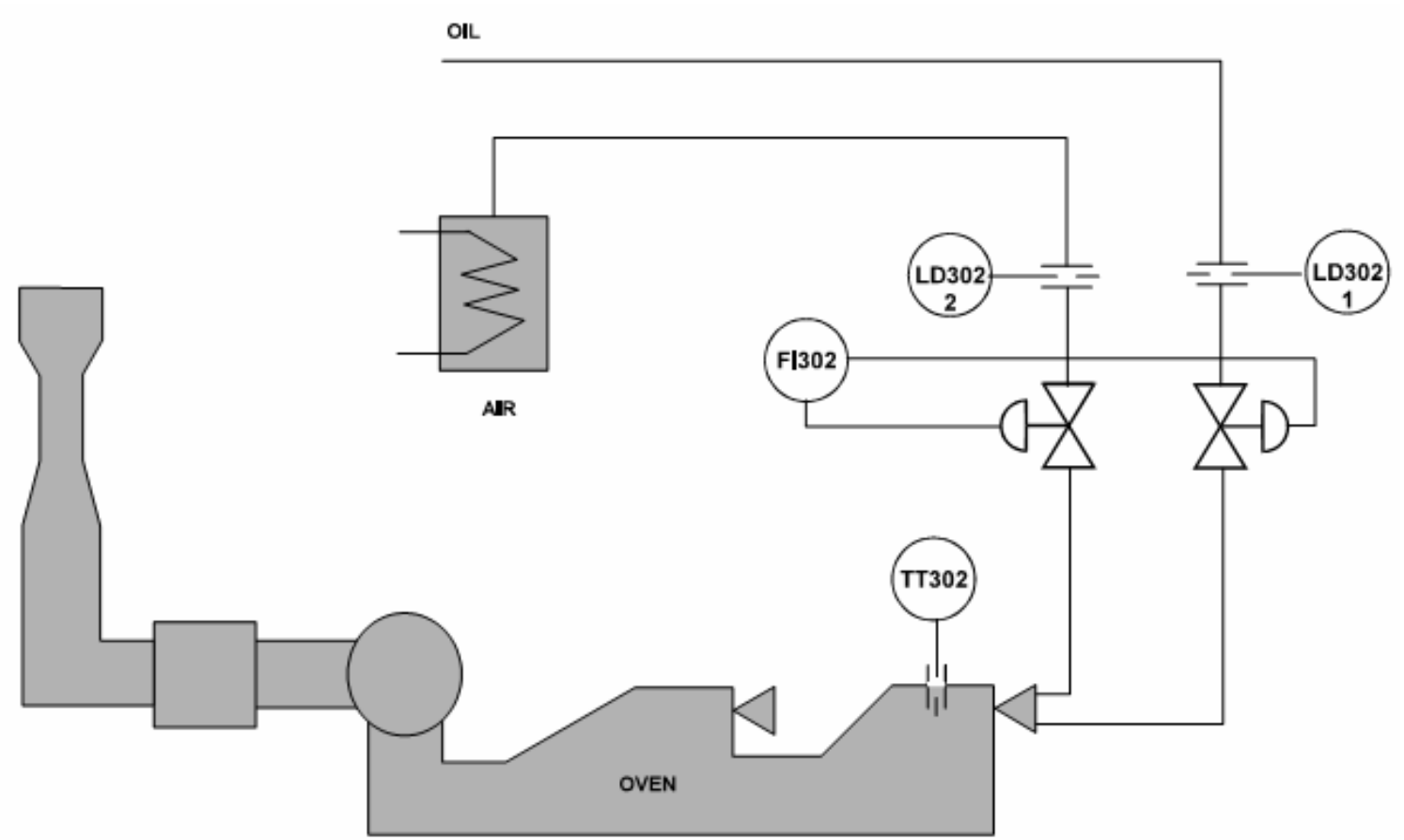

Figura 44 - "Duplo Limite Cruzado" para controlar a temperatura de um forno industrial

Este tipo de controle tentou manter a razão ar/combustível estritamente dentro dos limites designados na configuração da planta, já que uma mudança repentina na carga requeria uma variação tanto de ar como de combustível. O controle-mestre, enquanto estava estabilizado, forneceu valores de Setpoint para os controladores de ar e combustível. Durante as transições, o fluxo de ar determinou os limites máximo e mínimo do fluxo de combustível, e o mesmo ocorreu com o fluxo de ar, cujos limites foram fixados pelos do fluxo de combustível. Neste modo, até mesmo quando há grande alteração no sinal-mestre da razão ar/combustível, ela é mantida muito próximo do valor desejado. No caso de "duplo limite cruzado", ele previne que uma rápida variação desbalanceie a razão desejada (SMAR EQUIPAMENTOS INDUSTRIAIS, 2007d). A Tabela 3, a seguir, expõe os dispositivos utilizados neste experimento. 
Tabela 3 - Dispositivos e Blocos Funcionais da SMAR utilizados no experimento 2

\begin{tabular}{cc}
\hline DISPOSITIVOS & BLOCOS FUNCIONAIS \\
\hline LD302-1 & FY102-Analog Input \\
& FY-101_2-Input Selector \\
& FT-101-Analog Input \\
& FY-102_1-Arithmetic \\
FY-102_2-Input Selector \\
FIC-101-PID Control \\
TT-100-Analog Input \\
TIC-100-PID Control \\
FY-101_3-Arithmetic \\
FY-101_4-Input Selector \\
FY-102_3 - Arithmetic \\
FY-102_4-Input Selector \\
FIC-102-PID Control \\
FCV-102 - Analog Output \\
FCV-101-Analog Output \\
\hline FI302-1
\end{tabular}

Com base na Tabela 3, montou-se a estratégia para realizar a aplicação no configurador SYSCON (Figura 45). 


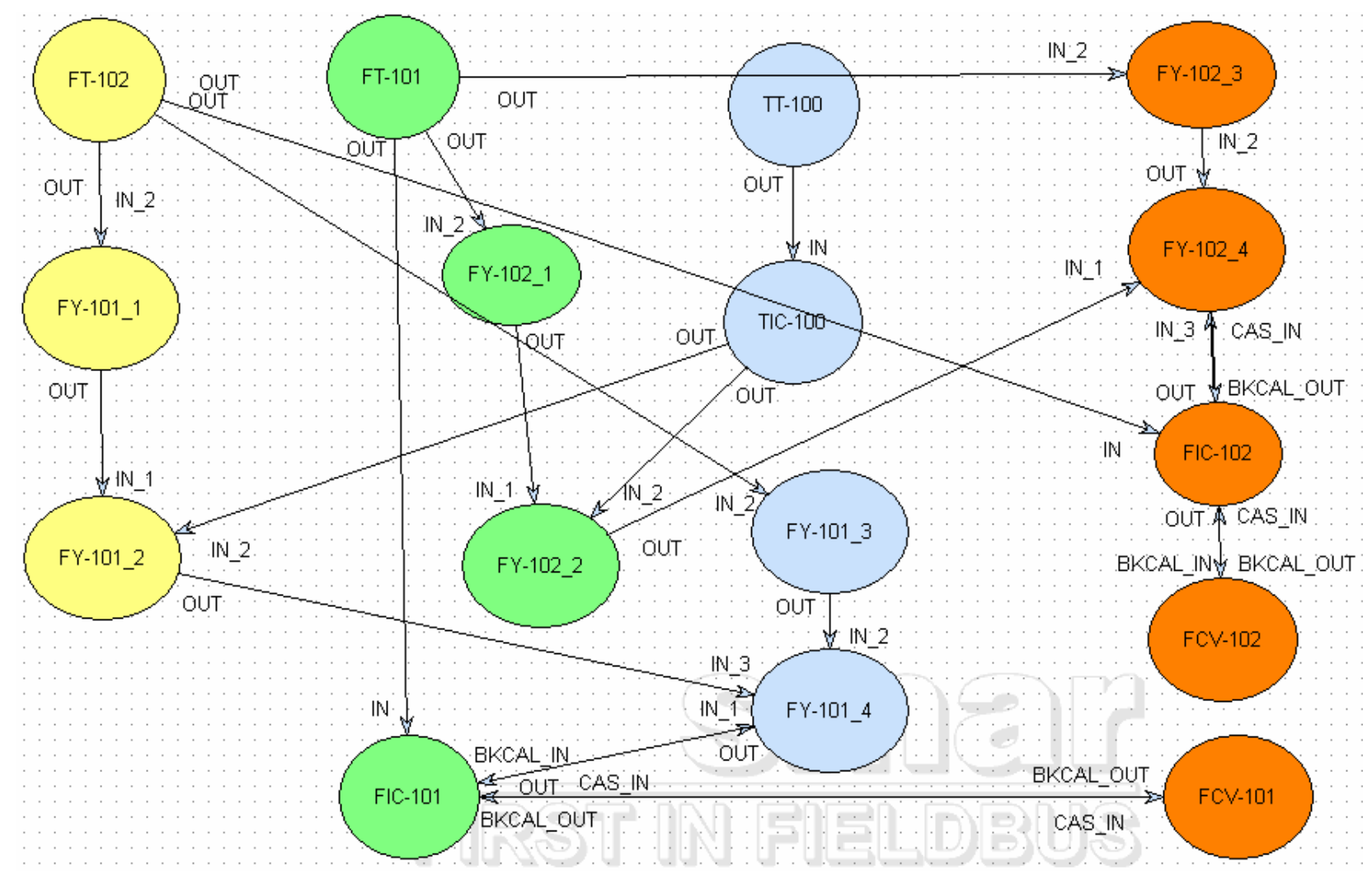

Figura 45 - Estratégia de blocos configurada no SYSCON do experimento 2

Estando a estratégia de blocos pronta pôde-se gerar o arquivo XML e iniciar o escalonamento. A Figura 46 apresenta a tabela com as informações da aplicação abstraídas do arquivo XML. Com base nestas informações, o FFSMART executou o escalonamento, e com isso gerou a tabela de resultados (Figura 47). O gráfico ilustrado na Figura 48 traz as informações de escalonamento da tabela de resultados. 


\begin{tabular}{|c|c|c|c|c|c|}
\hline Smart & & & & & \multirow[t]{2}{*}{$\square$} \\
\hline Load XML & Execute & & & & \\
\hline Índice & Tarefa & Pré-requisitos & Recurso & Tempo de Execuçã̃o & Prioridade \\
\hline 0 & FT-102 & & LD302-1 & 70 & 3 \\
\hline 1 & FY-101_1 & FT-102.OUT & LD302-1 & 59 & 3 \\
\hline 2 & FY-101_2 & FY-101_1.OUT & LD302-1 & 25 & 3 \\
\hline 3 & $\pi-100$ & & TT302-1 & 87 & 3 \\
\hline 4 & TIC-100 & TT-100.OUT & TT302-1 & 67 & 3 \\
\hline 5 & FY-101_3 & FT-102.OUT & TT302-1 & 59 & 3 \\
\hline 6 & FY-101_4 & FY-101_2.OUT & TT302-1 & 25 & 3 \\
\hline 7 & FT-101 & & LD302-2 & 70 & 3 \\
\hline 8 & FY-102_1 & FT-101.OUT & LD302-2 & 59 & 3 \\
\hline 9 & FY-102_2 & TIC-100.OUT & LD302-2 & 25 & 3 \\
\hline 10 & FIC-101 & FY-101_4.OUT & LD302-2 & 67 & 3 \\
\hline 11 & FY-102_3 & FT-101.OUT & FI302-1 & 59 & 3 \\
\hline 12 & $F Y-102 \_4$ & FY-102_2.OUT & FI302-1 & 25 & 3 \\
\hline 13 & FIC-102 & FT-102.OUT & FI302-1 & 67 & 3 \\
\hline 14 & $\mathrm{FCV}-102$ & FIC-102.BKCAL_OUT & FI302-1 & 50 & 3 \\
\hline 15 & FCV-101 & FIC-101.OUT & FI302-1 & 50 & 3 \\
\hline 16 & FT-102.OUT & FT-102 & LD302-1,Fieldbus1 & 10 & 2 \\
\hline 17 & FY-101_1.OUT & FY-101_1 & LD302-1 & 0 & 1 \\
\hline 18 & TT-100.OUT & TT-100 & TT302-1 & 0 & 1 \\
\hline 19 & TIC-100.0UT & TIC-100 & TT302-1,Fieldbus1 & 10 & 2 \\
\hline 21 & FY-101_2.OUT & FY-101_2 & LD302-1,Fieldbus 1 & 10 & 2 \\
\hline 22 & FY-101_3.OUT & FY-101_3 & Tा302-1 & 0 & 1 \\
\hline 23 & FIC-101.BKCAL_OUT & $\mathrm{FIC}-10 \overline{1}$ & LD302-2,Fieldbus1 & 10 & 4 \\
\hline 24 & FT-101.OUT & FT-101 & LD302-2,Fieldbus 1 & 10 & 2 \\
\hline 27 & FY-101_4.0UT & $\mathrm{FY}-101 \_4$ & TT302-1,Fieldbus1 & 10 & 2 \\
\hline 29 & FCV-101.BKCAL_OUT & FCV-101 & FI302-1,Fieldbus1 & 10 & 4 \\
\hline 31 & FY-102_2.OUT & FY-102_2 & LD302-2,Fieldbus1 & 10 & 2 \\
\hline 32 & FY-102_3.OUT & FY-102_3 & FI302-1 & 0 & 1 \\
\hline 33 & FIC-102.BKCAL_OUT & FIC-102 & FI302-1 & 0 & 4 \\
\hline 35 & FY-102_4.OUT & $\mathrm{FY}-102 \_4$ & FI302-1 & 0 & 1 \\
\hline 36 & FCV-102.BKCAL_OUT & FCV-102 & FI302-1 & 0 & 4 \\
\hline 38 & FIC-101.OUT & FIC-101 & LD302-2,Fieldbus 1 & 10 & 2 \\
\hline
\end{tabular}

Figura 46 - Tabela de informações da configuração do experimento 2

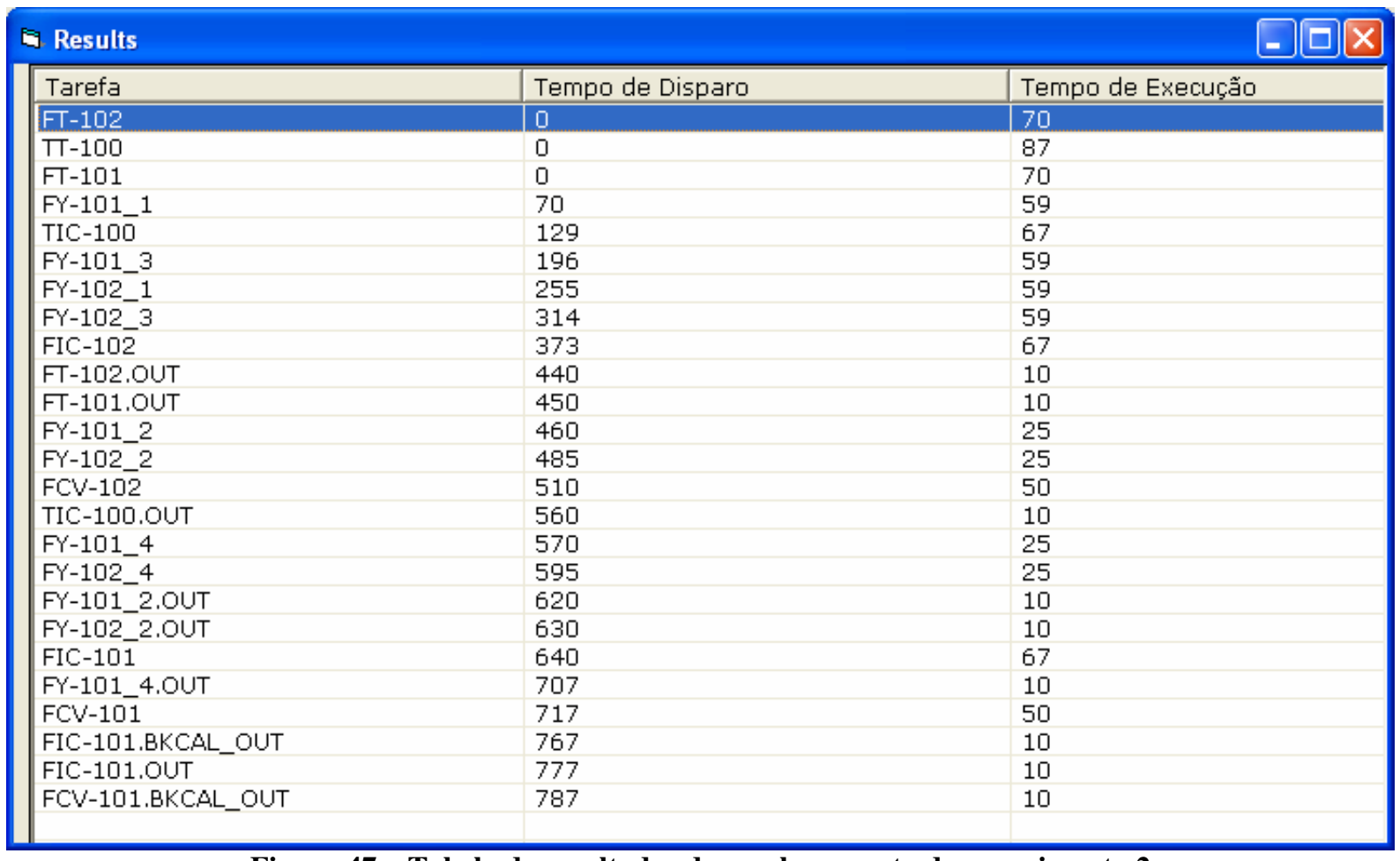

Figura 47 - Tabela de resultados do escalonamento do experimento 2 


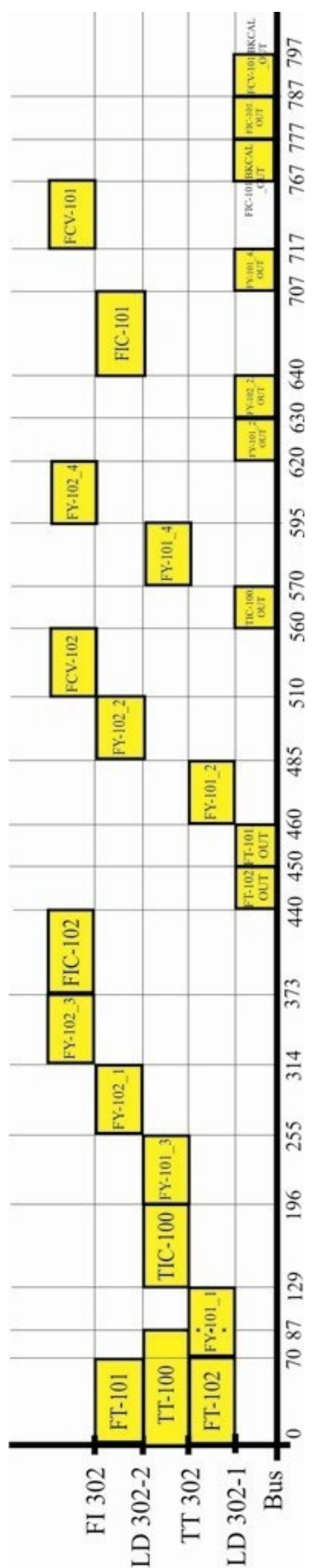

Figura 48 - Gráfico do Escalonamento para o experimento 2 
No experimento 2, aplicou-se a mesma estimativa empregada no cálculo do macrociclo do experimento 1, segundo SMAR EQUIPAMENTOS INDUSTRIAL (2007e), ou seja:

- Background Traffic

$$
\begin{gathered}
(\mathrm{BT}=(\text { NúmerosDispositivos * NúmerosBlocos }) * 30 \mathrm{~ms}) \\
((\mathrm{BT}=(4 * 2) * 30 \mathrm{~ms})) \\
\text { BT }=\mathbf{2 4 0} \mathbf{~ m s}
\end{gathered}
$$

- Foreground Traffic:

$$
\begin{gathered}
(\mathrm{FT}=(\text { NúmerosLinks*30 ms })) \\
(\mathrm{FT}=(23 * 30 \mathrm{~ms})) \quad(5.2) \\
\text { FT }=\mathbf{6 9 0} \mathbf{~ m s}
\end{gathered}
$$

- Macrociclo

$$
\begin{gathered}
(\text { Macrociclo }=(\mathrm{BT}+\mathrm{FT})+20 \%) \\
(\text { Macrociclo }=(240+690)+20 \%)
\end{gathered}
$$

\section{Macrociclo $=1116 \mathrm{~ms}$}

Ao se analisar o gráfico presente na Figura 48 observou-se que o macrociclo da aplicação levou um tempo de 797 ms para a transmissão das mensagens e de informações no barramento. Já o cálculo do macrociclo, segundo SMAR EQUIPAMENTOS INDUSTRIAL (2007e), estimou um tempo de 1116 ms. Assim, percebe-se que no método para estimar o macrociclo o algoritmo FFSMART apresentou uma otimização de 319 ms para sua aplicação. O gráfico da Figura 49 evidencia a análise do resultado. 


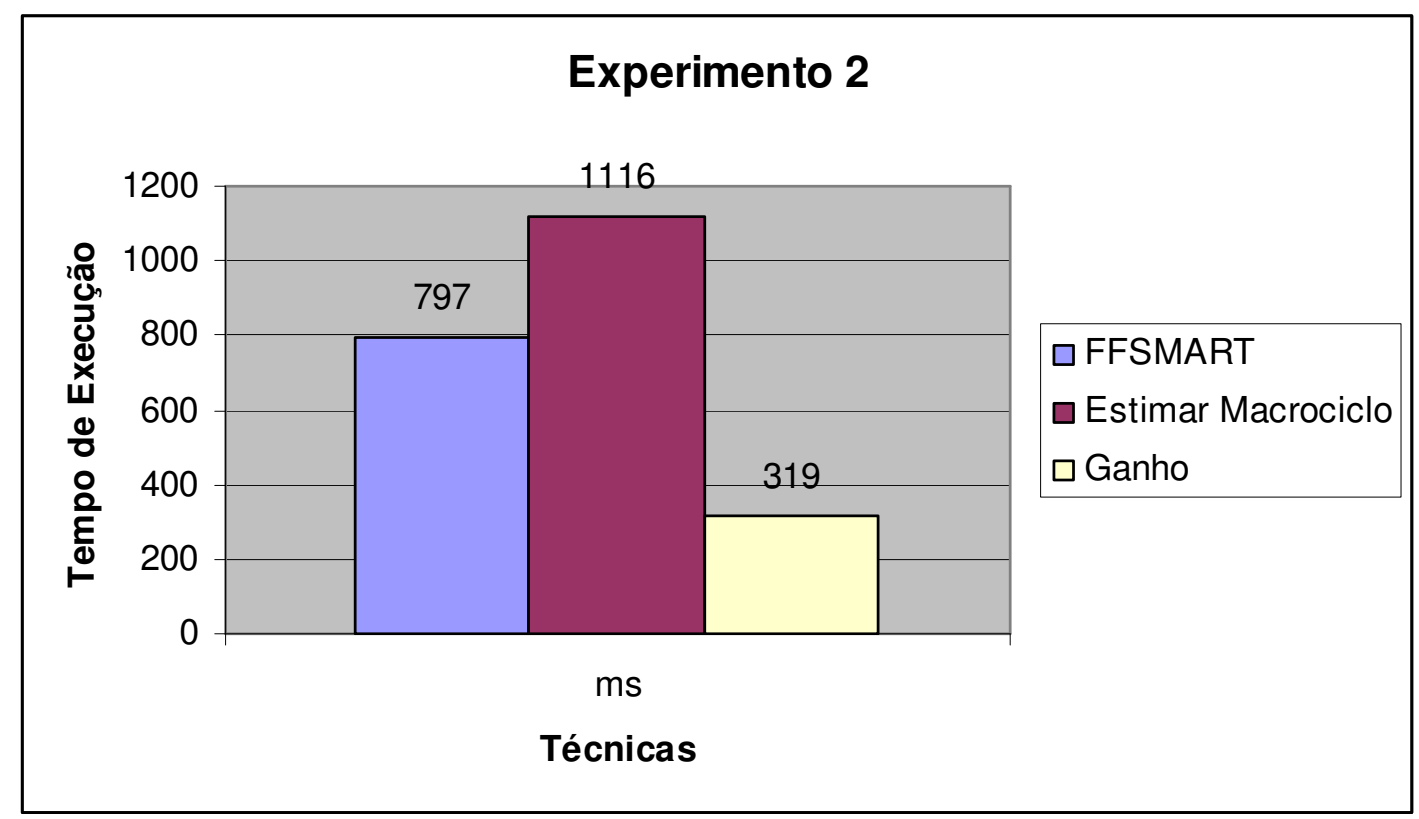

Figura 49 - Análise e otimização do resultado do algoritmo FFSMART para o experimento 2

\subsection{EXPERIMENTO 3 - APLICAÇÃO DO CONTROLE EM UMA EMPRESA DE FUNDIÇÃO DE FERRO}

O terceiro experimento mostrou-se de uma aplicação utilizada por Henriques (2005), parcialmente implementada por uma empresa que fez a fundição de ferro. Nesta aplicação o autor usou 4 dispositivos de campo, 21 blocos funcionais e 22 links. A Tabela 4 mostra quais dispositivos foram utilizados nesse experimento.

Tabela 4 - Dispositivos e Blocos Funcionais da SMAR utilizados no experimento 3

\begin{tabular}{cc}
\hline DISPOSITIVOS & BLOCOS FUNCIONAIS \\
\hline LD302 & Analog Input \\
& PID Control \\
TT302 & $1-$ Analog Input \\
& $2-$ Analog Input \\
& PID Control \\
\hline
\end{tabular}




\begin{tabular}{cc}
\hline Analog Alarm \\
Arithmetic \\
Integrator \\
$1-$ Analog Output \\
$2-$ Analog Output \\
$3-$ Analog Output \\
$1-$ PID Control t \\
$2-$ PID Control \\
Input Selector \\
Analog Alarm \\
$1-$ Analog Input \\
$2-$ Analog Input \\
$3-$ Analog Input \\
PID Control \\
Analog Output \\
Integrator \\
\hline DF62-2
\end{tabular}

Com base na Tabela 4, montou-se a estratégia para aplicação no configurador SYSCON, evidenciada na Figura 50. 


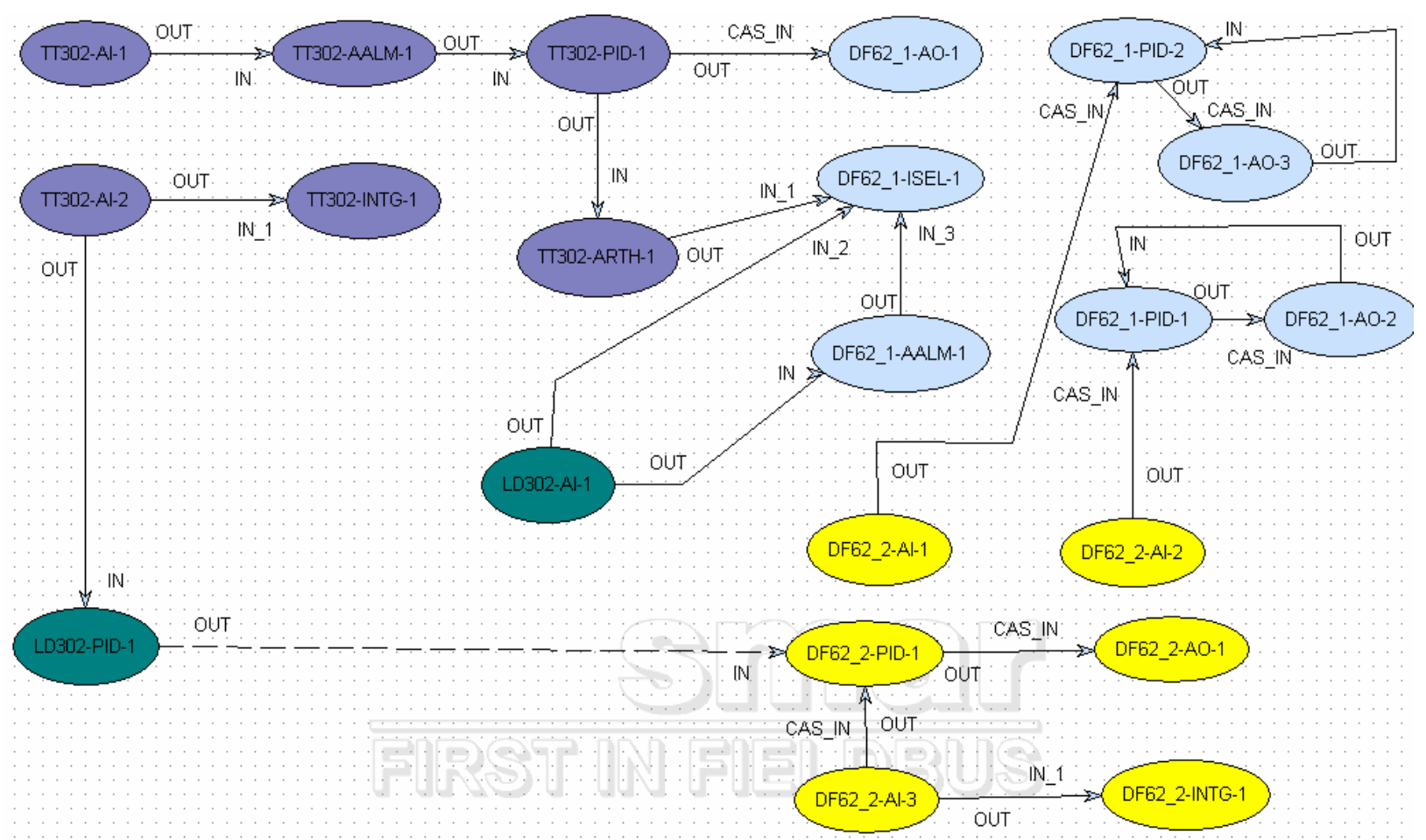

Figura 50 - Estratégia de blocos configurada no SYSCON para o experimento 3

Estando a estratégia de blocos pronta pôde-se gerar o arquivo XML e dar início ao escalonamento. A Figura 51 apresenta as informações da aplicação abstraídas do arquivo XML. Com base nestas informações, o FFSMART executou o escalonamento e gerou a tabela de resultados (Figura 52). No gráfico ilustrado na Figura 53 estão as informações de escalonamento da tabela de resultados. 


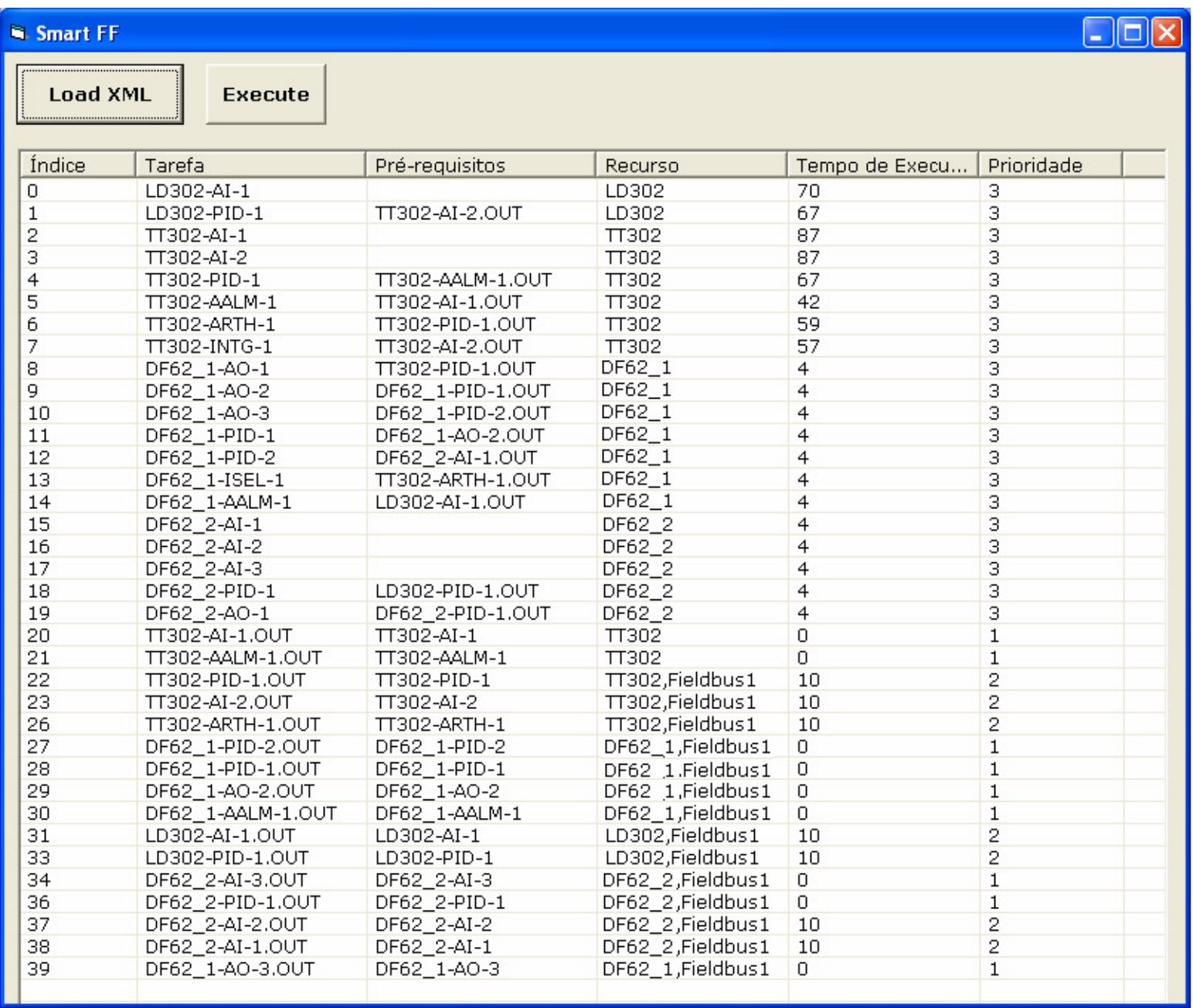

Figura 51 - Tabela de informações da configuração do experimento 3

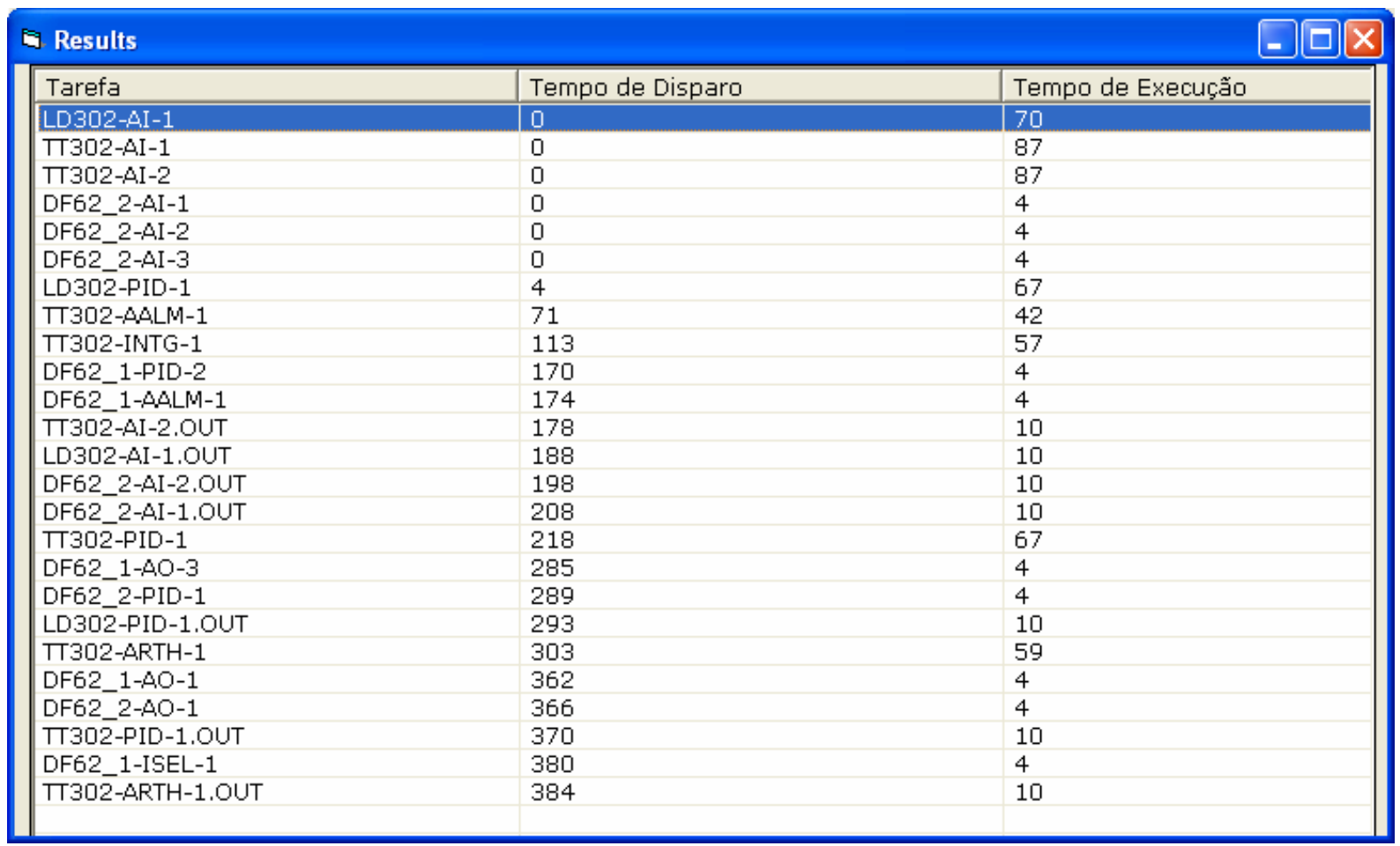

Figura 52 - Tabela de resultados do escalonamento do experimento 3 


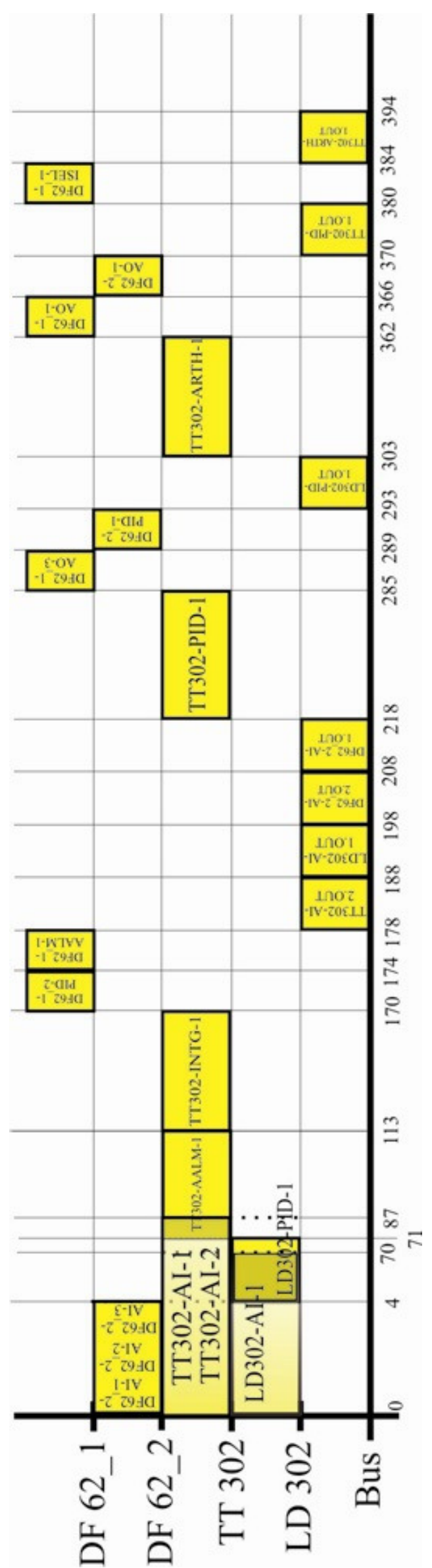

Figura 53 - Gráfico do escalonamento para o experimento 3 
Ao se analisar a aplicação do experimento 3, observou-se que a estratégia de blocos (Figura 50) diferiu da estratégia apresentada por Henriques (2005), possivelmente porque embora tenha-se usado a mesma quantidade (número) de dispositivos de campo, blocos funcionais e links, o software de configuração utilizado para montagem da estratégia foi diferente, o que diferenciou as ligações entre os blocos funcionais dos dispositivos de campo e o seu tempo de execução.

Observou-se, também, que o algoritmo FFSMART realizou o escalonamento mostrando o tempo de execução e o macrociclo para a transmissão das tarefas no barramento de comunicação, ordenando, assim, as mensagens conforme suas prioridades, precedência, porém respeitando sempre o tempo de cada bloco. Já no trabalho de Henriques (2005), o algoritmo trabalhou com um macrociclo predeterminado pelo usuário e ao escalonador coube, nesse tempo, verificar qual o melhor caminho para realizar a transmissão dos blocos e mensagens no barramento. Este algoritmo calculou o fator de alocação (fa), o que contribuiu para analisar a utilização de recursos em conjunto com os caminhos máximos de cada estratégia de controle (Henriques, 2005).

Para cálculo do fator de alocação de um bloco funcional, Henriques (2005) analisou o número de vezes que este bloco foi executado durante o macrociclo (MA), e multiplicou o valor encontrado pelo seu tempo de execução, que foi dividido pelo MA. O software apresentado em Henriques (2005) realizou o seguinte cálculo automático.

$$
f a(B F)=\frac{\text { tempo_de_execução }(B F)}{M A} \times 100 \%
$$

Neste experimento realizou-se uma amostragem que empregou apenas um dispositivo de campo e um bloco funcional. Este dispositivo de campo referiu-se ao TT302, cujo bloco funcional analisado foi o Analog Input (AI). O configurador SYSCON apresentou para este 
bloco um tempo de $87 \mathrm{~ms}$ e o algoritmo FFSMART executou a aplicação apresentando um macrociclo de 394 ms (Figura 53).

Empregando-se a fórmula do fator de alocação, segundo Henriques (2005), obteve-se o seguinte resultado:

$$
\begin{array}{r}
f a(B F)=\frac{87}{394} \times 100 \% \\
f a(B F)=22,08 \%
\end{array}
$$

Ainda de acordo com Henriques (2005), para o dispositivo de campo denominado "Disp1", que faz uso do bloco funcional Analog Input (AI) e de um macrociclo predefinido de $540 \mathrm{~ms}$, o fator de alocação foi de $11 \%$. Esta análise levou a conclusão de que, pelo fato dos macrociclos das aplicações serem diferentes, existe variação no fator de alocação entre os dois escalonadores. Com a aplicação mencionada em Henriques (2005) mostrou um macrociclo diferente que o do algoritmo FFSMART, o fator de alocação do bloco AI no barramento foi considerado menor, o que significa que sua alocação ocorreu em menor tempo que o do algoritmo FFSMART.

Para validação do FFSMART neste experimento 3, também utilizou-se a fórmula de estimar o tempo do macrociclo segundo SMAR EQUIPAMENTOS INDUSTRIAL (2007e), cujo cálculo foi:

- Background Traffic

$$
\begin{gathered}
(\mathrm{BT}=(\text { NúmerosDispositivos } * \text { NúmerosBlocos }) * 30 \mathrm{~ms}) \\
((\mathrm{BT}=(4 * 2) * 30 \mathrm{~ms})) \\
\mathbf{B T}=\mathbf{2 4 0} \mathbf{~ m s}
\end{gathered}
$$


- Foreground Traffic:

$$
\begin{gathered}
(\mathrm{FT}=(\text { NúmerosLinks* } 30 \mathrm{~ms})) \\
(\mathrm{FT}=(22 * 30 \mathrm{~ms})) \\
\text { FT }=\mathbf{6 6 0} \mathbf{~ m s}
\end{gathered}
$$

- Macrociclo

$$
\begin{gathered}
(\text { Macrociclo }=(\mathrm{BT}+\mathrm{FT})+20 \%) \\
(\text { Macrociclo }=(240+660)+20 \%)
\end{gathered}
$$

\section{Macrociclo $=1080 \mathrm{~ms}$}

Ao se analisar a Figura 53 observou-se que o macrociclo da aplicação levou um tempo de 394 ms para a transmissão das mensagens e informações no barramento. Já para o cálculo do macrociclo, segundo SMAR EQUIPAMENTOS INDUSTRIAL (2007e), estimou-se um tempo de 1080 ms. Percebe-se, então, que o método para estimar o macrociclo do algoritmo FFSMART apresentou uma otimização de 686 ms para sua aplicação. A Figura 54 evidencia a análise do resultado.

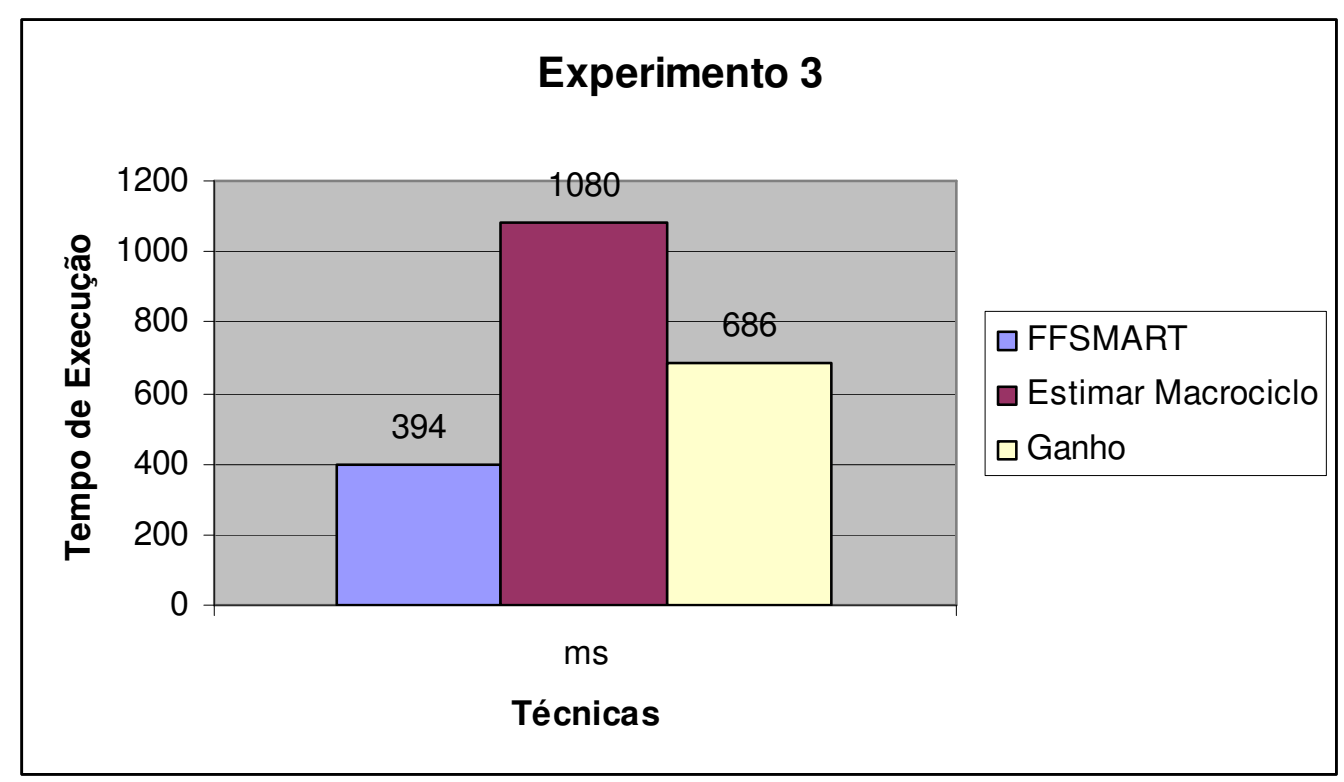

Figura 54 - Análise e otimização do resultado do algoritmo FFSMART para o experimento 3 



\section{CONCLUSÃO}

Este trabalho apresentou um algoritmo de escalonamento denominado FFSMART (FOUNDATION FIELDBUS SMART), classificado como um algoritmo de escalonamento pré-run-time; além de trabalhar com uma tabela off-line com as informações da aplicação, ele atua em redes de comunicação que utilizam a tecnologia FOUNDATION FIELDBUS.

O FFSMART tem a função escalonar as informações presentes na aplicação, como as tarefas dos blocos funcionais e mensagens, otimizando a seqüência de transmissão das tarefas no barramento de comunicação e, conseqüentemente, o macrociclo. Este algoritmo trabalha a partir da estratégia de aplicação configurada no software SYSCON, pertencente à SMAR EQUIPAMENTOS INDUSTRIAS, e permite ao usuário da aplicação gerar o arquivo XML, a partir do qual o FFSMART obtém as informações da estratégia da planta, a seguir, organizaas em uma tabela e escalonando-as na sequiência

Concluiu-se, assim, que os objetivos propostos no Capítulo 1 foram atendidos de forma satisfatória, já que o algoritmo de escalonamento foi implementado para o protocolo FOUNDATION FIELDBUS, respeitando-se as exigências de sua norma, bem como apresentando bons resultados quando comparados às aplicações existentes na literatura.

Para validar o algoritmo FFSMART, este estudo apresentou três experimentos, tendo cada um deles um cenário diferente; mesmo assim seus resultados foram confrontados conforme descrito no Capítulo 5.

Na realização do experimento 1, o algoritmo FFSMART mostrou um resultado mais otimizado que o apresentado por SMAR EQUIPAMENTOS INDUSTRIAIS (2007e), isso 
porque o FFSMART escalonou as informações em 351ms, enquanto em SMAR EQUIPAMENTOS INDUSTRIAIS (2007e) o macrociclo foi de 432ms. Desse modo, constatou-se um ganho de $81 \mathrm{~ms}$ ao utilizar o FFSMART.

No experimento 2, fez uso da aplicação de duplo limite cruzado e comparou os resultados obtidos da mesma maneira que fez no experimento 1, o que permitiu observar melhor desempenho do FFSMART para escalonar as tarefas e mensagens no barramento, com um macrociclo menor, uma vez que escalonou as informações em $797 \mathrm{~ms}$ enquanto em SMAR EQUIPAMENTOS INDUSTRIAIS (2007e) o macrociclo foi de $1116 \mathrm{~ms}$. O ganho para essa aplicação foi de 319 ms, com resultado melhor para o FFSMART, neste caso.

Os resultados do experimento 3 foram comparados com duas análises presentes na literatura: o fator de alocação proposto no trabalho de Henriques (2005) e o cálculo de estimar o macrociclo da aplicação, segundo SMAR EQUIPAMENTOS INDUSTRIAIS (2007e).

$\mathrm{Na}$ primeira análise, comparou-se com o fator de alocação, proposto por Henriques (2005). Neste caso, deveria se encontrar a porcentagem de tempo em que as tarefas ou mensagens ficavam alocadas no barramento para serem transmitidas. Por se tratarem de escalonadores diferentes, em Henriques (2005) o período do macrociclo foi predefinido, enquanto o mesmo não ocorreu com FFSMART. O primeiro autor definiu um período de macrociclo de 540 ms, enquanto FFSMART exibiu um período de 394 ms. Então, calculou-se o fator de alocação apenas para um bloco funcional da aplicação, e como resultado, para Henriques (2005), 11\% da tarefa ficou alocada no barramento, enquanto no FFSMART a alocação foi de 22,08\%. Assim, o desempenho do FFSMART foi menos otimizado.

Na segunda análise, este estudo utilizou o mesmo cenário de comparação apresentado nos experimentos 1 e 2, observou que o desempenho do FFSMART também foi mais otimizado em relação à SMAR EQUIPAMENTOS INDUSTRIAIS (2007e). 
O FFSMART escalonou as informações em $394 \mathrm{~ms}$, enquanto, para SMAR EQUIPAMENTOS INDUSTRIAIS (2007e) o macrociclo foi de 1080ms. Com isso, constatou-se um ganho de 686 ms ao utilizar o FFSMART.

O protocolo FOUNDATION FIELDBUS, como se observou neste trabalho, é uma tecnologia complexa, com muitas funcionalidades e vantagens. No entanto, como o fieldbus trabalha com um único barramento de comunicação, este fato pode ocasionar atraso na transmissão das mensagens e nas tarefas, no decorrer do processo. Para evitar esta desvantagem, a literatura indica o uso de aplicações direcionadas à técnica de escalonamento através de um algoritmo.

Desse modo, o algoritmo de escalonamento FFSMART aqui proposto, contribuiu para a otimização do período do macrociclo para as mensagens cíclicas em estratégias de configurações de processos ou plantas industriais.

\subsection{TRABALHOS FUTUROS}

Sugestões para trabalhos futuros nesta linha de pesquisa:

- Implementar no algoritmo FFSMART os resultados obtidos com o escalonamento em gráficos para que estes sejam gerados automaticamente conforme dados da "Tabela Resultados".

- Aperfeiçoar o algoritmo FFSMART para que ele possa analisar as mensagens acíclicas existentes no barramento. 



\section{REFERÊNCIA BIBLIOGRÁFICA}

ABDELZAHER, T.F.; SHIN, K.G. (1999). Combined task and messages scheduling in realtime systems. IEEE Transactions on Parallel and Distributed Systems, Washington, v.10, n.11, p.1179-1191, Nov.

ALMEIDA, L.; PASSADAS, R.; FONSECA, J.A. (1999). Using a planning. Control scheduler to improve the flexibility of real-time fieldbus networks Engineering Practice, Langford, v.7, n.1, p.101-108, Jan.

BARUAH, S.; GOOSSENS, J.; FUNK, S. (2003a). Robustness Results Concerning EDF Scheduling upon Uniform Multiprocessors. IEEE Transactions on Computers. Vol. 52, $\mathrm{n}^{\circ}$ 9, pages: 1185-1195, 2003a.

BARUAH, S.; GOOSSENS, J. (2003b). The Static-Priority Scheduling of Periodic Task Systems Upon Identical Multiprocessador Platforms. Proceeding of Parallel and Distributed Computing and Systems (PDCS 2003). Marina del REY, USA, 2003b.

BARUAH, S.; GOOSSENS, J. (2004). Scheduling Real-time Tasks: Algorithms and Complexity. In Handbook of Scheduling: Algorithms, Models, and Performance Analysis, Joseph Y-T Leung (ed). Chapman Hall/ CRC Press. 2004. 
BERGE J. (2002). Fieldbus for Process Control: Engineering, Operation, and Maintenance. ISA Books.

BLAZEWICZ, J.; ECKER, K. H.; PESCH, E.; SCHMIDT, G.; WEGLARZ, E. Scheduling Computer and Manufacturing Process. Germany, Springer, 1996.

BRANDÃO, D. (2005). Ferramenta de simulação para projeto, avaliação e ensino de redes fieldbus. 151f. Tese (Doutorado em Engenharia Mecânica) - Escola de Engenharia de São Carlos, Universidade de São Paulo, São Carlos, 2005.

BURN, A.; WELLINGS, A. (2001). Real-Time Systems and Programming Languages (Third Edition) - Ada 95, Real-Time Java and Real-Time POSIX. Addison Wesley Longmain, 2001.

CARDEIRA, C.; MAMMERI, Z. (1993). Using task scheduling algorithms for fieldbus traffic scheduling. Local: Editora. (Rapport Technique no.93-R-253, CRIN). . (1995). A schedulability analysis of tasks and network traffic in distributed real-time systems. Measurement, Amsterdam, v.15, n.2, p.71-83, May.

CAVALIERI, S.; DI STEFANO, A.; MIRABELLA, O. (1995). Pre-run-time scheduling to reduce schedule length in thefieldbus environment. IEEE Transactions on Software Engineering, New York, v.21, n.11, p.865-880, Nov. 
CAVALIERI, S. et al. (1996). Petri net-based performance evaluation of asynchronous traffic management in fieldbus. In: IEEE INTERNATIONAL SYMPOSIUM ON INDUSTRIAL ELECTRONICS, 1996, Warsaw. Proceedings... New York: IEEE. p.1031-1036.

CAVALIERI, S.; CORSARO, A; MIRABELLA, O.; SCAPELLATO, G. (1998). Scheduling Periodic Information Flow in Fieldbus and Multi-Fieldbus Enviroments, Proceedings International Conferecence on Automation hold in BIAS'98, p.24-25, Nov. 1998.

CAVALIERI, S.; STEFANO, A. D.; BELLO, L. L.; MIRABELLA, O. (1998). Jitter-based Policies to Improve Asynchronous Bandwidth Exploitation in Fieldbus Communication Systems. IEEE Institute of Informatic and Telecommunications, Italy. p.916-921, 1998.

FARINES, J. M.; FRAGA, J. S.; OLIVEIRA, R. S. (2000). Sistemas de Tempo Real. 12a Escola de Computação, IME-USP, São Paulo-SP, julho de 2000.

FIELDBUS FOUNDATION (1999). Foundation specification $31.25 \mathrm{kbit} / \mathrm{s}$ physical layer profile: FF-816-1.4. Austin. (1999a). Foundation specification system architecture: FF-800-1.4. Austin. (1999b). Foundation specification function block application process: FF-890-1.3. part 1. Austin. . (1995). A schedulability analysis of tasks and network traffic in distributed real-time systems. Measurement, Amsterdam, v.15, n.2, p.71-83, May. 
(2003). Technical Overview: FD-043. Rev 3.0. Austin.

FRANCO, L. R. H. R. (1998). Escalonamento de Mensagens para a Comunicação no Fieldbus. 124f. Tese (Doutorado) - Escola Politécnica da Universidade de São Paulo, São Paulo, 1998.

HENRIQUES, A. M. (2000). Algoritmo de Escalonamento da Comunicação Para o Fieldbus da Fieldbus Foundation. 87f. Dissertação (Mestrado) - Escola Federal de Engenharia de Itajubá, Minas Gerais, 2000.

HENRIQUES, A. M. (2005). Escalonamento No Fieldbus. 177f. Tese (Doutorado em Engenharia de Sistemas) - Escola Politécnica da Universidade de São Paulo, São Paulo, 2005.

IEC - International Electrotechnical Comission (2000). IEC 61158: Digital data communications for measurement and control - fieldbus for use in industrial control systems. Suíça. CD-ROM.

IEC - International Electrotechinal Commission (2005). IEC 61158-SER (Edition 1.0), Digital data communications for measurement and control - Fieldbus for use in industrial control system - ALL PARTS, 2005. Disponível em: http://www.iec.ch, Acesso em: 07 set 2005.

HONG, S. H.; CHOI, I. H. (2001). Experimental Evaluation of a Bandwidth Allcation Scheme for Foundation Fieldbus. IEEE Instrumentation and Measuremente Technology Conference. Budapest, Hungray, may, 2001. 
JONSSON, J.; SHIN K. G. (1997) Deadline Assigment in Distributed Hard Real-Time Systems with Relaxed Localit Constraints. 1997. IEEE. p.432-440.

KOLLER, G.; SAUTER, T.; RAUSCHER, T. (2003). Effects of network delay quantization is distributed control systems. In: IFAC CONFERENCE ON FIELDBUS SYSTEMS AND THEIR APPLICATION, 2003, Aveiro. Proceedings Laxenburg: IFAC.

LIU, C.L.; LAYLAND, J.W. (1973). Scheduling algorithms for multi programming in a hardreal_time environment. Journal of the Association for Computing Machinery, New York, v.20, n.1, p.46-61, Jan.

MERCER, C. W. (1992). An Introduction to Real-Time Operating Systems: Scheduling Theory, Pittsburgh-Pennsylvania, Nov. 1992. Draft issue.

PANTONI, R. P. (2006). Desenvolvimento e Implementação De Uma Descrição De Dispositivos Aberta e Não-Proprietária Para Equipamentos FOUNDATION FIELDBUS Baseada Em XML. 164f. Dissertação (Mestrado em Engenharia Mecânica) - Escola de Engenharia de São Carlos, Universidade de São Paulo, São Carlos, 2006.

PINEDO, M. (1995). Scheduling - Theory, Algoritms and Systems. Prentice-Hall, 1995.

RAJA, P.; NOUBIR, G. (1993). Static and dynamic polling mechanisms for fieldbus networks. Operating Systems Review, New York, v.27, n.3, p.34-45, July. 
REHG, J. A.; SWAIN, W. H.; YANGULA, B. P. (1999). Fieldbus in the Process Control Laboratory - Its Time Has Come. $29^{\text {th }}$ ASEE/ IEEE Frontiers in Education Conference, San Juan, Puerto Rico, November, 1999.

SÁENZ, L. V.; THOMESSE J. -P. (1995). Temporal Properties in Distributed Real-Time Applications Cooperation Models and Communications Types. In $13^{\text {th }}$ Workshop on Distributed Computer Control Systems, DCCS'95, Toulouse (France), Sep 1995.

SCOTT, A. V.; BUCHANAN, _W. J. (2000) Truly Distributed Control Systems using Fieldbus Technology. $7^{\text {th }}$ IEEE International Conference and Workshop on the Engineering of Computer Based Systems. Edinburg, Scotland, 2000, p. 165.

SMAR EQUIPAMENTOS INDUSTRIAIS (2007). Disponível em: <http://www.smar.com>. Acesso em: 24 abril 2007. . (2007a). Disponível em: <http://www.smar.com>. Acesso em: 24 abril 2007. . (2007b). Disponível em: <http://www.smar.com/products/syscon.asp>. Acesso em: 24 abril 2007. (2007c). Disponível em: < http://www.smar.com/products/syscon.asp>. Acesso em: 21 junho 2007. (2007d). Disponível em:<http://www.smar.com/products/fb_blocks.asp>. Acesso em: 26 junho 2007. 
(2007e). Disponível em: <http://www.smar.com/products/dfi302.asp>. Acesso em:

26 junho 2007.

SPRUNT, B.; SHA, L.; LEHOCZKY, J. (1989). Aperiodic Task Scheduling for Hard-RealTime Systems. The Journal of Real-Time System, Boston. 1989. p. 27-60.

TANEMBAUM, A. S. (1997). Redes de Computadores, Rio de Janeiro: Campus 1997.

THOMESSE, J. P. (1998). A Review oh the Fieldbuses. Annual Reviews in Control, 1998.

VERHAPPEN, I.; PEREIRA, A. (2002). Foundation fieldbus: a pocket guide. Research Triangle Park: ISA Books.

XU, C.; LAU, F. C. M. (1997). Load Balancing In Parallel Computers: Theory and Pratice. Kluwer Academic Publishers, Boston, USA, 1997.

XU, J.; PARNAS, D.L. (1990). Scheduling processes with release times, deadlines, precedence and exclusion relations. IEEE Transactions on software engineering, New York, v.16, n.3, p.360-369, Mar.

ZHOU, Y.; YU, H. (2002). Wang T.; Zhu, B. Analysis and Heuristic Scheduling for Periodic Messages in FF System. 15 ${ }^{\text {th }}$ Triental World Congress, Barcelona, Spain, 2002.

ZWEBEN, M.; FOX, M.S. (1994). Intelligent Scheduling. San Francisco-California, Morgan Kaufmann, 1994. 


